Florida International University FIU Digital Commons

7-27-1992

\title{
Investigation of the axial binding of phosphrus (sic) ligands to tetraphenylporphinato iron (II)
}

Donghui Cui

Florida International University

DOI: $10.25148 /$ etd.FI14061558

Follow this and additional works at: https://digitalcommons.fiu.edu/etd

Part of the Chemistry Commons

\section{Recommended Citation}

Cui, Donghui, "Investigation of the axial binding of phosphrus (sic) ligands to tetraphenylporphinato iron (II)" (1992). FIU Electronic Theses and Dissertations. 2682.

https://digitalcommons.fiu.edu/etd/2682

This work is brought to you for free and open access by the University Graduate School at FIU Digital Commons. It has been accepted for inclusion in FIU Electronic Theses and Dissertations by an authorized administrator of FIU Digital Commons. For more information, please contact dcc@fiu.edu. 


\title{
ABSTRACT OF THE THESIS \\ Investigation of The Axial Binding of Phosphorus Ligands To \\ Tetraphenylporphinato Iron(II)
}

by

\author{
Donghui Cui \\ Florida International University, 1993 \\ Miami, Florida \\ Dr. John T. Landrum, Major Professor
}

Phosphines and phosphites have been investigated as ligands to tetraphenylporphinato iron(II) (FeTPP) by spectrophotometric titration in tetrahydrofuran. A least squares method for determination of the equilibrium constants $K_{1}$ and $K_{2}\left(K_{1}\right.$ and $K_{2}$ correspond to the sequential binding constants for the formation of FeTPPL and FeTPPL 2 , respectively) was developed. This method eliminates the errors associated with fundamental assumptions intrinsic to the more conventional Hill plot. The visible spectrum of the 5-coordinate complex, FeTPPL, was also determined for each ligand. The equilibrium constants obtained are: $\left\{\mathrm{L}\left(\log \mathrm{K}_{1}, \log \mathrm{K}_{2}\right)\right\}, \mathrm{PMe}_{3}(5.53,4.60) ; \mathrm{PEt}_{3}(5.61,4.30) ; \mathrm{P}(\mathrm{n}$ $\mathrm{Bu})_{3}(6.13,5.02) ; \mathrm{P}(\mathrm{OEt})_{3}(3.87,2.82) ; \mathrm{P}(\mathrm{O}-\mathrm{i}-\mathrm{Pr})_{3}(3.28,1.13)$. The equilibrium constants are dependent upon steric bulk, $\sigma$-basicity and $\pi$-acidity. 


\title{
FLORIDA INTERNATIONAL UNIVERSITY \\ Miami, Florida
}

Investigation of The Axial Binding of Phosphrus Ligands To

Tetraphenylporphinato Iron (II)

\begin{abstract}
A thesis submitted in partial satisfaction of the requirements for the degree of Master of Science in Chemistry
\end{abstract}

by

Donghui Cui 

To professors: $\quad$ Dr. John T. Landrum

Dr. Ramon Lopez de la Vega

Dr. Jeffrey Joens

This thesis, having been approved in respect to form and mechanical execution, is referred to you for judgment upon its substantial merit.

Dean, Arthur W. Herriott

College of Arts and Sciences

The thesis of Donghui Cui is approved.

Ramon Lopez de la Vega

Jeffrey Joens

John T. Landrum, Major Professor

Date of Examination: July 27, 1992

Dean Dr. Richard L. Campbell

Division of Graduate Studies

Florida International University, 1992 


\section{Table of Contents}

Chapter 1, Introduction

Chapter 2, General Theory

Chapter 3, Experimental Methods and Data

Chapter 4, Results and Discussion

Reference

Appendix 


\section{List of Figures}

Figure

1-1. The pyramidal structure of phosphine/phosphite compounds.

1-2. $\pi$-back bonding between metal center and ligand.

1-3. Cone-angle of phosphine/phosphite ligand

2-1. Illustration of a theoretical Hill plot, calculated using $K_{1}=20000, K_{2}=10$ and typical experimental values from the titration of FeTPP with phosphorus ligand.

2-2. Sample graph of the Hill plot when $K_{1}$ and $K_{2}$ are close in value, calculated using $K_{1}=8000, K_{2}=240$ and real experimental values for absorbances of FeTPP phosphorus complexes at wavelength of $426 \mathrm{~nm}$.

2-3. Sample graph of the Hill plot when $\mathrm{K} 1$ and $\mathrm{K} 2$ are close in value, calculated using $\mathrm{K} 1=8000, \mathrm{~K} 2=240$ and real experimental values for absorbances of FeTPP phosphorus complexes at wavelength of $457 \mathrm{~nm}$.

2-4. The flow chart of the logic of the "least error" method to calculate $\mathrm{K}_{1}$ and $\mathrm{K}_{2}$. 
2-5. The floe chart of calculating the five-coordinate $\mathrm{Fe}_{(\mathrm{II})} \mathrm{TPP}$ spectrum.

3-1. UV-visible spectrum of $\mathrm{Fe}^{(\mathrm{II})} \mathrm{TPP}$ in THF.

3-2a. UV-visible spectrum of the titration of FeTPP with trimethyl phosphine THF.

3-2b. Soret bands of the titration of FeTPP with trimethyl phosphine in THF.

3-2c. $\alpha-\beta$ region of the titration of FeTPP with trimethyl phosphine in THF.

3-3a. UV-visible spectrum of the titration of FeTPP with triethyl phosphine in THF.

3-3b. Soret bands of the titration of FeTPP with triethyl phosphine in THF.

3-3c. $\alpha-\beta$ region of the titration of FeTPP with triethyl phosphine in THF.

3-3d. UV-visible spectrum of the titration of FeTPP with triethyl phosphine in benzene. 
3-4a. UV-visible spectrum of the titration of FeTPP with tri(n-butyl) phosphine in THF.

3-4b. Soret bands of the titration of FeTPP with tri(n-butyl) phosphine in THF.

3-4c. $\alpha-\beta$ region of the titration of FeTPP with tri(n-butyl) phosphine in THF.

3-5a. UV-visible spectrum of the titration of FeTPP with triethyl phosphite in THF.

3-5b. Soret bands of the titration of FeTPP with triethyl phosphite in THF.

3-5c. $\alpha-\beta$ region of the titration of FeTPP with triethyl phosphite in THF.

3-6a. UV-visible spectrum of the titration of FeTPP with triisopropyl phosphite in THF.

3-6b. Soret bands of the titration of FeTPP with triisopropyl phosphite in THF.

3-6c. $\alpha-\beta$ region of the titration of FeTPP with triisopropyl phosphite in THF. 
3-7. UV-visible spectrum of the titration of FeTPP with tribenzyl phosphine in THF.

3-8. UV-visible spectrum of the titration of $\mathrm{FeTPPClO}_{4}$ with imidazole in chloroform at $\mathrm{T}=14.9^{\circ} \mathrm{C}$.

3-9. UV-visible spectrum of the titration of $\mathrm{FeTPPClO}_{4}$ with imidazole in chloroform at $\mathrm{T}=19.1^{\circ} \mathrm{C}$.

3-10. UV-visible spectrum of the titration of $\mathrm{FeTPPClO}_{4}$ with imidazole in chloroform at $\mathrm{T}=29.8^{\circ} \mathrm{C}$.

4-1. The matching graph of the plots of $\mathrm{A}$ (exp.) vs. wavelength and $\mathrm{A}$ (cal.) vs. wavelength.

4-2. The calculated UV-visible spectrum of the five-coordinate complex of $\operatorname{FeTPP}\left(\mathrm{P}(\mathrm{Me})_{3}\right)$.

4-3. The calculated UV-visible spectrum of the five-coordinate complex of FeTPP $\left(\mathrm{P}(\mathrm{Et})_{3}\right)$.

4-4. The calculated UV-visible spectrum of the five-coordinate complex of $\operatorname{FeTPP}\left(\mathrm{P}(\mathrm{n}-\mathrm{Bu})_{3}\right)$.

4-5. The calculated UV-visible spectrum of the five-coordinate complex of $\operatorname{FeTPP}\left(\mathrm{P}(\mathrm{OEt})_{3}\right)$. 
4-6. The calculated UV-visible spectrum of the five-coordinate complex of FeTPP $\left(\mathrm{P}(\mathrm{O}-\mathrm{i}-\mathrm{Pr})_{3}\right)$.

4-7. Plot of $\ln \mathrm{K}_{0}$ vs. $1 / \mathrm{T}$ for the titrations of $\mathrm{FeTPPClO}_{4}$ with imidazole at different temperatures.

4-8. Plot of $\log \mathrm{K}_{0}$ vs. $\mathrm{pK}_{\mathrm{a}}$ for trimethyl, triethyl and tri(n-butyl) phosphines. 


\section{List of Tables}

Table

2-1. The results of sample calculations obtained by using Hill equation

3-1. Titration of Fe (II)TPP with trimethyl phosphine

3-2a. Titration of Fe(II)TPP with triethyl phosphine

3-2b. Titration of $\mathrm{Fe}^{(\mathrm{II})} \mathrm{TPP}$ with triethyl phosphine in benzene

3-3. Titration of Fe ${ }^{(I I)}$ TPP with tri-n-butyl phosphine

3-4. Titration of $\mathrm{Fe}^{(\mathrm{II})} \mathrm{TPP}$ with triethyl phosphite

3-5. Titration of $\mathrm{Fe}^{(\mathrm{II})} \mathrm{TPP}$ with triisopropyl phosphite

3-6. Titration of Fe ${ }^{(I I)}$ TPP with tribenzyl phosphine

3-7. Titration of FeTPPCLO 4 with imidazole at $\mathrm{T}=14.9{ }^{\circ} \mathrm{C}$

3-8. Titration of FeTPPCLO 4 with imidazole at $\mathrm{T}=19.1^{\circ} \mathrm{C}$

3-9. Titration of FeTPPCLO 4 with imidazole at $\mathrm{T}=29.8^{\circ} \mathrm{C}$

4-1. The equilibrium constants of the reaction of Fe (II)TPP with phosphorus ligands

4-2. Equilibrium constants for the titration of FeTPPCLO 4 with imidazole at different temperatures 


\section{Chapter 1 Introduction}

Heme systems play important roles in nature. The different functions that the heme system has are due to the versatile chemistry of the porphyrin macrocycle. ${ }^{1}$ One aspect of the chemistry of metallo-porphyrins is the ability of the metal ion within the large ring system to form a stable adduct with a Lewis base. The result is that the properties of the metal ion are modified, enabling it to participate in the catalytic events of importance to biochemical processes. Knowledge of the binding properties between the metal center and the axial ligands is needed to better understand the mechanisms of various heme functions.

Synthetic chemical models for heme systems, such as FeTPP, have been used successfully to delineate the range of chemical properties and reactivity of heme systems. ${ }^{2,3}$ The binding between the metal ion and small molecules $\left(\mathrm{O}_{2}, \mathrm{CO}, \mathrm{NO}, \mathrm{RNC} \mathrm{R}=\right.$ alkyl or aryl $)$ has been studied.4-8 There are also a number of studies concerning the binding between porphyrins with different imidazole and pyridine compounds. ${ }^{9-14}$ But only a few phosphine $\left(\mathrm{PR}_{3}\right)$ or phosphite $\left(\mathrm{P}(\mathrm{OR})_{3}\right)$ complexes of metalloporphyrins have been described.18,2024 The variation of both steric size and electron donor/acceptor capabilities of the phosphorus compounds should provide an opportunity to study the effect of these two parameters of ligand binding to iron porphyrin. Both steric interacton of the ligand with the metalloporphyrin and the strength of $\pi$-back binding may be significant factors affecting the metal-ligand adduct stability, so crucial to the biological function of iron porphyrins, in addition to straightforward $\sigma$ binding. 
The molecular geometry of a phosphine $\left(\mathrm{PR}_{3}\right)$ or phosphite $\left(\mathrm{P}(\mathrm{OR})_{3}\right)$ compound is pyramidal with a lone pair of electrons on phosphorus, Figure 1-1.15. They can form stable complexes with transition metals not only by the $\sigma$-donating bond but also through $\pi$-back bonding from the metal center. The $\pi$-back bonding is the overlap between the empty d-orbitals of phosphorus and the d-orbital of the metal in the same plane, Figure 1-2.15 The electron density that builds up on the metal center via $\sigma$ donation can be dispersed by the $\pi$-back donation. The synergism of these two effects makes the coordination compounds of phosphorus more stable. Generally speaking, phosphite compounds are better $\pi$ acceptors but weaker $\sigma$ donors than phosphines due to the strong electronegativity of the oxygen atom. Comparison of the electron donor-acceptor strength for different phosphine and phosphite compounds can be based on carbonyl stretching frequencies in the I.R. spectrum in substituted transition metal carbonyls. 16

The binding ability of the phosphorus compounds with transition metals also depends on steric factors. The size of the phosphorus ligands can be described by the minimum cone angles, the apex angle of a cone, Figure 13.17 The estimated minimum cone angles of different phosphorus compounds have been calculated by Tolman et al17.as the angle centered at the metal ion and includes the van der Waals' radii of the outmost atoms of the ligands. From the study of the phosphorus ligand exchange equilibria on zero-valent nickel, $\mathrm{Ni}(0)$, Tolman et al. concluded that the ability of the phosphorus ligand to enter the coordination sphere of the metal cannot be accounted for on the basis of ligand size alone, $\pi$-back bonding must be accounted for as well. The steric size of the phosphorus ligands is quite 


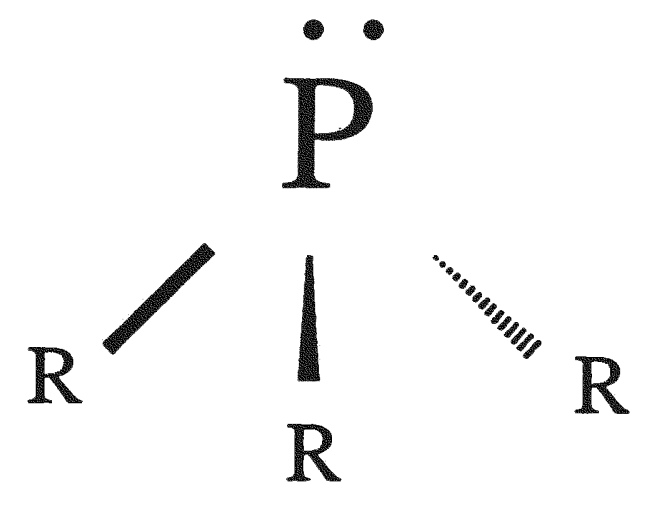

Figure 1-1. The pyrimidal structure of phosphine compounds. ${ }^{15}$ 


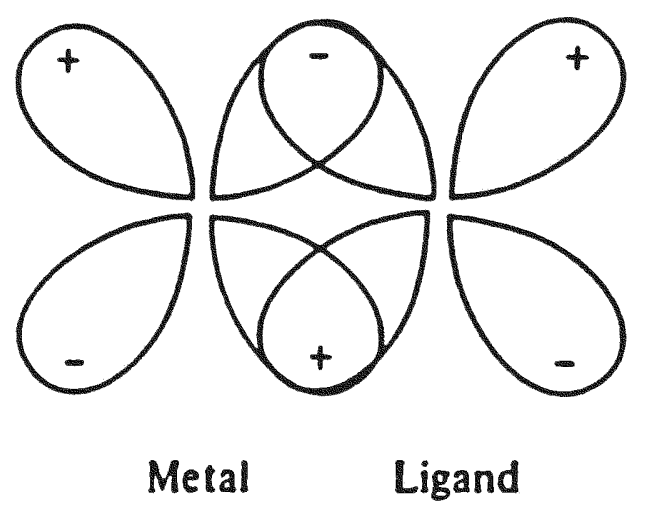

Figure 1-2. The back-bonding from a filled metal d-orbital to an empty phosphorus ligand d-orbital. ${ }^{15}$ 


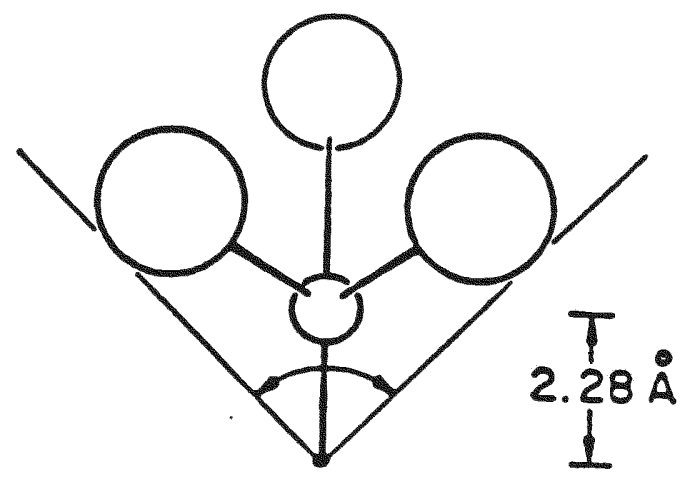

Figure 1-3. The cone angle of a phosphine/phosphite ligand.17 The small ball in the picture indicates the $P$ atom and the big balls are $-R /-O R$ groups. 
important in determining the relative stability of nickel phosphorus complexes.

The electronic and steric properties of the phosphorus compounds suggest that they might serve as valuable probes for studying how these factors affect axial coordination in metalloporphyrins. Some research has been done on the complexes formed between phosphorus ligands and iron(II) porphyrins. $18,20-24$

The Mössbauer spectra of some bis-phosphorus complexes of iron porphyrin with phosphine and phosphite ligands with varying $\pi$-bonding capabilities have been reported. 18 The metalloporphyrin system studied was tetrakis(p-methoxy-phenyl) porphinatoiron(II) (PMXPPFe).

The Mösssbauer parameters include the isomer shift $(\delta)$ and the quadrapole splitting $\left(\Delta \mathrm{E}_{\mathrm{Q}}\right)$. The relative isomer shift, $\delta$, is dependent upon the s-character of the electronic wave function, which is related to the shielding of $\mathrm{s}$ electrons by the $\mathrm{p}$ or $\mathrm{d}$ electrons. ${ }^{19}$ Isomer shift gives a relative measure of the total electron density on the metal ion. It is used to judge the relative oxidation state, which must lie between $2^{+}$and $3^{+}$for most iron prphyrins. The bigger the $\delta$ value, the smaller the $\mathrm{p}$ or $\mathrm{d}$ electron density. The quadrapole splitting,$\Delta \mathrm{E}_{\mathrm{Q}}$, reflects the asymmetry of the electron cloud around the nuclei. The $\Delta \mathrm{E}_{\mathrm{Q}}$ value in the iron porphyrin complexes are expected to increase with a decrease in $\delta$ basicity of the ligand, decrease in $\pi$ acidity of the ligand, and an increase in steric requirements of the axial phosphorous ligands. ${ }^{18}$

The data show that the average isomer shift of the bisphosphine/phosphite iron(II) porphyrin complexes at $298 \mathrm{~K}$ is $+0.52 \pm 0.03$ $\mathrm{mm} / \mathrm{s}$. This value is between that found for the bis(amine), 
$(+0.67 \pm 0.03 \mathrm{~mm} / \mathrm{s})$, (bis(pyridine), $0.66 \mathrm{~mm} / \mathrm{s})^{31}$, and the carbonylamine, $(+0.46 \pm 0.03 \mathrm{~mm} / \mathrm{s}),(\mathrm{PMXPPFe} \cdot \mathrm{py} \bullet \mathrm{CO}, 0.46 \mathrm{~mm} / \mathrm{s})^{32}$. The d-electron density of the iron in the phosphorus complexes is less than that in the bis(amine) but greater than in the carbonylamine complexes, which indicates the partial $\pi$-bonding character in phosphorus complexes, lower $\mathrm{d}$ electron density. The quadrapole splittings increase in the order TMPPE (trimethylolpropanephosphine ester) $<(\mathrm{n}-\mathrm{BuO})_{2} \mathrm{PhP}<(\mathrm{EtO})_{3} \mathrm{P}<(\mathrm{n}-\mathrm{Bu})_{3} \mathrm{P} \approx \mathrm{n}-$ $\mathrm{BuOPh}_{2} \mathrm{P}<\mathrm{MeOPh}_{2} \mathrm{P} .18$ Rationalization for this order involves both $\pi$ acidity and steric factors.

Other iron(II) complexes with bis(phosphine) or bis(phosphite) axial ligands have also been studied. ${ }^{20}$ These include FeTPP and FePc. The trends of the Mossbauer parameters in $\delta$ and $\Delta \mathrm{E}_{\mathrm{Q}}$ may be summarized as follows: $(\mathrm{Pc}=$ phthalocyanine, $\mathrm{L}=$ trialkylphosphine or trialkylphosphite, $\mathrm{P}=\mathrm{TPP}$ or $\mathrm{Pc}$ ),

(1) $\delta(\mathrm{FeTPP}) \mathrm{L}_{2}>\delta\left(\mathrm{FePcL}_{2}\right)$

(2) $\delta\left(\mathrm{Fe}(\mathrm{P})\left(\mathrm{PR}_{3}\right)_{2}\right)>\delta\left(\mathrm{Fe}(\mathrm{P})\left(\mathrm{P}(\mathrm{OR})_{3}\right)_{2}\right)$

(3) $\Delta \mathrm{E}_{\mathrm{Q}}\left(\mathrm{Fe}(\mathrm{TPP}) \mathrm{L}_{2}\right)<\Delta \mathrm{E}_{\mathrm{Q}}\left(\mathrm{FePcL}_{2}\right)$

(4) $\Delta \mathrm{E}_{\mathrm{Q}}\left(\mathrm{Fe}(\mathrm{P})\left(\mathrm{PR}_{3}\right)_{2}\right)<\Delta \mathrm{E}_{\mathrm{Q}}\left(\mathrm{Fe}(\mathrm{P})\left(\mathrm{P}(\mathrm{OR})_{3}\right)_{2}\right)$

Trends 1 and 3 can be explained by the stronger phthalocyanine to $\mathrm{Fe}(4 \mathrm{~s}) \sigma$ donation compared to that of TPP to $\mathrm{Fe}(4 \mathrm{~s})$, placing greater electron density on iron. Trend 2 shows that $\mathrm{P}(\mathrm{OR})_{3}$ is a weaker $\sigma$ donor and stronger $\pi$ acceptor than $\mathrm{PR}_{3} .{ }^{21}$ Trend 4, however, can not be explained by simple $\sigma$ - and $\pi$ bonding characteristics. It has been proposed that the macrocyclic ligands are able to modify their bonding to suit the requirement of the axial ligands. This is also called the "electron sink" or "electron buffer" capability of the macrocyclic ligands. The red-shift of the Soret band in the electronic spectra 
of these complexes is due to this interaction between phosphorus ligands and the porphyrin ring system.

The $\pi$-back bonding character of the metal center is shown by the I.R. spectra of the mixed ligand phosphine carbonyl complexes of iron(II) porphyrins. ${ }^{22}$ The I.R.spectroscopic data is consistent with a greater $\pi$-acceptor ability of aromatic phosphines compared with those of trialkylphosphines ${ }^{17}$ and a concomitant decrease in $\pi$-back bonding from iron to the $\mathrm{CO}$ bond because of trans $\pi$-competition.

The ${ }^{1} \mathrm{H}$ and ${ }^{31} \mathrm{P}$ N.M.R. properties of phosphines $\left(\mathrm{PR}_{3}=\mathrm{PMe}_{3}, \mathrm{PMe}_{2} \mathrm{Ph}\right.$, $\mathrm{PMePh}_{2}$ and $\mathrm{PH}_{2} \mathrm{Ph}$ ) in iron(II) porphyrin complexes have been studied. 22 The porphyrin ring protons lie between 7-9 ppm. The signals of the protons of the alkyl phosphines bound to iron are found at high field (-2.5 to $-3.0 \mathrm{ppm})$. This is the shielding effect of porphyrin ring current. The ${ }^{31 P}$ N.M.R. spectra of complexes [FeTPP $\left(\mathrm{PR}_{3}\right)_{2}$ ] have similar but distinguishable chemical shifts. It was also found that ${ }^{31} \mathrm{P}$ resonance is sensitive to the nature of the trans ligand.

Full crystal structures of FeTPP $\left(\mathrm{PMe}_{2} \mathrm{Ph}\right)_{2}$ and FeTPP $\left(\mathrm{Pn}-\mathrm{Bu}_{3}\right)_{2}$ have been determined by $X$-ray diffraction. 22,23 The structure of $\operatorname{FeTPP}\left(\mathrm{PMe}_{2} \mathrm{Ph}\right)_{2}$ shows that the phenyl ring of the axial ligand is oriented such that it minimizes the steric interaction with the adjacent porphyrinate phenyl rings. The Fe-P bond distance is $2.284 \AA$ and $2.346 \AA$ in FeTPP $\left(\mathrm{PMe}_{2} \mathrm{Ph}\right)_{2}$ and $\operatorname{FeTPP}\left(\mathrm{P}(\mathrm{n}-\mathrm{Bu})_{3}\right)_{2}$ respectively. The structural parameters are consistent with the low-spin electronic state typical of six-coordinate complexes of iron(II) porphyrins. The longer $\mathrm{Fe}-\mathrm{P}$ bond distance in $\operatorname{FeTPP}\left(\mathrm{P}(\mathrm{n}-\mathrm{Bu})_{3}\right)_{2}$ relative to FeTPP $\left(\mathrm{PMe}_{2} \mathrm{Ph}\right)_{2}$ is due to steric factors. ${ }^{23}$ 
Kinetic studies of axial ligand substitution reactions of low-spin sixcoordinate hemes have been done by D.V.Stynes and co-workers. ${ }^{24}$ They used the spectrophotometric titration method to obtain the equilibrium constants for tri-butylphosphine $\left(\mathrm{PBu}_{3}\right)$ and tri-butylphosphite $\left(\mathrm{P}(\mathrm{OBu})_{3}\right)$ binding to $\mathrm{N}$ methylimidazole complexes of iron porphyrins. The binding of a strong $\pi$ acceptor (CO) to the N-MeIm heme complexes was also studied. In this system the order of the trans effect of the axial ligands is $\mathrm{PBu}_{3}>\mathrm{P}(\mathrm{OBu})_{3}>\mathrm{MeIm}>$ CO. ${ }^{24}$ The results of this research have led to a better understanding of the nature of the trans-effects of $\sigma$-donor $/ \pi$-acceptor ligands. Stynes et al also compared the values obtained from the porphyrin system with iron(II) phthalocyanine (FePc) and iron(II) dimethylglyoxiime $\left(\mathrm{Fe}(\mathrm{DMGH})_{2}\right)$ analogues. The generalizations are:

1. Strong $\pi$-acceptors, like $C O$, delabilize (slow loss of) trans $\sigma$-donors through synergistic bonding interaction.

2. Weaker $\pi$-acceptors show a similar but smaller effect in all three $\mathrm{FeN}_{4}$ systems.

3. Strong $\pi$-acceptors mutually labililize each other in trans positions.

The conclusion of these kinetic studies was that it is hard to divide the net axial bond energy between the two ligands, because of the synergistic effects by the whole system. However kinetic data may provide a rational basis for dividing the bond energies in the complexes.

A five-coordinate phosphine and phosphite $\mathrm{Fe}(\mathrm{II})(\mathrm{cap})$ porphyrin complex model has been reported. 25 It was found that tri-n-butylphosphine and triethyl phosphite ligands form monomeric, 1:1 base adducts with $\mathrm{Fe}(\mathrm{II})$ (cap) porphyrins. The five-coordinate, $\pi$-acid complexes appear to be 
diamagnetic, low-spin $(S=0)$ in toluene solution at $35^{\circ} \mathrm{C}$ under $\mathrm{N}_{2}$. The magnetic susceptibility was determined by the Evans' N.M.R. method. Unlike the high spin $(S=2)$ five-coordinate complexes of iron porphyrins with sterically hindered bases, such as $\mathrm{Fe}^{(\mathrm{III})}(\mathrm{Por})(2-\mathrm{MeIm})$, the low- spin character of the complexes of $\mathrm{Fe}^{(\mathrm{II})}$ (cap) with one phosphorus ligand (known for their good $\pi$-acid properties) is explained by the $\pi$-back bonding concept.

The results described in this dissertation are the thermodynamic studies of a series of phosphine and phosphite ligands binding to Fe(II)TPP and an iterative approach to determine the equilibrium constants, $K_{1}, K_{2}$ and $\mathrm{K}_{0}\left(\mathrm{~K}_{0}=\mathrm{K}_{1} \times \mathrm{K}_{2}\right)$ under the conditions when the Hill Equation 26 is not applicable. 


\section{Chapter 2 General Theory}

Fe (II)TPP has two potential axial sites. ${ }^{27}$ Binding may occur sequentially in two steps, equation 1 and 2.

$$
\begin{aligned}
& \mathrm{Fe}^{(\mathrm{II})} \mathrm{TPP}+\mathrm{L}==\stackrel{\mathrm{K}_{1}}{==}=\mathrm{Fe} \mathrm{III}^{(\mathrm{TPPL}} \\
& \mathrm{K}_{2} \\
& \mathrm{Fe}^{(\mathrm{III})} \mathrm{TPPL}+\mathrm{L}=====\mathrm{Fe}(\mathrm{II}) \mathrm{TPPL}_{2}
\end{aligned}
$$

In equation 1 and 2 :

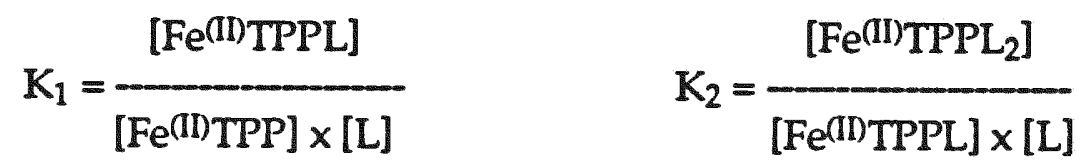

The first step, the formation of the $1: 1$ five-coordinate complex of $\mathrm{Fe}$ (II)TPP, is characterized by an equilibrium constant, $\mathrm{K}_{1}$. The second step is the formation of the $2: 1$ six-coordinate complex and is characterized by an equilibrium constant, $\mathrm{K}_{2}$.

Given the equilibria represented by equations 1 and 2, equation 3 may be written where $K_{0}=K_{1} \times K_{2} \cdot 28$

$$
\begin{gathered}
\mathrm{Fe}^{(\mathrm{III})} \mathrm{TPP}+2 \mathrm{~L}======\mathrm{Fe}^{(\mathrm{III})} \mathrm{TPPL}_{2} \\
\mathrm{~K}_{0}=\mathrm{K}_{1} \times \mathrm{K}_{2}
\end{gathered}
$$

The chemistry of axial coordination is best viewed as three cases dependent upon the relative values of $K_{1}$ and $K_{2}$. Case $1,\left(K_{1} \gg K_{2}\right)$, equation 1 proceeds to completion prior to significant reaction of iron with a second ligand. Case 2, $\left(K_{2} \gg K_{1}\right)$, reaction proceeds with little or no observation of the five-coordinate species, which is more reactive than the four-coordinate 
compound. In Case $3,\left(K_{1}=K_{2}\right)$, the formation and the disappearance of the five-coordinate compound is observable during the titration process.and the six-coordinate iron porphyrin is formed when excess ligand is added.

A conventional way to calculate the equilibrium constant for axial binding is by using the Hill equation ${ }^{26}$ : (see appendix 2-1 for derivation)

$$
\log \frac{A_{0 b s}-A_{0}}{A_{C}-A_{0 b s}}=n \log [L]+\log K
$$

In the Hill equation [L] is the ligand concentration, Aobs is the absorbance at a specific concentration of ligand and at the wavelength of interest, $A_{0}$ is the initial absorbance of $\mathrm{Fe}(\mathrm{II}) \mathrm{TPP}$ when $[\mathrm{L}]=0$ and $\mathrm{A}_{\mathrm{C}}$ is the absorbance of the completely ligated complex at high ligand concentration. The value of $\log \mathrm{K}$ is obtained from the intercept of the regression line of a plot of log (Aobs $\left.\mathrm{A}_{0}\right) /\left(\mathrm{A}_{\mathrm{C}}-\mathrm{A}_{\mathrm{Obs}}\right)$ vs. $\log [\mathrm{L}]$.

In Case 1 , when $K_{1} \gg K_{2}$, isosbestic points will be seen in the titration spectra during the early and late portions of the reaction. The plot of $\log \left(\mathrm{A}_{\mathrm{obs}}{ }^{-}\right.$ $\left.A_{0}\right) /\left(A_{c}-A_{o b s}\right)$ vs. $\log [L]$ should show two separated straight line-segments with a slope of 1 according to Hill equation. (see Figure 2-1). In the first linesegment, line "A" in Figure 2-1, $A_{0}$ is the absorbance of the pure Fe(II)TPP and $A_{c}$ is the absorbance at the point where only the 5-coordinate complex is observed. In the second line-segment $A_{0}$ is the absorbance of the 5-coordinate complex (equal to the $A_{c}$ in the first line) and $A_{c}$ is the absorbance of the 6coordinate complex. $\mathrm{K}_{1}$ and $\mathrm{K}_{2}$ are determined from the intercepts of the two lines, respectively. Figure 2-1 is a sample plot of the Hill equation when using $K_{1}=20000$ and $K_{2}=10$. The model sample uses reasonable values of $A_{0}$ and $A_{c}$ near those of typical $\mathrm{Fe}^{(\mathrm{II})}$ phosphine complexes and was calculated by 


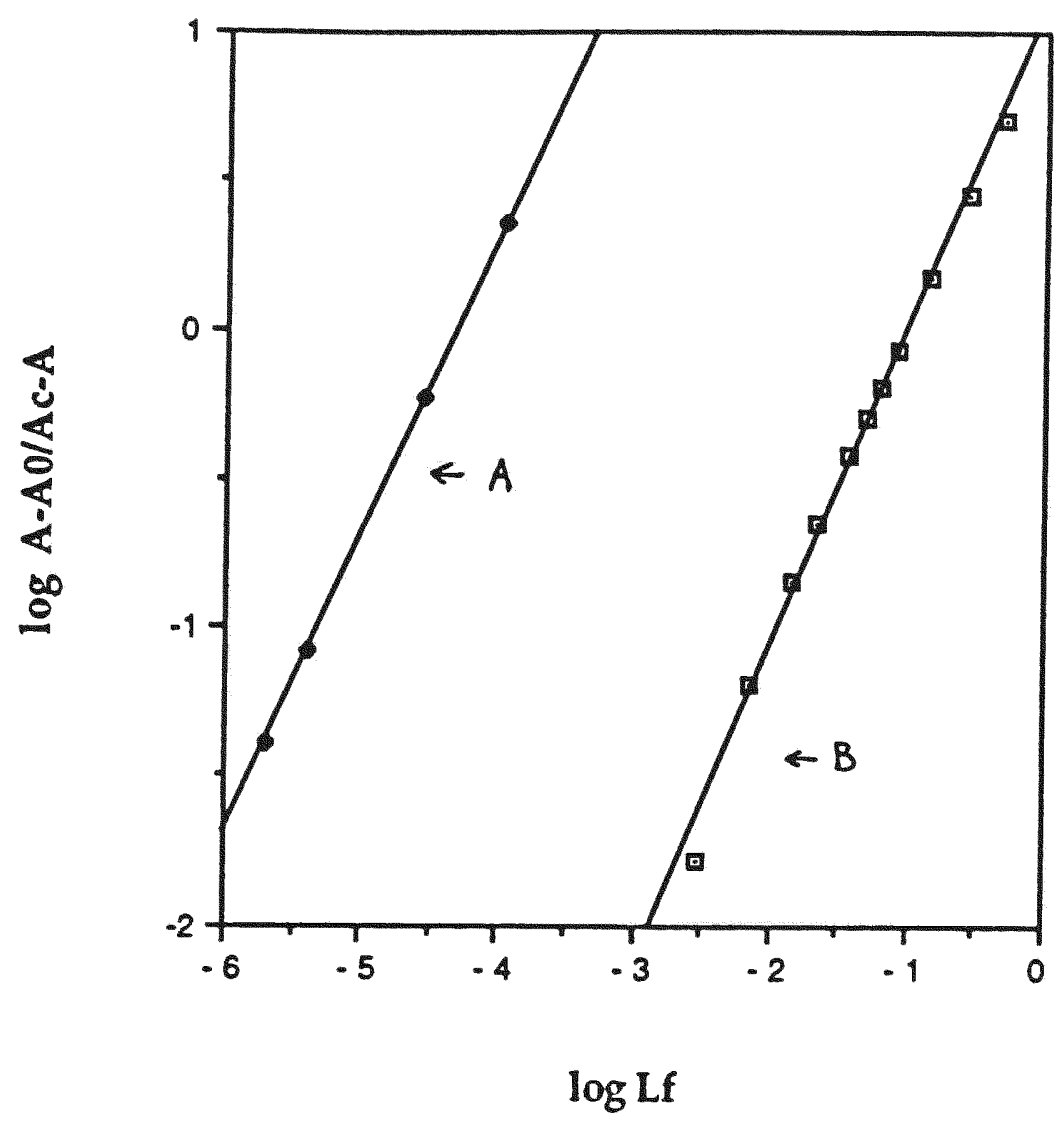

Figure 2-1. Ilustration of a theoretical Hill plot, calculated using $\mathrm{K}_{1}$

$=20000, K_{2}=10$ and typical experimental values from the titration of $\mathrm{Fe}(\mathrm{II}) \mathrm{TPP}$ with phosphorus ligand.

Line A: slope $=0.997, Y$ intercept $=4.30, R^{2}=1.000$

Line $B$ : slope $=1.07, Y$ intercept $=1.07, R^{2}=0.994$ 
using the computer program shown in Appendix 2-3. From the sample plot it is seen that when $K_{1}$ is a thousand times bigger than $K_{2}$ the Hill plot is a good way to determine $K_{1}$ and $K_{2}$ using the spectrophotometric titration method.

In Case 2, when $K_{2} \gg K_{1}$, a plot of $\log \left(A_{0 b s}-A_{0}\right) /\left(A_{C}-A_{O b s}\right)$ vs. $\log [L]$ should yield a single straight line with a slope of 2 and a $Y$-intercept equal to $\log \mathrm{K}_{0}\left(\mathrm{~K}_{0}=\mathrm{K}_{1} \times \mathrm{K}_{2}\right)$. Titration of FeTPPCl with nitrogenous bases yields data in this class. ${ }^{10}$

In Case 3, when $K_{1}$ and $K_{2}$ are suitably close in value to each other, the three species $\left.\mathrm{Fe}^{(\mathrm{II})}\right)_{\mathrm{TPP}}, \mathrm{Fe} \mathrm{(II}_{\mathrm{TPPL}}$ and $\left.\mathrm{Fe}{ }^{(\mathrm{II})}\right)_{\mathrm{TPPL}}$ are simultaneously present in solution, and the spectrophotometric titration spectrum shows no clear isosbestic points. The Hill equation is no longer applicable. This can be aggravated if the extinction coefficient of the five-coordinate complex is greatly different from that of the six-coordinate complex.

In addition to the problems discussed above another significant approximation made in applying the Hill equation is the use of the total ligand concentration rather than free ligand concentration. When $K$ is large there is a significant difference between the total ligand concentration and the free ligand concentration. This can lead to additional error when using the Hill equation.

In order to investigate the effect of these variables on the determination of $K_{1}$ and $K_{2}$ from spectrophotometric data when using the Hill equation a model system was studied. Theoretical absorbance data were generated for a photometric titration according to equations 1 and 2 . Using the values of $\mathrm{K}_{1}, \mathrm{~K}_{2}, \mathrm{M}_{\mathrm{T}}$ (the total FeTPP concentration) $\mathrm{L}_{\mathrm{T}}$ (the total ligand concentration), and $\mathrm{L}_{\mathrm{F}}$, (the free ligand concentration), the concentrations of the four-coordinate [FeTPP], five-coordinate [FeTPPL] and six coordinate 
[FeTPPL $\mathrm{T}_{2}$ ] iron porphyrins can be iteratively calculated (see program in Appendix 2-2). Figure 2-2 shows the plot of $\log \left(A-A_{0}\right) /(A c-A)$ vs. $\log L_{T}$ and vs. $\log L_{F}$, for values of $K_{1}=8000, K_{2}=240$. Values of the extinction coefficients were chosen to match the values typical of the $\mathrm{Fe}^{(\mathrm{II})} \mathrm{TPP}$ complexes studied in this work at $426 \mathrm{~nm}$. Figure 2-3 shows an identical pair of plots using extinction coefficients typical near wavelength $457 \mathrm{~nm}$.

It is seen in Table 2-1 that the slope of the Hill plot is quite dramatically affected by the values of the extinction coefficients and by the substitution of $L_{T}$ as an approximation of $L_{F}$, the free ligand concentration. The intercept, "log $K_{0}$ ", obtained from these graphs varies from 4.3 to 1.9. A log $K_{0}$ of 6.3 is the target value and the large errors clearly show the problems with the use of the Hill plot for determination of equilibrium constants when $K_{1}$ and $K_{2}$ are sufficiently "close" in value.

In this investigation $K_{1}$ and $K_{2}$ were calculated by a "least error" method. This method makes no assumption concerning the effect of the fivecoordinate species on the observed photometric titration. This method has the added advantage that the UV-visible spectrum of the 5-coordinate complex can be determined.

The logic of the "least error" method is diagrammatically explained by the flow chart in Figure 2-4.

When using the program the approximate values of $K_{1}$ and $K_{2}$ are initially guessed. While keeping $K_{1}$ a constant, $K_{2}$ is varied over a wide range to find a value that gives the minimum error. Then, while keeping $K_{2}$ constant, $K_{1}$ is varied to find the best $K_{1}$. The two steps are repeated until a pair of $K_{1}$ and $K_{2}$ values which give a minimum error is obtained. The minimum on the surface defined by $f\left(K_{1}, K_{2}\right)=$ error $^{2}$ is the best $K_{1}$ and $K_{2}$ for 


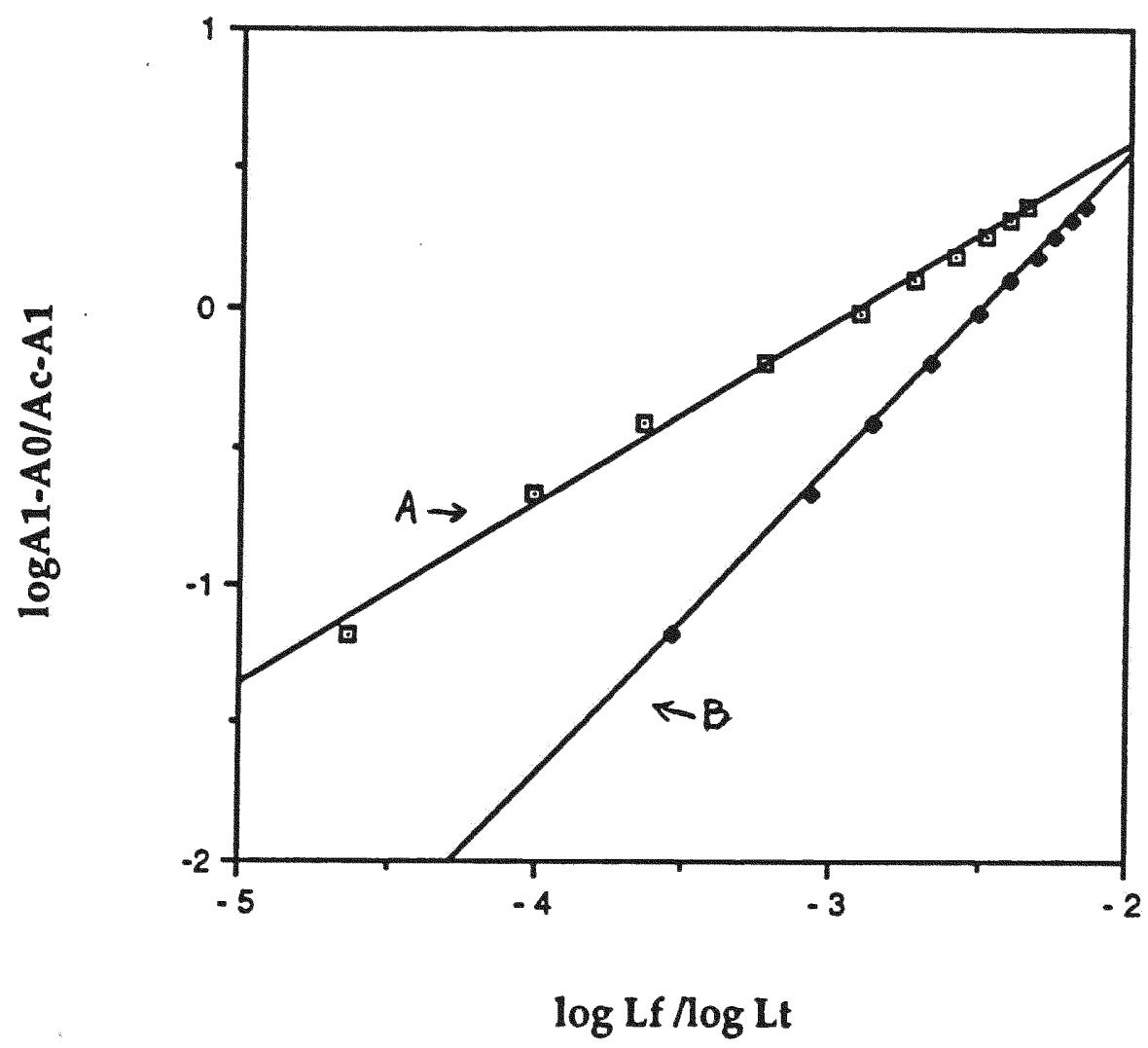

Figure 2-2. Sample graph of The Hill Plot when $K_{1}$ and $K_{2}$ are close in value.

The plot was calculated using $K_{1}=8000, K_{2}=240$ and extinction coefficient typical of iron-porphyrin complexes at $\lambda=426 \mathrm{~nm}$.

Line $A: \log A-A_{0} / A_{C}-A$ vs. $\log L_{F}$

$$
\text { slope }=0.64, \mathrm{Y} \text { intercept }=1.86, \mathrm{r}^{2}=0.995
$$

Line $B: \log A-A_{0} / A_{c}-A$ vs. $\log L_{T}$

$$
\text { slope }=1.12, Y \text { intercept }=2.76, \mathrm{r}^{2}=1.000
$$




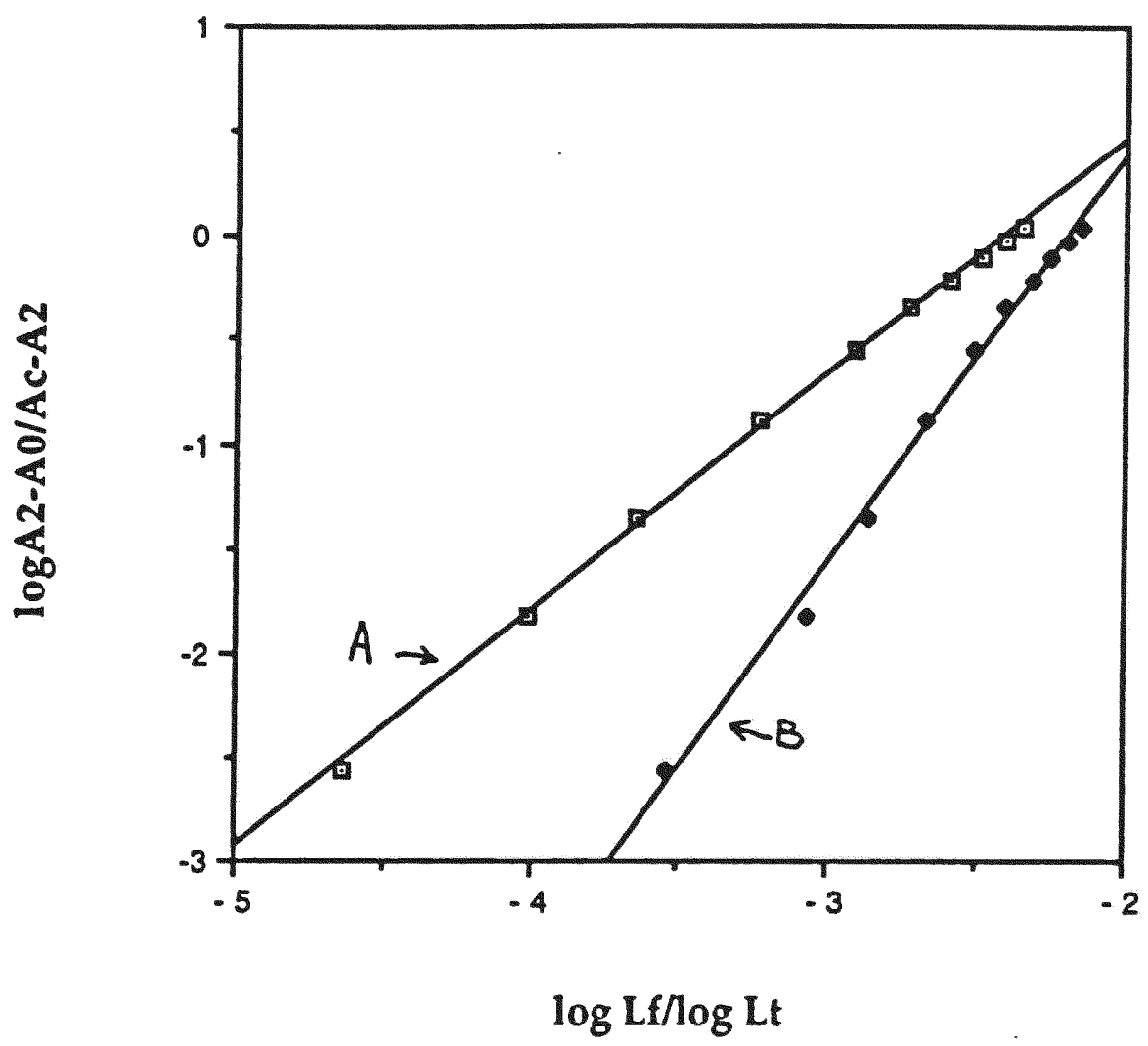

Figure 2-3. Sample graph of the Hill plot when $\mathrm{K}_{1}$ and $\mathrm{K}_{2}$ are close in value. The plot was calculated using $\mathrm{K}_{1}=8000, \mathrm{~K}_{2}=240$ and extinction coefficient typical of iron-porphyrin complexes at $\lambda=457 \mathrm{~nm}$.

Line $A: \log A-A_{0} / A_{C}-A$ vs. $\log L_{F}$

$$
\text { slope }=1.13, \mathrm{Y} \text { intercept }=2.72, \mathrm{r}^{2}=0.999
$$

Line $B: \log A-A_{0} / A_{c}-A$ vs. $\log L_{T}$

$$
\text { slope }=1.95, Y \text { intercept }=4.28, \mathrm{r}^{2}=0.996
$$




\begin{tabular}{|c|c|c|c|}
\hline $\begin{array}{l}\text { Sample graph } \\
\# 1, \text { from } L_{T}\end{array}$ & $\begin{array}{l}\text { Sample graph } \\
\# 2 \text {, from } L_{F}\end{array}$ & $\begin{array}{l}\text { Sample graph } \\
\text { \#3, from } L_{T} \\
\end{array}$ & $\begin{array}{l}\text { Sample graph } \\
\# 4 \text {, from } L_{F}\end{array}$ \\
\hline \multicolumn{2}{|c|}{$\begin{array}{c}\varepsilon_{M}=2.45 \times 10^{4}, \varepsilon_{M L}=1.78 \times 10^{4} \\
\varepsilon_{M L 2}=6.44 \times 10^{3}\end{array}$} & \multicolumn{2}{|c|}{$\begin{array}{c}\varepsilon_{M}=1.78 \times 10^{3}, \varepsilon_{M L}=2.02 \times 10^{3} \\
\varepsilon_{M L 2}=2.32 \times 10^{4}\end{array}$} \\
\hline Slope $(n)=1.1$ & Slope $(n)=0.6$ & Slope $(n)=1.9$ & Slope $(n)=1.1$ \\
\hline $\log \mathrm{K}=2.8$ & $\log \mathrm{K}=1.9$ & $\log K=4.3$ & $\log K=2.7$ \\
\hline$r^{2}=1.000$ & $r^{2}=0.995$ & $r^{2}=0.996$ & $r^{2}=0.999$ \\
\hline
\end{tabular}

Table 2-1. The results of the sample calculations obtained using Hill equation.

The data are calculated based upon typical $\varepsilon$ values for the titration of $\mathrm{Fe}^{(\mathrm{II})} \mathrm{TPP}$ with a phosphorus ligand, and $\mathrm{K}_{1}=8000, \mathrm{~K}_{2}=240$ and $\log \mathrm{K}_{0}=6.3 .\left(\mathrm{K}=\mathrm{K}_{1} \times \mathrm{K}_{2}\right)$. None of these results adequately estimates the $\mathrm{K}_{1}, \mathrm{~K}_{2}$ or $\mathrm{K}_{0}$ values. 


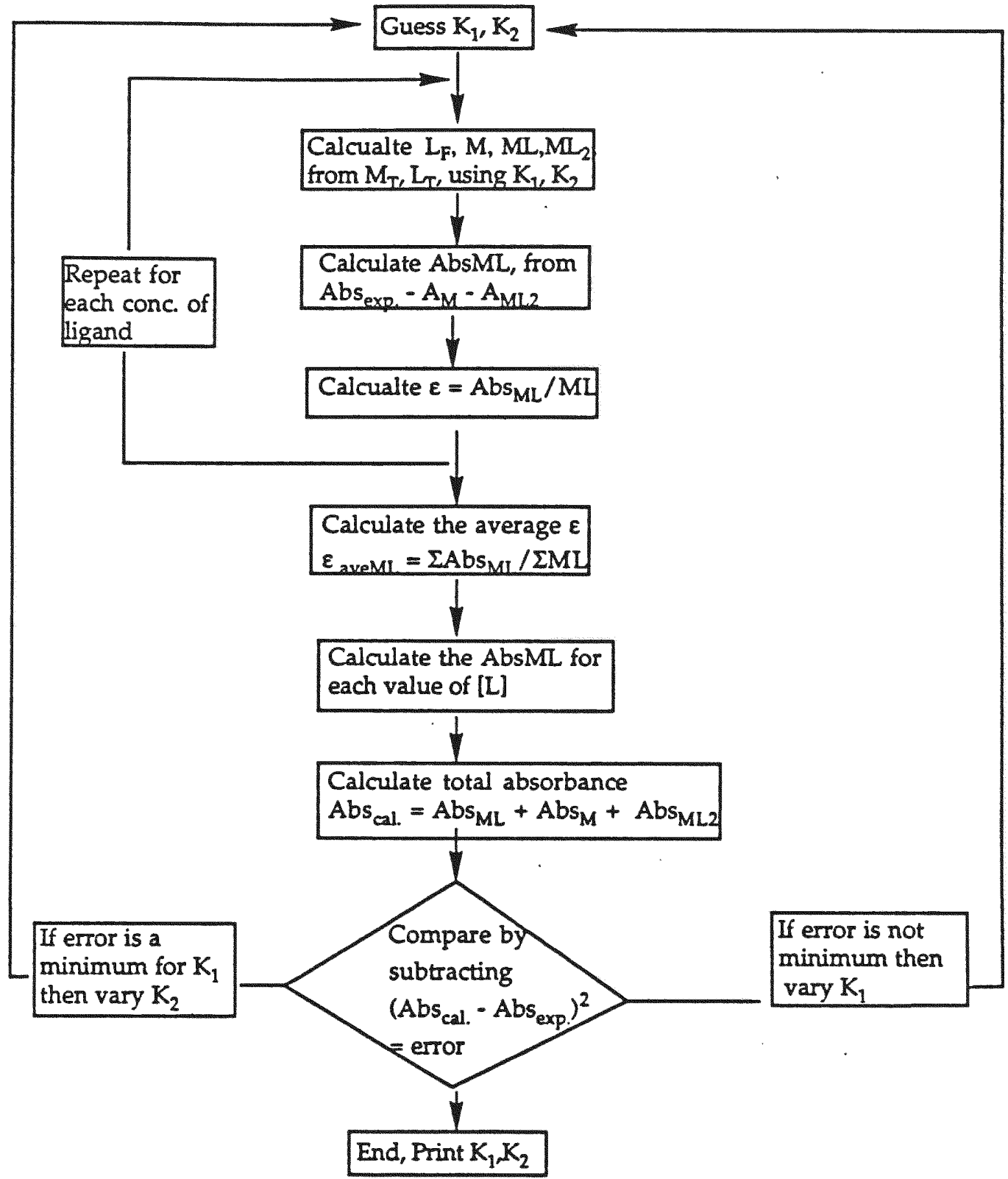

Figure 2-4. The flow chart of the logic of the "least error" method to calculate $\mathrm{K}_{1}$ and $\mathrm{K}_{2}$. 


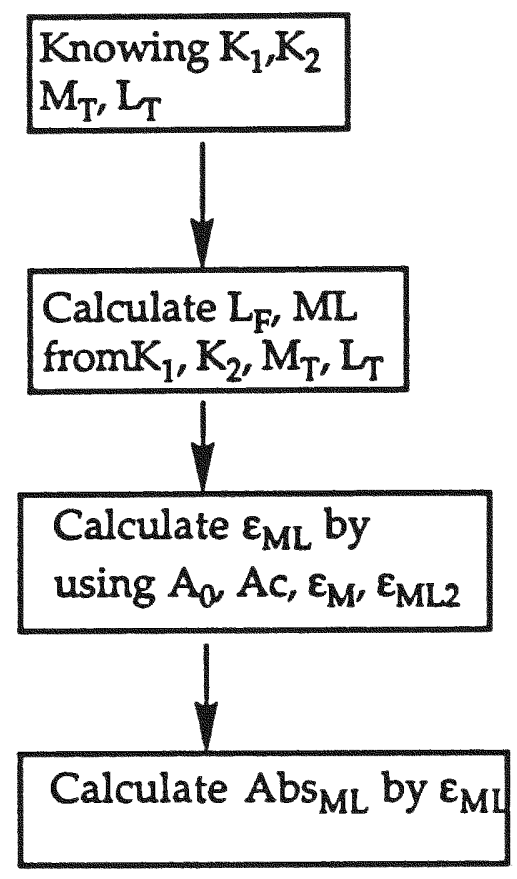

Figure 2-5. The flow chart of calculating the five-coordinate $\mathrm{Fe}^{(\mathrm{II})} \mathrm{TPP}$ spectrum. 
that specific reaction. The resulting values of $\mathrm{K}_{1}$ and $\mathrm{K}_{2}$ are compared to the data by graphing Abs.(calculated) and Abs.(experiment) vs. $\mathrm{L}_{\mathrm{T}}$, for example see Figure 4-1. A chemically reasonable match must be achieved - i.e. the maxima must reasonably correspond, and $\mathrm{K}_{1}, \mathrm{~K}_{2}$ must not require any non-realistic values of the extinction coefficient for the 5 coordinate species (i.e.-negative absorbance).

The method described above eliminates the problems of the Hill equation when there is no isosbestic point in a spectrophotometric titration spectrum. When $K_{1}$ and $K_{2}$ values are known the UV-visible spectrum of the 5-coordinate complex can also be determined. The calculation method for determination of the spectrum of the 5-coordinate complex is outlined in Figure 2-5. The calculations shown in Figure 2-5 were done at $4 \mathrm{~nm}$ intervals.

In Figure $2-4$ and $2-5, M_{T}$ is the total iron-porphyrin concentration, $\mathrm{L}_{\mathrm{T}}$ is the total ligand concentration at each aliquot, $\mathrm{L}_{\mathrm{F}}$ is the free ligand concentration at each aliquot, $M$ is the free iron-porphyrin concentration, $M L$ is the concentration of the five-coordinate product, $\mathrm{ML}_{2}$ is the concentration of the six-coordinate product, $\mathrm{n}$ is the the number of aliquots in the titration, Absn is the absorbance after the $n^{\text {th }}$ aliquot, $\varepsilon_{M}, \varepsilon_{M L}, \varepsilon_{M L_{2}}$ are extinction coefficients for free iron-porphyrin, five-coordinate phosphorus adduct and six-coordinate phosphorus adduct, respectively.

Reaction of $\mathrm{Fe}^{(\mathrm{II})} \mathrm{TPP}$ with different phosphine and phosphite ligands shows a lack of isosbestic points. The formation of the 5-coordinate product is easy to observe. These titrations are Case 3 examples and the formation of the five-coordinate product is significant, i.e. $\mathrm{K}_{1}$ and $\mathrm{K}_{2}$ are sufficiently close that the Hill plot are not useful. 


\section{Chapter 3. Experimental Methods and Data}

The equilibrium constants $K_{1}$ and $K_{2}$ of the coordination reactions of $\mathrm{Fe}^{(\mathrm{II})} \mathrm{TPP}$ with different phosphorus ligands were measured by the spectrophotometric method.29 A sample solution was titrated while its absorbance was monitored as a function of titrant volume. The measurement was done by titrating a THF solution of $\mathrm{Fe}^{(\mathrm{II})} \mathrm{TPP}$ successively with the ligand solution. The concentrations of the two solutions are known. A Shimazu UV-2101 PC spectrophotometer was used to follow the reaction. The changes in the absorption at a specific wavelength can be used to calculate the equilibrium constants based on the "least error" method discussed in Chapter 2.

\section{PART I EXPERIMENTAL}

\section{Solvents}

All reactions were carried out in a Vacuum Atmospheres glove box under $\operatorname{Ar}\left(\mathrm{H}_{2} \mathrm{O}, \mathrm{O}_{2}<1 \mathrm{ppm}\right)$. Solvents (AR) were degassed outside the glove box and then dried by distillation inside the glove box from $\mathrm{CaH}_{2}$ (heptane) or from purple sodium/benzophenone dianion (THF, toluene, benzene).

\section{2. $\mathrm{Fe}^{(\mathrm{II})} \mathrm{TPP}$}

Fe(II)TPP were obtained by the reduction of $\mathrm{Fe}(\mathrm{Cl}) \mathrm{TPP}$. Excess $\mathrm{Cr}(\mathrm{AcAc})_{2}$ $(0.5 \mathrm{~g})$ was added to a solution of $\mathrm{Fe}(\mathrm{Cl}) \mathrm{TPP}(1.0 \mathrm{~g})$ in benzene (about $100 \mathrm{ml})$. The reacting solution was heated to boiling and allowed to gently reflux for 


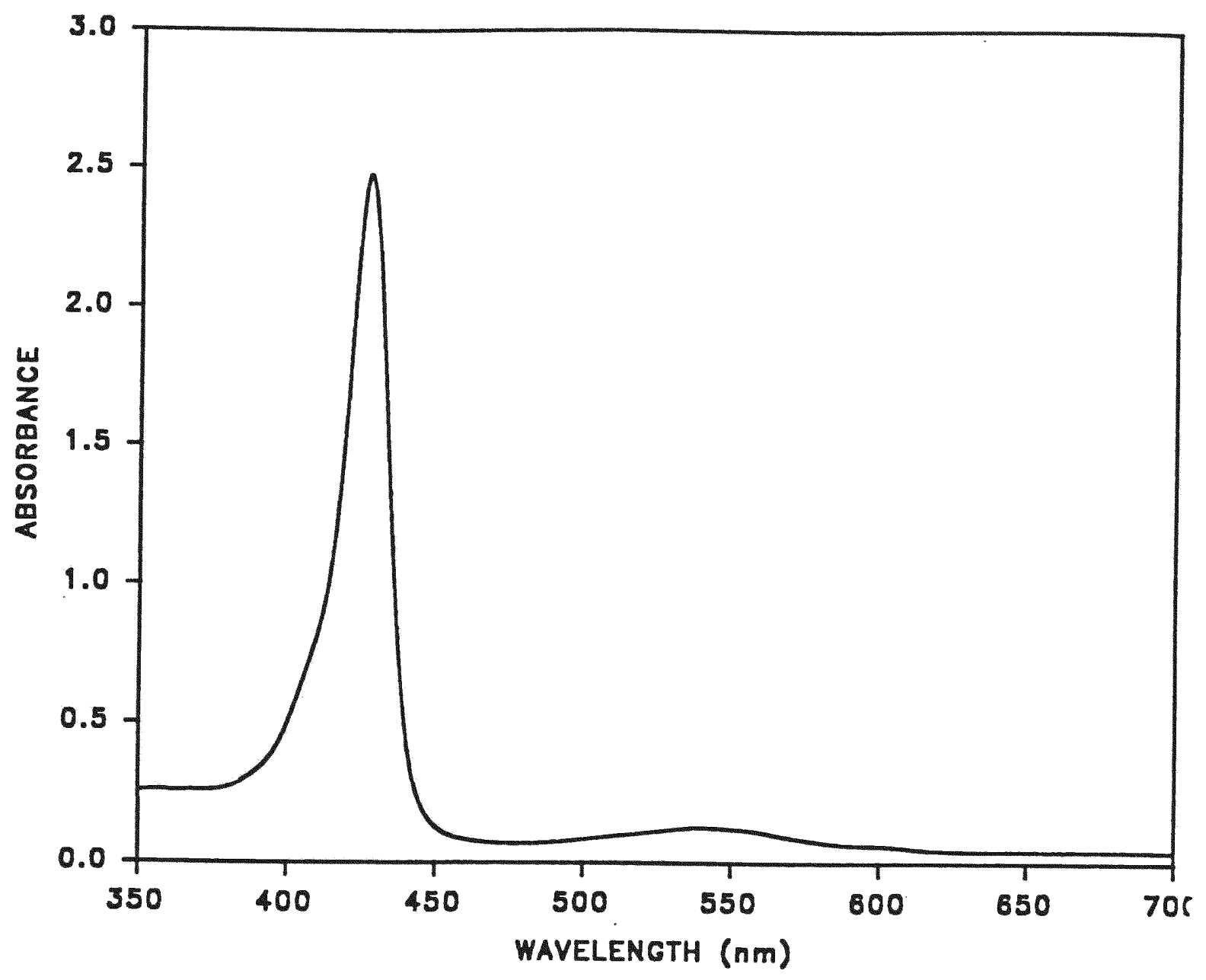

Figure 3-1. UV-Visible spectrum of Fe (II)TPP in THF. 
about 5 minutes. The resulting solution was filtered through a medium frit to remove the insoluble impurities. Slow addition of ethanol $(60 \mathrm{ml})$ yielded crystals. Addition of $80 \mathrm{ml}$ ethanol (2 hours later) and $50 \mathrm{ml}$ heptane (4 hours later) resulted in maximal crystallization. The yield was $0.7 \mathrm{~g}$, about $65 \%$ based on $\mathrm{Fe}(\mathrm{Cl}) \mathrm{TPP}$. The UV-visible spectrum of the product in THF exhibits a 426 $\mathrm{nm}$ Soret band which is the characteristic of the desired Fe(II)TPP. (Figure 3-1).

\section{3, Titrations}

All titrations of $\mathrm{Fe}^{(\mathrm{II})} \mathrm{TPP}$ with phosphine and phosphite compounds were carried out in the glove box at room temperature, $23.0 \pm 2.0^{\circ} \mathrm{C}$. All titrations were done in THF except the titration with triethyl phosphine which was done in both THF and benzene. The reaction was done in a 0.05 $\mathrm{cm}$ cell and the change of volume due to the addition of the ligand solution was corrected in all the titrations by mutiplying by the volume factor $\left(\left(\mathrm{V}_{\mathrm{t}}+\right.\right.$ V) $\left(V_{t}\right)$. The UV-visible spectrum of the titration was recorded by a Shimadzu UV-2101 PC spectrophotometer. The phosphine and the phosphite compounds were purchased from the Strem or Aldrich.

4. Determination of the concentration of the Fe(II)TPP solution

To avoid the errors due to weighing, the concentration of the initial $\mathrm{Fe}^{(\mathrm{II})} \mathrm{TPP}$ solution was determined from its UV-visible spectrum. The accurate pathlength of the $0.05 \mathrm{~cm}$ cells was determined by measurement using air-stable FeTPPCl whose extinction coefficient was measured by using a $1.0 \mathrm{~cm}$ cell and a solution with an accurate known concentration, $2.63 e-4 \mathrm{M}$ 
(made by dissolving $0.0462 \mathrm{gFeTPPCl}$ in a $250 \mathrm{ml}$ volumetric flask with $\mathrm{CH}_{2} \mathrm{Cl}_{2}$ ). The extinction coefficient of $\mathrm{Fe}(\mathrm{II}) \mathrm{TPP}$ was then determined by using a Fe(II) TPP solution with an accurate concentration $(1.47 \mathrm{e}-3 \mathrm{M})$, prepared by weghing out $0.0980 \mathrm{~g} \mathrm{Fe}^{(\mathrm{II}) \mathrm{TPP}}$ and dissolving in $100 \mathrm{ml}$ volumetric flask with THF, and the two calibrated $0.05 \mathrm{~cm}$ cells $(0.0416 \mathrm{~cm}, 0.0443 \mathrm{~cm})$. The measured absorbances were 1.703 and 1.778 respectively. The resulting extinction coefficient for Fe(II) TPP is $2.77( \pm 0.02) e+4$ in THF. The concentrations of $\mathrm{Fe}^{(\mathrm{II})} \mathrm{TPP}$ in the following titrations were calculated from the measured absorbance using the known $\varepsilon$ and pathlength.

5, Titration of Fe(II)TPP with Trimethyl Phosphine

A THF solution of $\mathrm{Fe}^{(\mathrm{II})} \mathrm{TPP}(1.44 \mathrm{e}-3 \mathrm{M})$ was prepared by dissolving $10.0 \pm 2 \mathrm{mg}$ of $\mathrm{Fe}(\mathrm{II}) \mathrm{TPP}$ in a $10 \mathrm{ml}$ volumetric flask. The solution of trimethyl phosphine $(3.77 \mathrm{e}-2 \mathrm{M})$ was made by dissolving $40 \mu \mathrm{l}$ of pure $\mathrm{P}(\mathrm{Me})_{3}$ in a $10 \mathrm{ml}$ volumetric flask. Aliquots of $\mathrm{P}(\mathrm{Me})_{3}$ solution were added successively to a 1.0 $\mathrm{ml}$ volume of $\mathrm{Fe}(\mathrm{II}) \mathrm{TPP}$ solution. The UV-visible titration spectra (Figure 3$2 a, 2 b, 2 c)$ showed no clear isosbestic points and also showed the loss of the Soret band at $426 \mathrm{~nm}$ and the growth of a new Soret band at $455 \mathrm{~nm}$. The absorption changes at several wavelengths during the titration process and the total ligand concentration at each titration point are recorded in Table 3-1.

6. Titration of Fe ${ }^{(I I)}$ TPP With Triethyl Phosphine

A THF solution of $\mathrm{Fe}^{(\mathrm{II})} \mathrm{TPP}(1.56 \mathrm{e}-3 \mathrm{M})$ was prepared by dissolving 10.0 $\pm 2 \mathrm{mg}$ of $\mathrm{Fe}(\mathrm{II}) \mathrm{TPP}$ in a $10 \mathrm{ml}$ volumetric flask, and the solution of triethyl phosphine (1.35e-2M) was prepared by dissolving $20 \mu \mathrm{l}$ of pure $\mathrm{PEt}_{3}$ in a $10 \mathrm{ml}$ volumetric flask. $20 \mu \mathrm{l}$ aliquots of $\mathrm{PEt}_{3}$ solution were added successively to a 


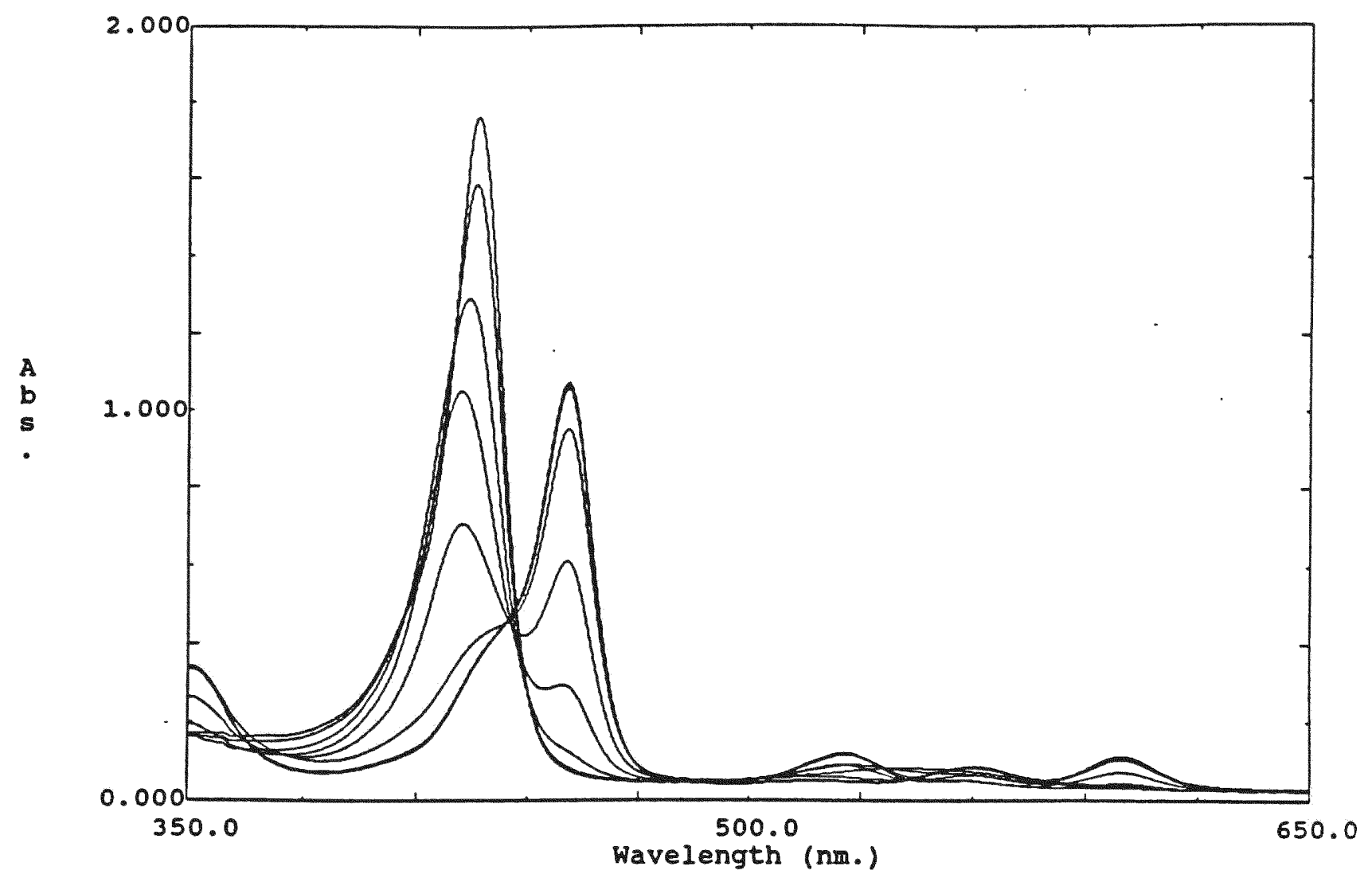

Figure 3-2a. UV-Visible spectrum of the titration of Fe(II)TPP with trimethyl phosphine in THF. 


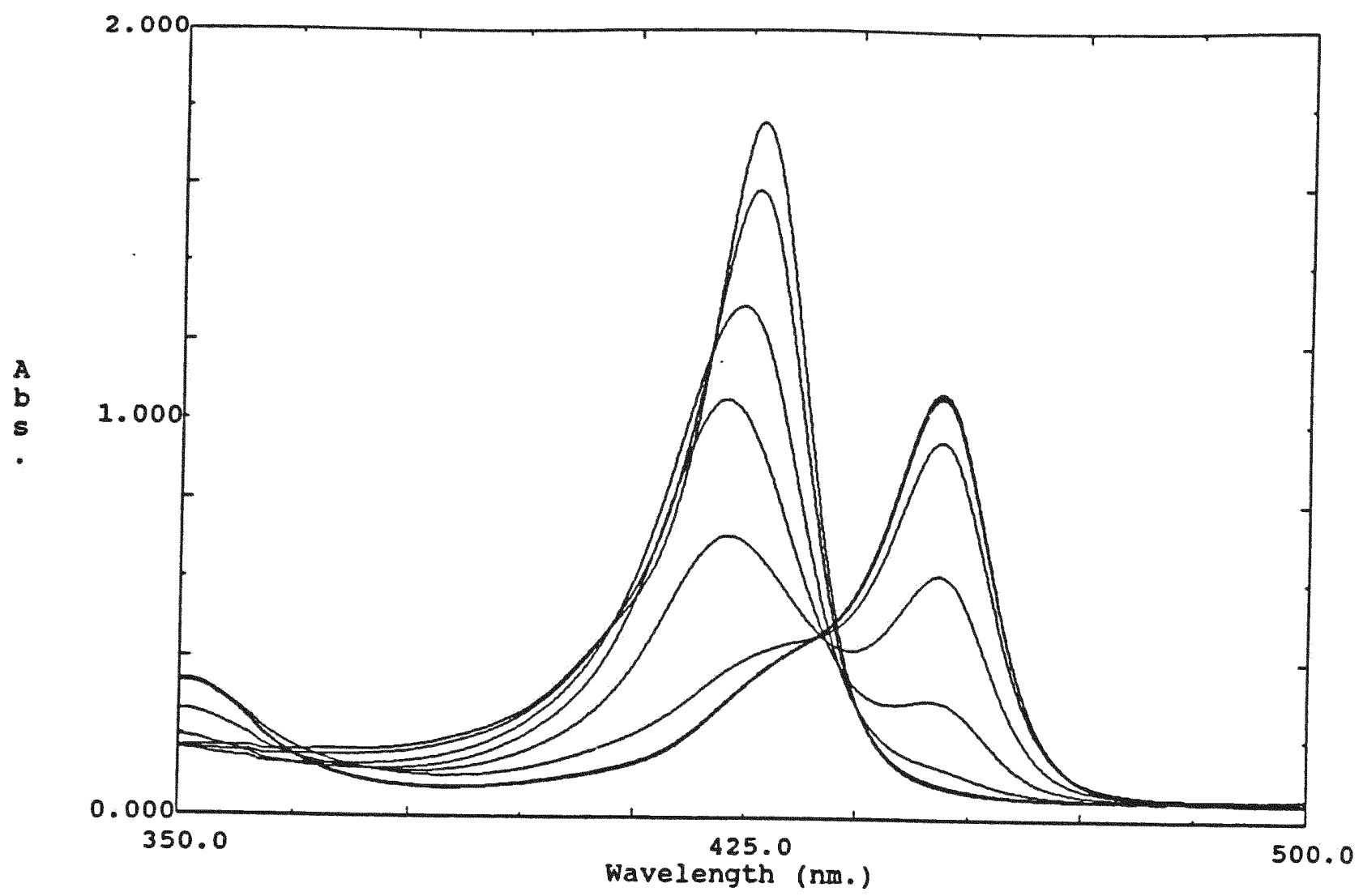

Figure 3-2b. Soret bands of the titration of $\mathrm{Fe}^{(\mathrm{II})} \mathrm{TPP}$ with trimethyl phosphine in THF. New Soret band formed at $455 \mathrm{~nm}$. No clear isosbestic points are observed. 


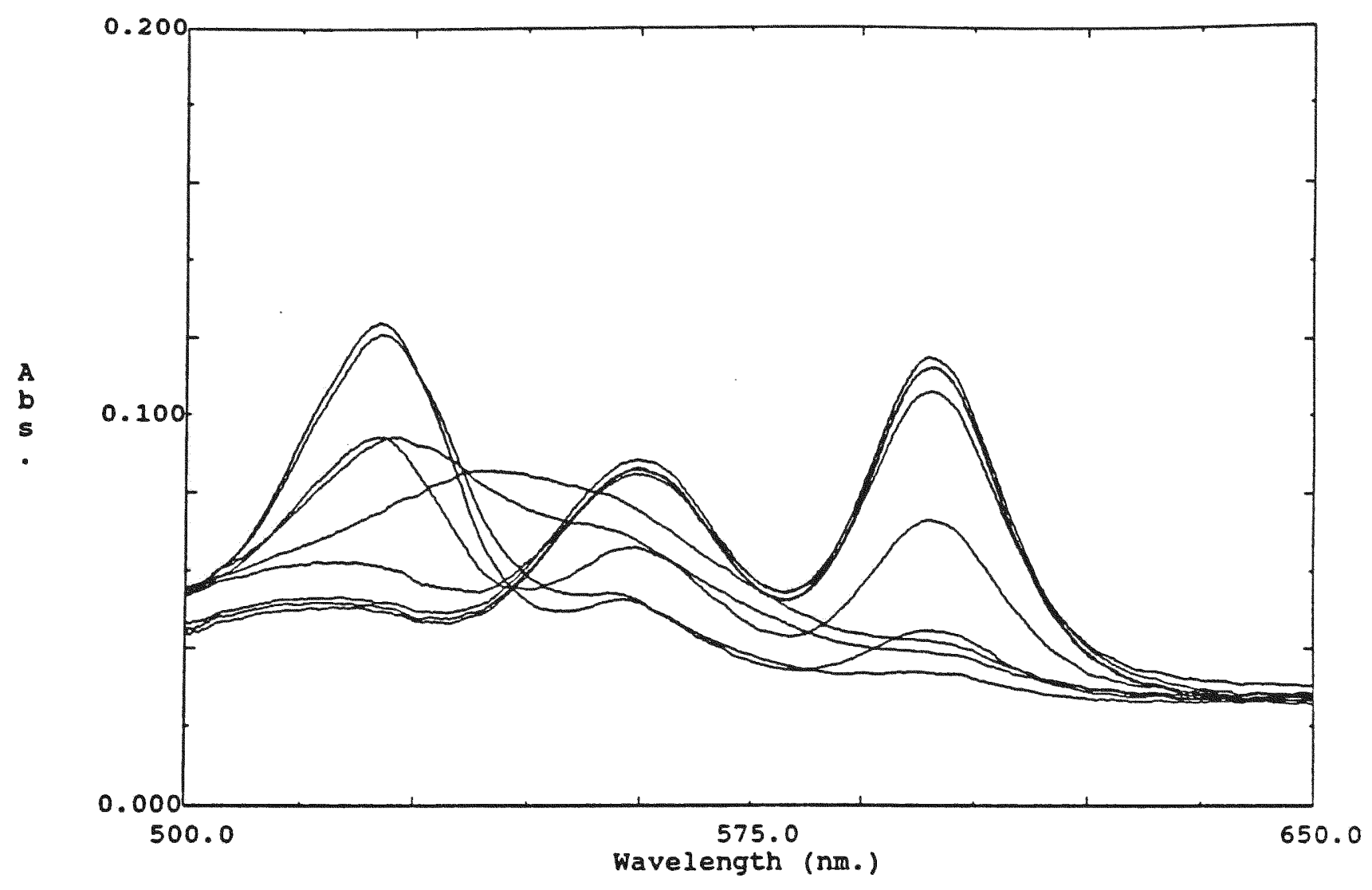

Figure 3-2c. $\alpha-\beta$ region of the titration of Fe(II)TPP with trimethyl phosphine. No clear isosbestic points are observed. 


\begin{tabular}{|c|c|c|c|c|c|}
\hline $\begin{array}{l}\text { Vol. of } \\
\text { P(Me) } 3^{\circ} \\
\text { (ul) }\end{array}$ & $\begin{array}{l}\text { Total } \\
\text { Conc. of } \\
\text { P(Me) } \\
(M) \\
\end{array}$ & $\frac{A}{(426.6 \mathrm{~nm})}$ & $\left(437^{A} .1 \mathrm{~nm}\right)$ & $\left.\stackrel{A}{A}{ }^{A} .0 \mathrm{~nm}\right)$ & $\frac{A}{(525.4 \mathrm{~nm})}$ \\
\hline 0 & 0 & 1.767 & 0.501 & 0.080 & 0.075 \\
\hline 10 & $3.73 e-4$ & 1.586 & 0.466 & 0.087 & 0.093 \\
\hline 30 & $1.10 e-3$ & 1.244 & 0.413 & 0.129 & 0.121 \\
\hline 50 & $1.80 e-3$ & 0.942 & 0.401 & 0.294 & 0.124 \\
\hline 70 & $2.47 e^{-3}$ & 0.661 & 0.434 & 0.614 & 0.094 \\
\hline 90 & $3.11 e-3$ & 0.414 & 0.481 & 0.955 & 0.061 \\
\hline 110 & $3.74 e^{-3}$ & 0.361 & 0.495 & 1.063 & 0.051 \\
\hline 130 & $4.34 e^{-3}$ & 0.358 & 0.495 & 1.070 & 0.049 \\
\hline Excess & & 0.362 & 0.500 & 1.076 & 0.052 \\
\hline
\end{tabular}

Table 3-1. Titration of Fe $\mathrm{FPP}^{\mathrm{M}}$ with Trimethyl Phosphine. The initial volume of FeTPP is $1.0 \mathrm{ml}$ ( $1.44 \mathrm{e}-3 \mathrm{M}$ ). 
$1.0 \mathrm{ml}$ volume of $\mathrm{Fe}$ (II)TPP solution. The titration spectra (Figure 3-3a, 3b, 3c) show no clear isospestic points, the loss of the Soret band at $426 \mathrm{~nm}$ (FeTPP) and the growth of a new Soret band at $455 \mathrm{~nm}$. The changes of the absorbance at several wavelength and the total concentration of $P(E t)_{3}$ at each aliquot are recorded in Table 3-2a. The titration spectrum in benzene is shown in Figure 3-3d, and the absorbance at different wavelength are recorded in Table 3-2b.

7. Titration of Fe(II)TPP with Tri-n-butyl Phosphine

A THF solution of Fe ${ }^{(I I)}$ TPP $(1.43 e-3 \mathrm{M})$ was prepared by dissolving $10.0 \pm 2 \mathrm{mg} \quad \mathrm{Fe}^{(\mathrm{II})} \mathrm{TPP}$ in a $10 \mathrm{ml}$ volumetric flask, and the tri-n-butyl phosphine solution (1.61e-2M) was made by dissolving $40 \mu \mathrm{l}$ of pure tri- $\mathrm{n}$ butyl phosphine in $10 \mathrm{ml}$ volumetric flask with THF. Aliquots of $\mathrm{P}\left(\mathrm{n}-\mathrm{C}_{4} \mathrm{H}_{9}\right)_{3}$ solution, typical $20 \mu \mathrm{l}$, were added to a $1.0 \mathrm{ml}$ volume of Fe(II)TPP solution. The titration spectra show no clear isosbestic points and a new Soret band formed at $456 \mathrm{~nm}$ (Figure 3-4a, 4b, 4c). The absorbance data and the total concentration of the ligand at each titration point are recorded in Table 3-3.

8, Titration of Fe(II)TPP With Triethyl Phosphite
A THF solution of $\mathrm{Fe}^{(\mathrm{II}) \mathrm{TPP}}$
(1.66e-3M) was prepared by dissolving $10.0 \pm 2 \mathrm{mg} \mathrm{Fe}(\mathrm{II}) \mathrm{TPP}$ in a $10 \mathrm{ml}$ volumetric flask, and the triethyl phosphite solution( $2.90 \mathrm{e}-2 \mathrm{M}$ ) was made by dissolving $50 \mu \mathrm{l}$ of pure $\mathrm{P}\left(\mathrm{OC}_{2} \mathrm{H}_{5}\right)_{3}$ in 10 $\mathrm{ml} \mathrm{THF}$. Aliquots in $20 \mu \mathrm{l}$ of triethyl phosphite solution were added successively to a $1.0 \mathrm{ml}$ volume of the Fe(II) TPP solution. The titration spectrum shows no clear isosbestic points and a new Soret band formed at 446 nm. (Figure 3-5a,5b,5c). The absorbance changes and the total concentrations of the ligand are recorded in Table $3-4$. 


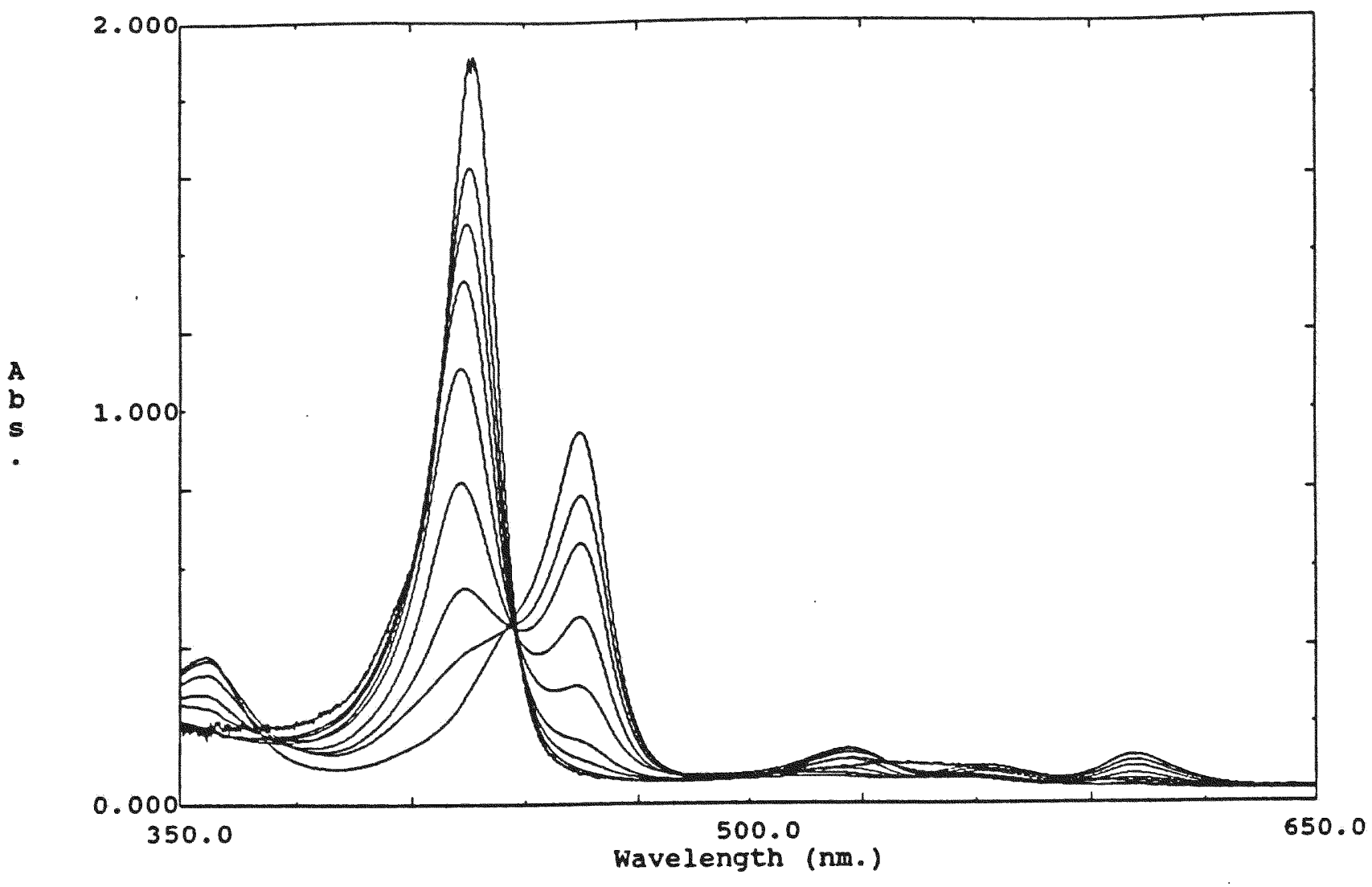

Figure 3-3a. UV-Visible sspectrum of the titration of Fe(II)TPPP with triethyl phosphine in THF. 


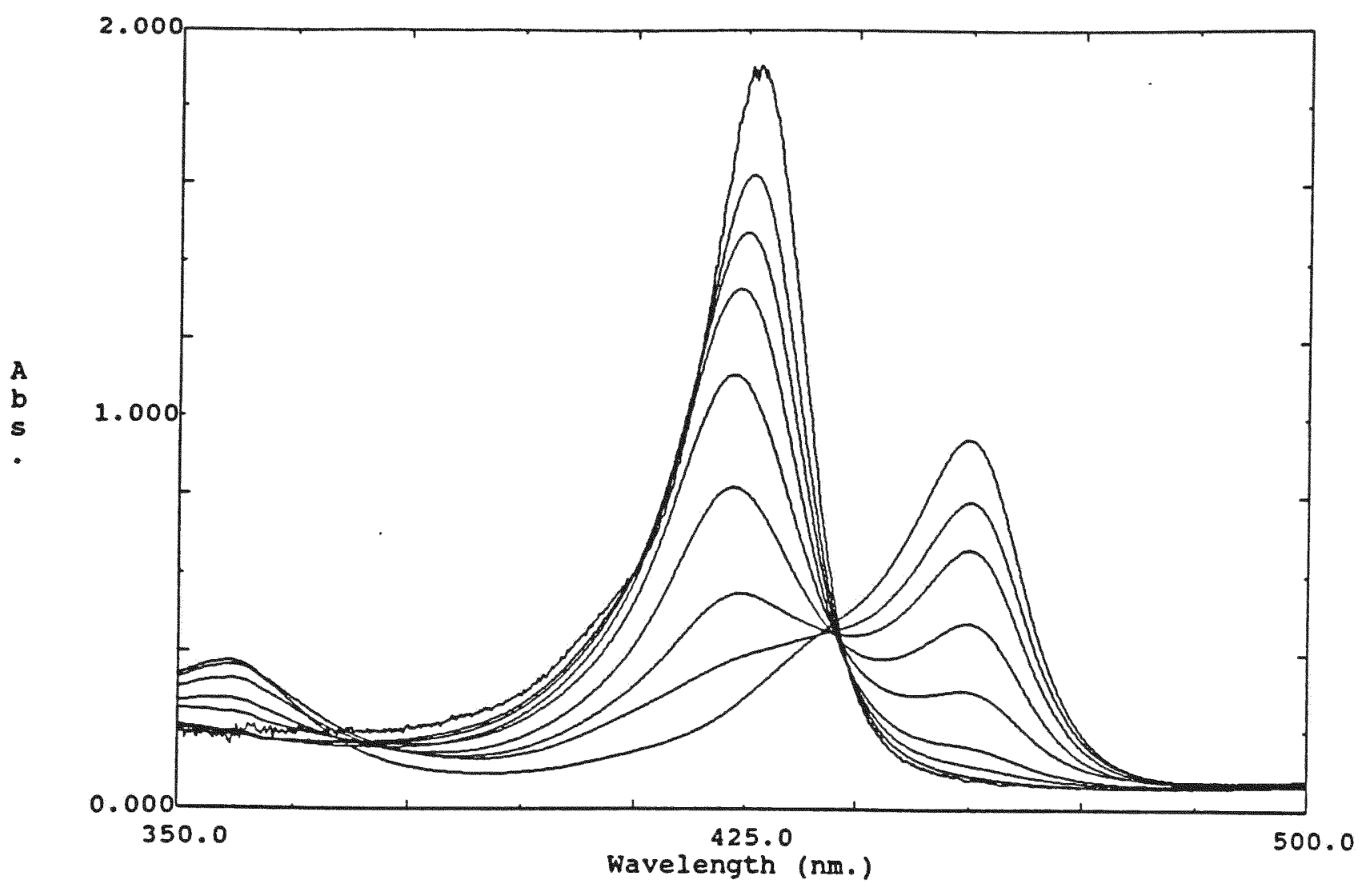

Figure 3-3b. Soret bands of the titration of Fe(II)TPP with triethyl phosphine in THF. New Soret band formed at $455 \mathrm{~nm}$. No clear isosbestic points are observed. 


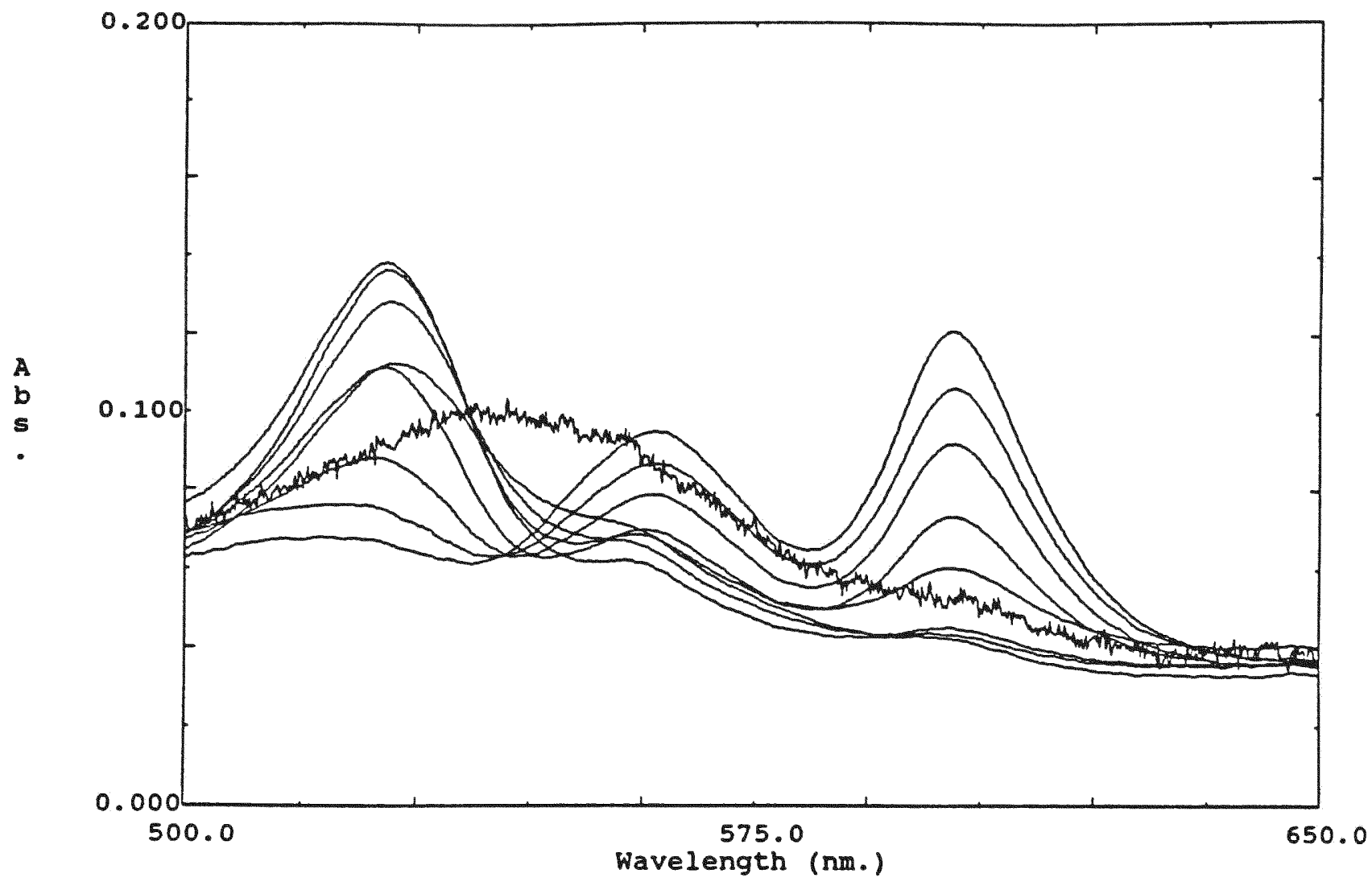

Figure 3-3c. $\alpha-\beta$ region of the titration of $\mathrm{Fe}^{(\mathrm{II})} \mathrm{TPP}$ with triethyl phosphine. No clear isosbestic points are observed. 


\begin{tabular}{|c|c|c|c|c|c|}
\hline $\begin{array}{l}\text { Vol. of } \\
\text { P(Et) } \\
\quad(u 1)^{3}\end{array}$ & $\begin{array}{c}\text { Total } \\
\text { Conc. of } \\
P(E t)_{3} \\
(M)^{2}\end{array}$ & $(426.8 \mathrm{~nm})$ & $\frac{A}{(454.6 \mathrm{~nm})}$ & $\frac{\mathrm{A}}{(526.2 \mathrm{~nm})}$ & $\frac{\mathrm{A}}{(601.2 \mathrm{~nm})}$ \\
\hline 0 & 0 & 1.909 & 0.078 & 0.092 & 0.052 \\
\hline 10 & $1.34 e^{-4}$ & 1.799 & 0.080 & 0.102 & 0.048 \\
\hline 30 & $3.93 e-4$ & 1.607 & 0.089 & 0.113 & 0.042 \\
\hline 50 & $6.43 e-4$ & 1.438 & 0.115 & 0.129 & 0.043 \\
\hline 70 & $8.83 e-4$ & 1.260 & 0.161 & 0.137 & 0.045 \\
\hline 100 & $1.23 e-3$ & 1.024 & 0.302 & 0.139 & 0.060 \\
\hline 130 & $1.55 e-3$ & 0.766 & 0.478 & 0.112 & 0.073 \\
\hline 160 & $1.86 e-3$ & 0.540 & 0.666 & 0.088 & 0.092 \\
\hline 200 & $2.25 e-3$ & 0.404 & 0.787 & 0.075 & 0.106 \\
\hline 240 & $2.61 e-3$ & 0.397 & 0.807 & 0.073 & 0.109 \\
\hline Excess & & 0.314 & 0.949 & 0.067 & 0.121 \\
\hline
\end{tabular}

Table 3-2a. Titration of $\mathrm{Fe}^{(\mathbb{M})} \mathrm{TPP}$ with Triethyl Phosphine. The initial volume of FeTPP is $1.0 \mathrm{ml}(1.56 \mathrm{e}-3 \mathrm{M})$. 


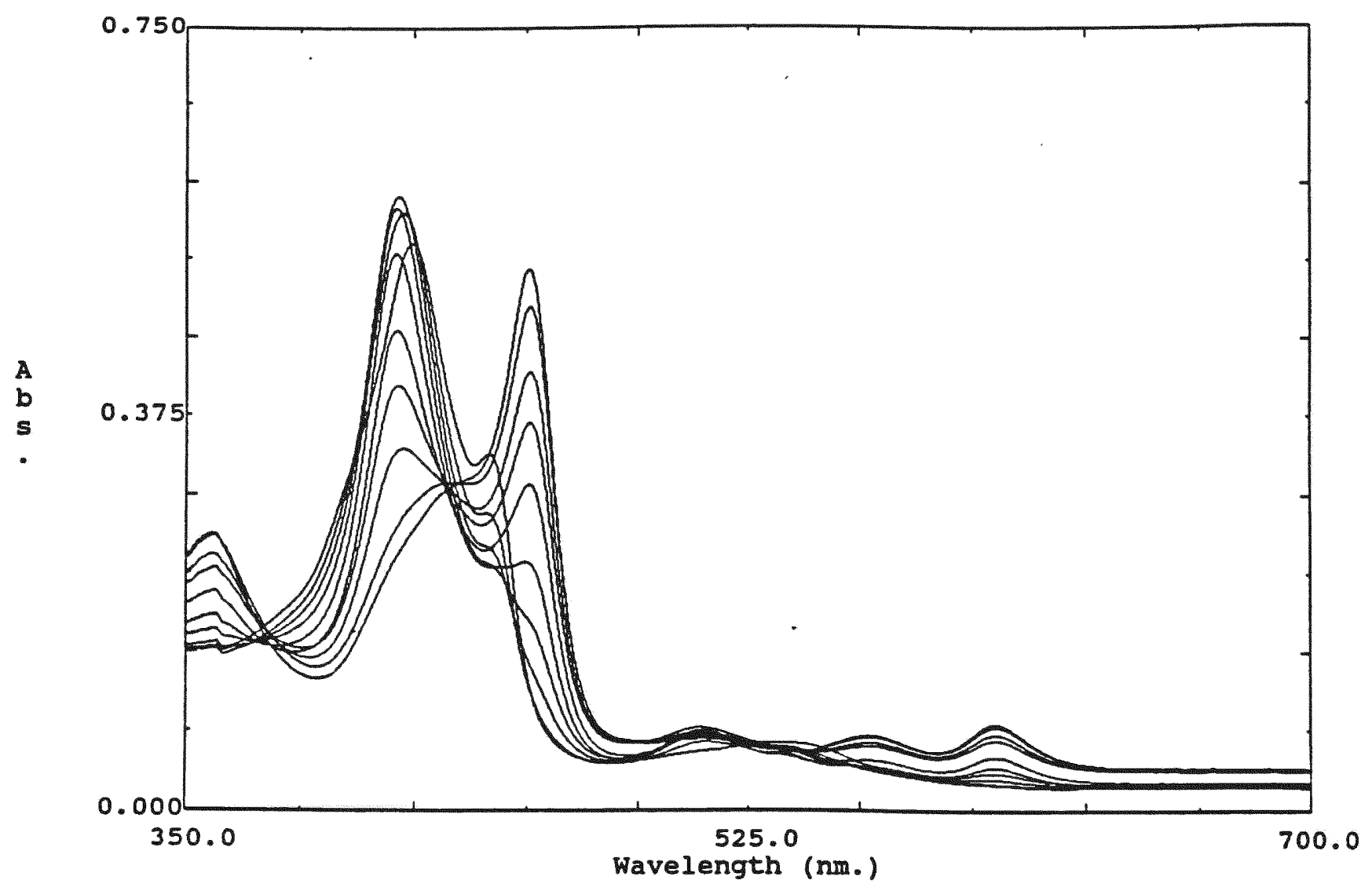

Figure 3-3d. UV-visible spectrum of the titration of $\mathrm{Fe}^{(\mathrm{II})} \mathrm{TPP}$ with triethyl phosphine in benzene. 


\begin{tabular}{|c|c|c|c|c|}
\hline $\begin{array}{l}\text { Vol. of } \\
\mathrm{P}\left(\mathrm{C}_{2} \mathrm{H}_{5}\right)_{3} \\
(\mathrm{UI})^{3}\end{array}$ & $\begin{array}{c}\text { Total Conc. } \\
\text { of } \mathrm{P}\left(\mathrm{C}_{2} \mathrm{H}_{5}\right)_{3} \\
(\mathrm{M})\end{array}$ & $\frac{\mathrm{A}}{(415.8 \mathrm{~nm})}$ & $(443.0 \mathrm{~nm})$ & $\begin{array}{c}\text { A } \\
(455.6 \mathrm{~nm})\end{array}$ \\
\hline 0 & 0 & 0.518 & 0.340 & 0.121 \\
\hline 10 & $1.09 e-4$ & 0.549 & 0.309 & 0.116 \\
\hline 20 & $2.16 e-4$ & 0.569 & 0.284 & 0.117 \\
\hline 30 & $3.20 e-4$ & 0.584 & 0.267 & 0.128 \\
\hline 40 & $4.23 e-4$ & 0.587 & 0.251 & 0.141 \\
\hline 50 & $5.24 e-4$ & 0.585 & 0.241 & 0.159 \\
\hline 60 & $6.23 e-4$ & 0.572 & 0.235 & 0.181 \\
\hline 70 & $7.20 e-4$ & 0.555 & 0.233 & 0.207 \\
\hline 80 & $8.15 e^{-4}$ & 0.527 & 0.232 & 0.236 \\
\hline 90 & $9.08 e-4$ & 0.493 & 0.237 & 0.271 \\
\hline 100 & $1.00 e-3$ & 0.455 & 0.249 & 0.311 \\
\hline 110 & $1.09 e-3$ & 0.405 & 0.275 & 0.369 \\
\hline 120 & $1.18 e-3$ & 0.345 & 0.294 & 0.417 \\
\hline 130 & $1.27 e-3$ & 0.291 & 0.317 & 0.465 \\
\hline 140 & $1.35 e^{-3}$ & 0.277 & 0.324 & 0.479 \\
\hline excess & & 0.249 & 0.338 & 0.516 \\
\hline
\end{tabular}

Table 3-2b. Titration of $F e^{(\mathbb{1})}$ TPP with triethyl phosphine in benzene. The initial volume of FeTPP is $1.0 \mathrm{ml}$ $(1.20 e-3 \mathrm{M})$. 


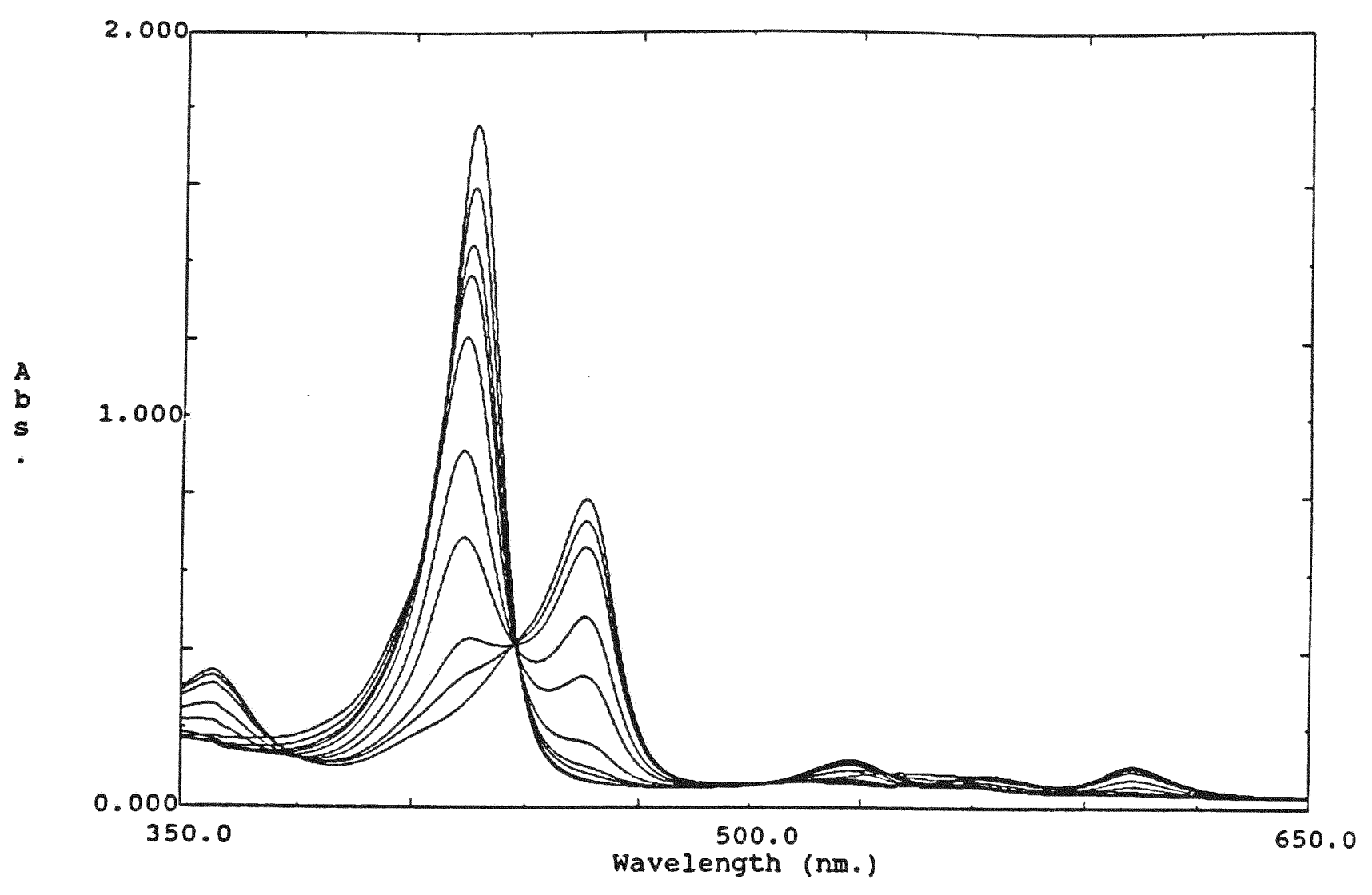

Figure 3-4a. UV-Visible spectrum of the titration of Fe(II)TPP with tri(n-butyl) phosphine in THF. 


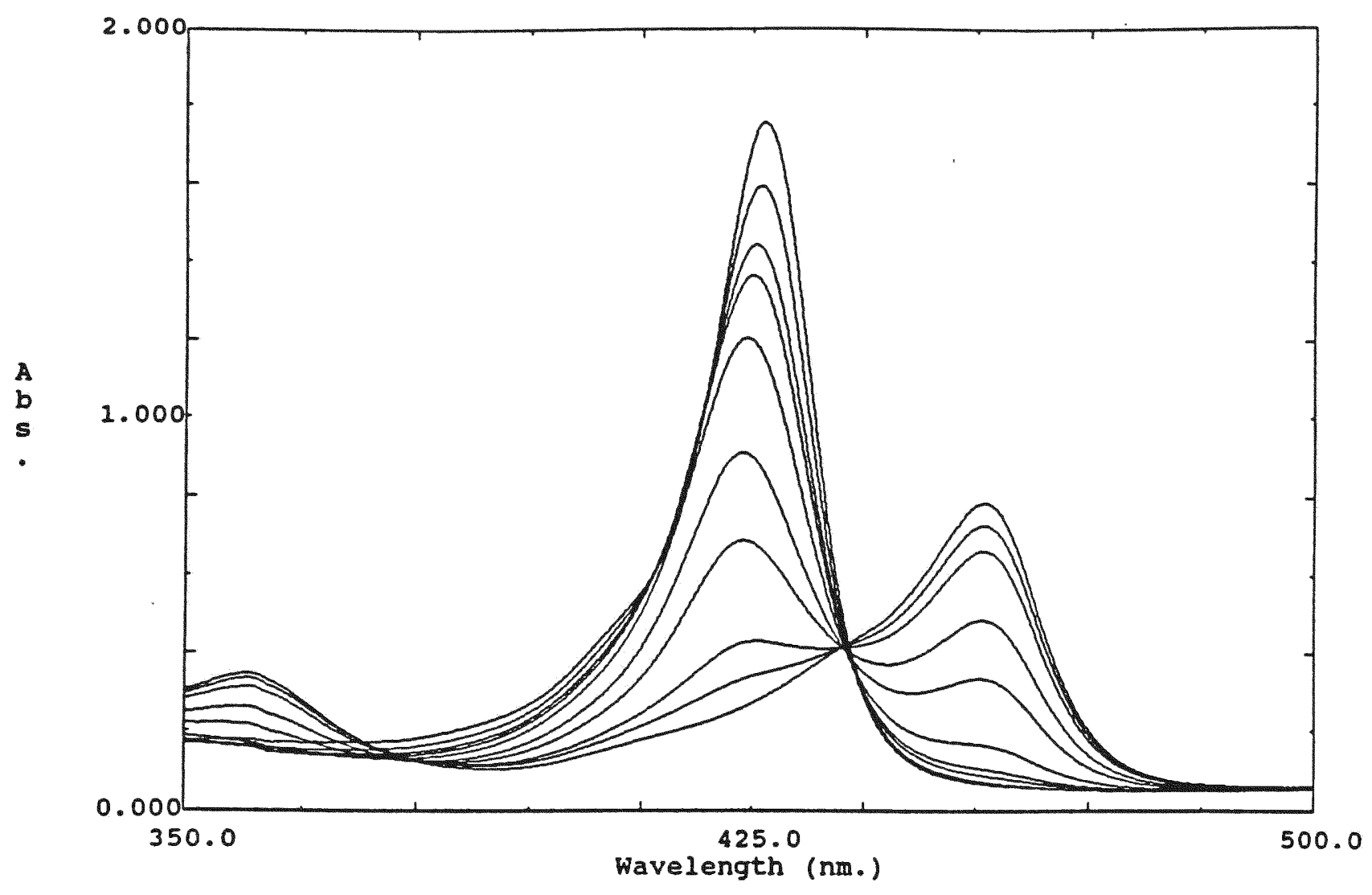

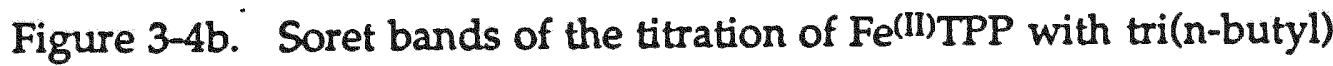
phosphine in THF. New Soret band formed at $455 \mathrm{~nm}$. No clear isosbestic points are observed. 


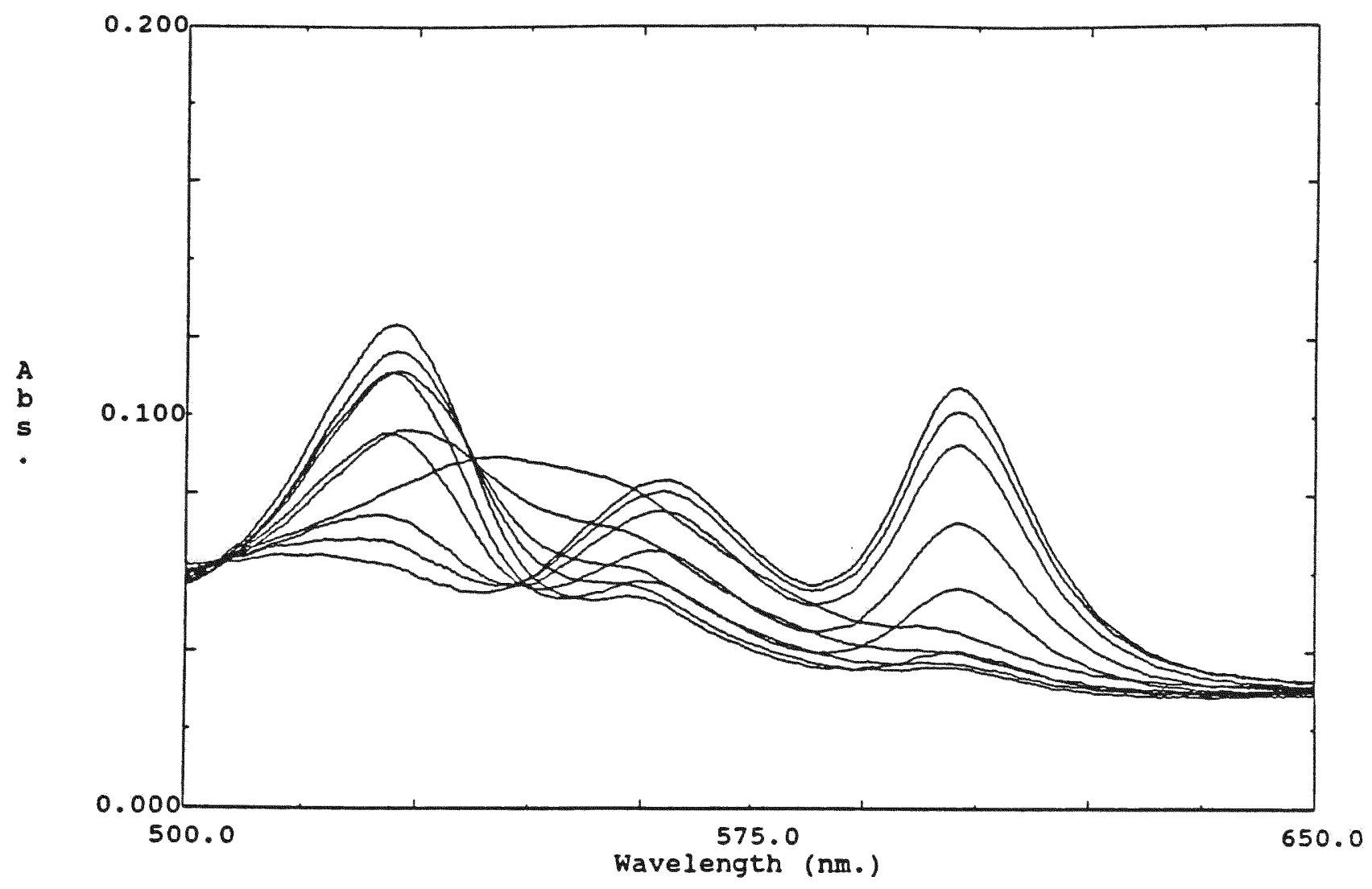

Figure 3-4c. $\alpha-\beta$ region of the titration of $\mathrm{Fe}^{(\mathrm{II}) \mathrm{TPP}}$ with tri(n-butyl) phosphine in THF. No clear isosbestic points are observed. 


\begin{tabular}{|c|c|c|c|c|c|}
\hline $\begin{array}{l}\text { Vol. of } \\
\mathrm{P}(\mathrm{n}-\mathrm{Bu})_{3} \\
(\mathrm{ul})\end{array}$ & $\begin{array}{l}\text { Total } \\
\text { Conc. of } \\
\mathrm{P}(\mathrm{n}-\mathrm{Bu})_{3} \\
(\mathrm{M})\end{array}$ & $\frac{\mathrm{A}}{(426.6 \mathrm{~mm})}$ & $\stackrel{A}{(437.9 \mathrm{~nm})}$ & $\frac{\mathrm{A}}{(456.2 \mathrm{~nm})}$ & $\stackrel{A}{(527.0 \mathrm{~nm})}$ \\
\hline 0 & 0 & 1.757 & 0.429 & 0.068 & 0.082 \\
\hline 20 & $3.16 e-4$ & 1.591 & 0.412 & 0.072 & 0.096 \\
\hline 40 & $6.19 e-4$ & 1.424 & 0.401 & 0.089 & 0.111 \\
\hline 50 & $7.67 e-4$ & 1.334 & 0.396 & 0.105 & 0.116 \\
\hline 70 & $1.05 e-3$ & 1.152 & 0.392 & 0.166 & 0.123 \\
\hline 100 & $1.46 e-3$ & 0.858 & 0.396 & 0.335 & 0.111 \\
\hline 120 & $1.73 e-3$ & 0.659 & 0.405 & 0.486 & 0.096 \\
\hline 150 & $2.10 e^{-3}$ & 0.430 & 0.417 & 0.664 & 0.074 \\
\hline 180 & $2.45 e-3$ & 0.351 & 0.422 & 0.731 & 0.068 \\
\hline Excess & & 0.290 & 0.427 & 0.783 & 0.062 \\
\hline
\end{tabular}

Table 3-3. Titration of $\mathrm{Fe}^{(11)} \mathrm{TPP}$ with Tri-n-butyl Phosphine. The initial volume of FeTPP is $1.0 \mathrm{ml}(1.43 \mathrm{e}-3 \mathrm{M})$. 


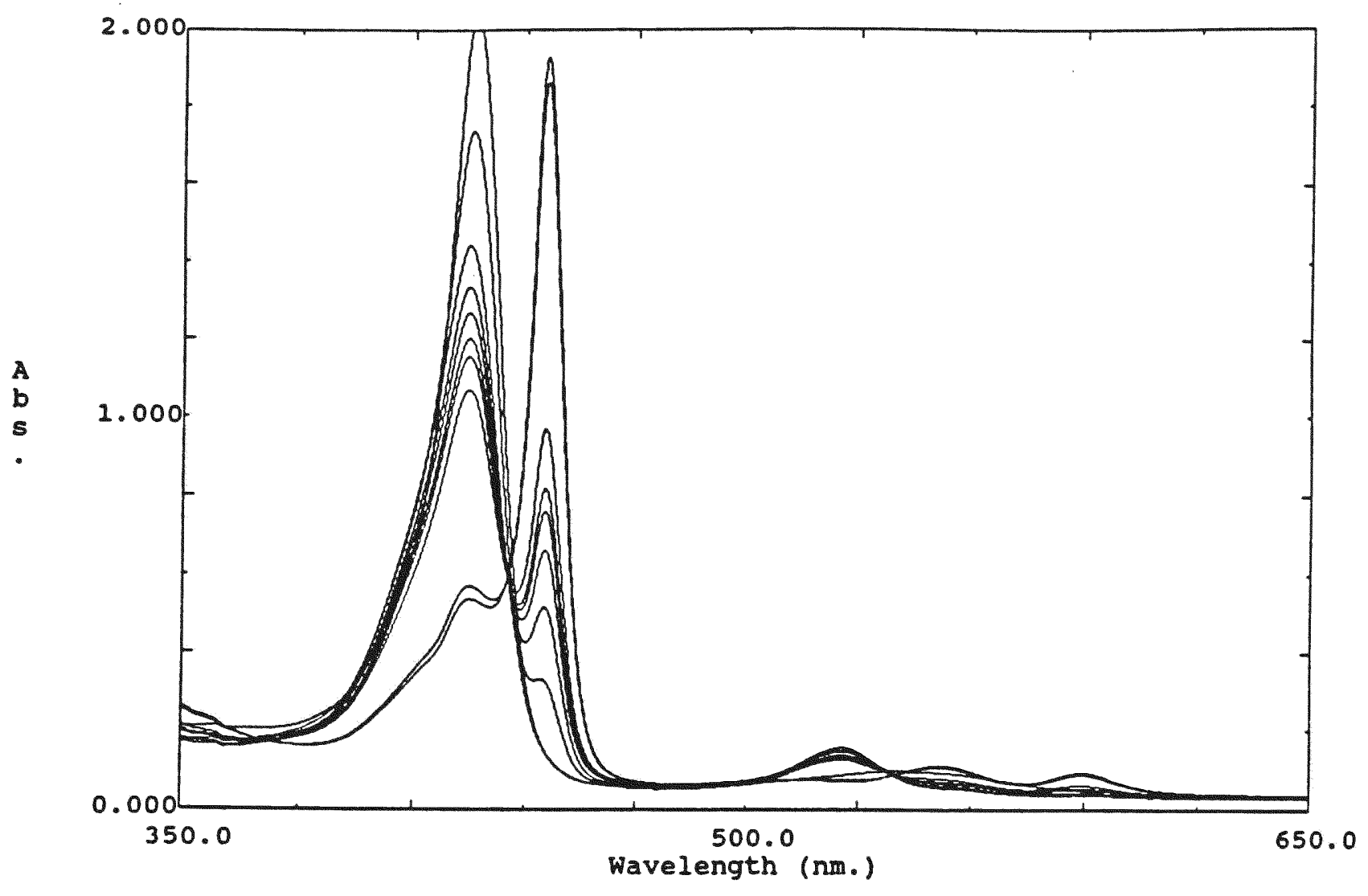

Figure 3-5a. UV-Visible spectrum of the titration of $\mathrm{Fe}^{(\mathrm{II}) \mathrm{TPP}}$ with triethyl phosphite in THF. 


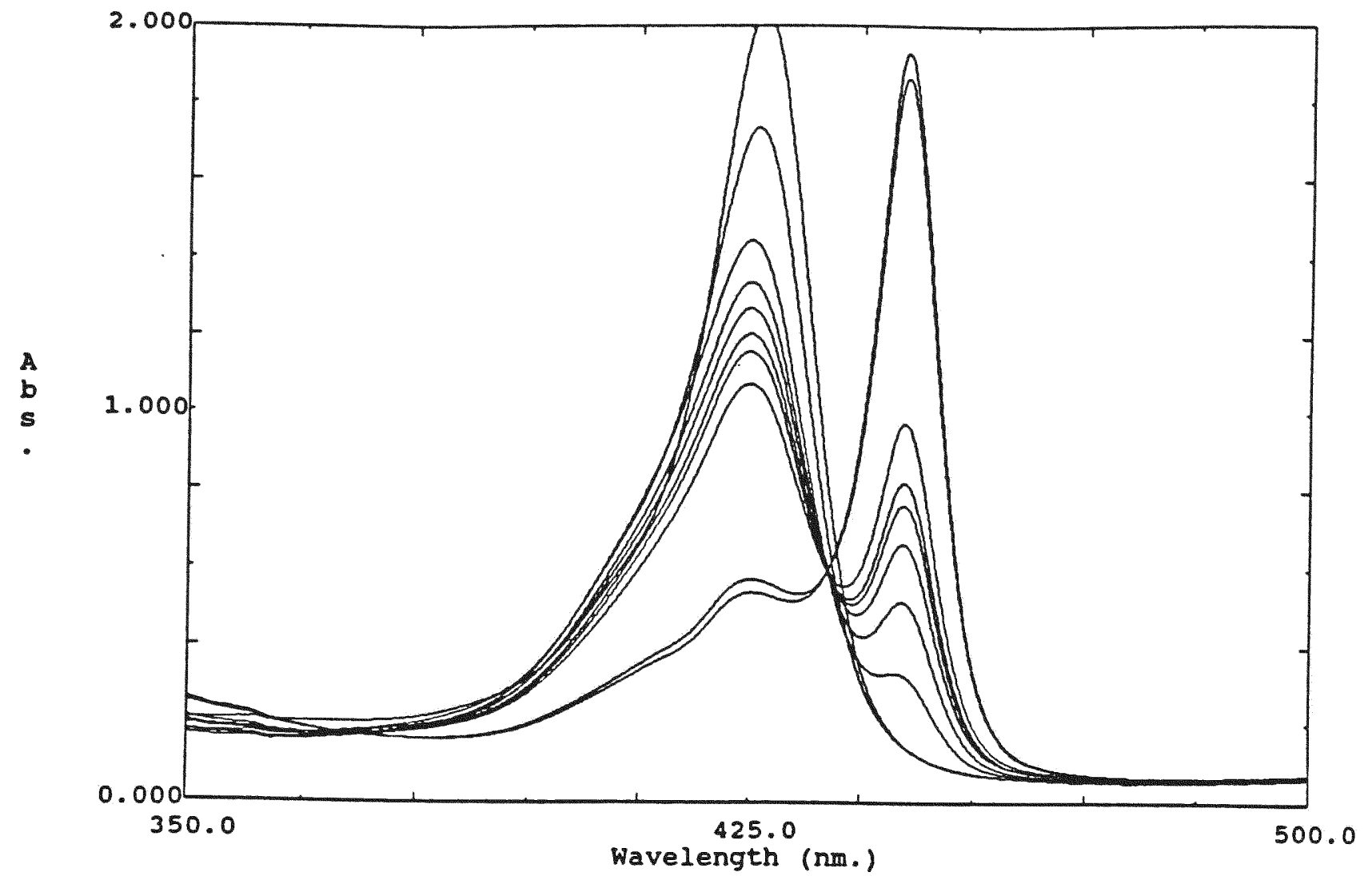

Figure 3-5b. Soret bands of the titration of Fe(II)TPP with triethyl phosphite in THF. New Soret band formed at $446 \mathrm{~nm}$. No clear isosbestic points are observed. 


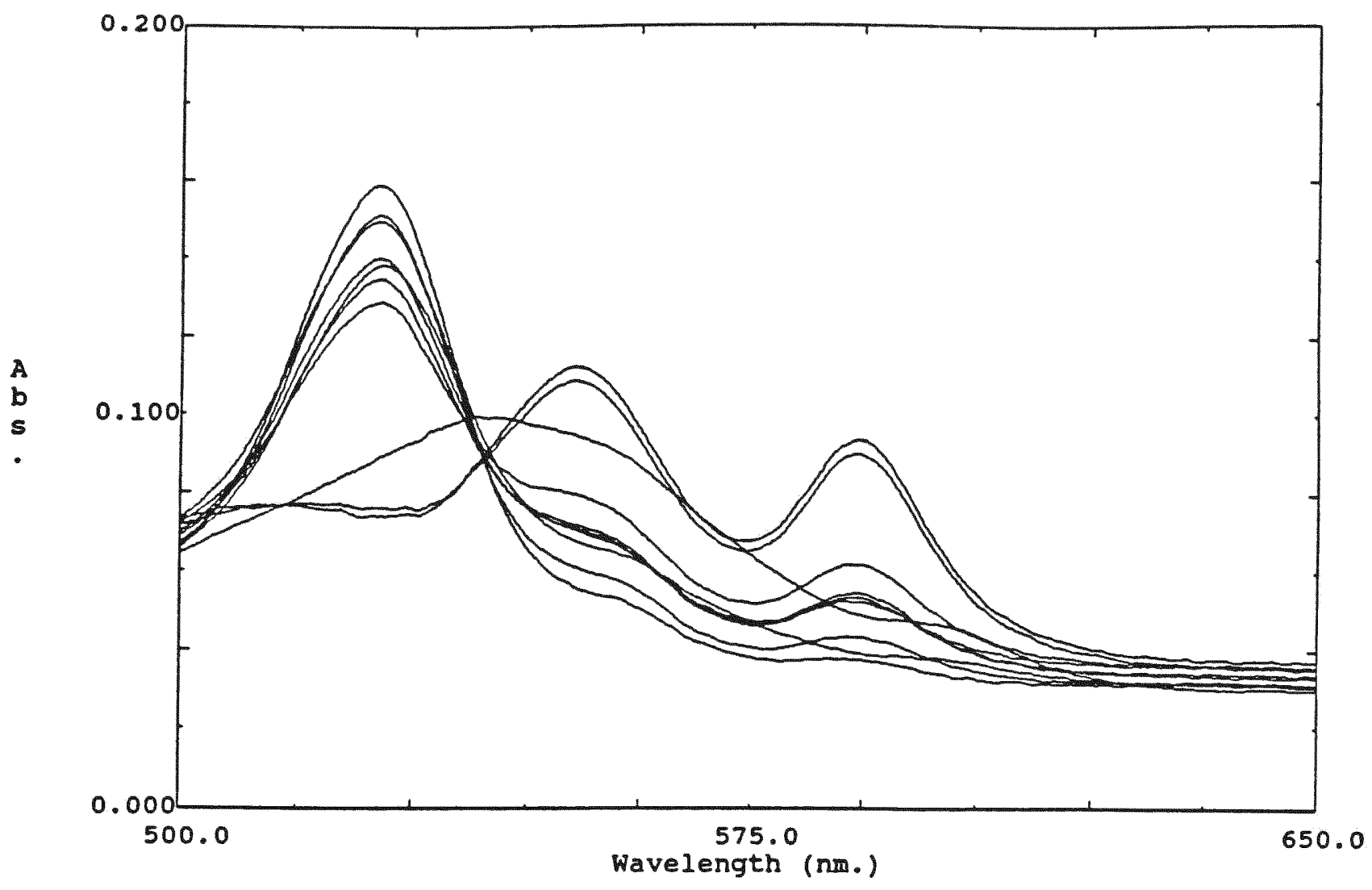

Figure 3-5c. $\alpha-\beta$ region of the titration of $\mathrm{Fe}^{(\mathrm{II})}$ TPP with triethyl phosphite in THF. No clear isosbestic points are observed. 


\begin{tabular}{|c|c|c|c|c|c|}
\hline $\begin{array}{l}\text { Vol. of } \\
\left.\text { P(OC } \mathrm{H}_{5}\right)_{3} \\
(\mathrm{ul})\end{array}$ & $\begin{array}{l}\text { Total } \\
\text { Conc. of } \\
\mathrm{P}\left(\mathrm{OC}_{2} \mathrm{H}_{5}\right)_{3} \\
(\mathrm{M}) \\
\end{array}$ & $\begin{array}{c}\text { A } \\
(426.6) \\
(\mathrm{nm})\end{array}$ & $\begin{array}{c}A \\
(436.7) \\
(\mathrm{nm})\end{array}$ & $\frac{A}{(445.8 \mathrm{~nm})}$ & $\frac{A}{(525.8 \mathrm{~nm})}$ \\
\hline 0 & 0 & 2.036 & 0.643 & 0.147 & 0.089 \\
\hline 10 & $2.89 e-4$ & 1.971 & 0.612 & 0.144 & 0.105 \\
\hline 30 & $8.45 e-4$ & 1.727 & 0.548 & 0.146 & 0.138 \\
\hline 50 & $1.38 \mathrm{e}-3$ & 1.542 & 0.506 & 0.183 & 0.158 \\
\hline 80 & $2.15 e-3$ & 1.412 & 0.507 & 0.325 & 0.159 \\
\hline 120 & $3.11 \mathrm{e}-3$ & 1.307 & 0.522 & 0.515 & 0.151 \\
\hline 160 & $4.00 e^{-3}$ & 1.241 & 0.543 & 0.663 & 0.149 \\
\hline 200 & $4.83 e-3$ & 1.177 & 0.547 & 0.763 & 0.140 \\
\hline 240 & $5.61 e-3$ & 1.132 & 0.549 & 0.819 & 0.135 \\
\hline 280 & $6.34 e-3$ & 1.088 & 0.556 & 0.901 & 0.131 \\
\hline 320 & $7.03 e-3$ & 1.052 & 0.564 & 0.972 & 0.129 \\
\hline Excess & & 0.567 & 0.645 & 1.864 & 0.076 \\
\hline Excess & & 0.534 & 0.652 & 1.929 & 0.074 \\
\hline
\end{tabular}

Table 3-4. Titration of Fe (II) $^{(1)}$ with Triethyl Phosphite. The initial volume of FeTPP is $1: 0 \mathrm{ml}(1.66 \mathrm{e}-3 \mathrm{M})$. 
9, Titration of Fe(II)TPP with Tri-isopropyl Phosphite

A THF solution of $\mathrm{Fe}^{(\mathrm{II})} \mathrm{TPP}(1.29 \mathrm{e}-3 \mathrm{M})$ was prepared by dissolving $10.0 \pm 2 \mathrm{mg} \mathrm{Fe}(\mathrm{II}) \mathrm{TPP}$ in a $10 \mathrm{ml}$ volumetric flask, and the tri-isopropyl phosphite solution $(4.28 \mathrm{e}-2 \mathrm{M})$ was made by dissolving $1.0 \mathrm{ml}$ pure triisopropyl phosphite in a $10 \mathrm{ml}$ volumetric flask in THF. Aliquots of $20 \mu \mathrm{l}$ of $\mathrm{P}\left(\mathrm{O}-\mathrm{i}-\mathrm{C}_{3} \mathrm{H}_{7}\right)_{3}$ solution were added successively to a $1.0 \mathrm{ml}$ volume of $\mathrm{Fe}$ (II)TPP solution. The titration spectra (Figure 3-6a,6b,6c) show no clear isosbestic points and a new Soret band formed at $447 \mathrm{~nm}$. The absorbance changes at several wavelengths and the total ligand concentration at each titration are recorded in Table $3-5$.

10, Titration of Fe ${ }^{(I I)}$ TPP with Tribenzyl Phosphine

A THF solution of $\mathrm{Fe}^{(\mathrm{II})} \mathrm{TPP}(1.47 \mathrm{e}-3 \mathrm{M})$ was prepared by dissolving $10.0 \pm 2 \mathrm{mg}$ of $\mathrm{Fe}^{(\mathrm{II})} \mathrm{TPP}$ in a $10 \mathrm{ml}$ volumetric flask with THF, and the solution of tribenzyl phosphine was made by dissolving $508 \mathrm{mg}$ tribenzyl phosphine in a $10 \mathrm{ml}$ volumetric flask. Aliquots of $20 \mu \mathrm{l}$ of $\mathrm{P}\left(\mathrm{C}_{6} \mathrm{H}_{5} \mathrm{CH}_{2}\right)_{3}$ solution were added successively to a $1.0 \mathrm{ml}$ volume of the Fe(II)TPP solution. The baseline shift associated with the change of refractive index due to the large volume of $\mathrm{P}\left(\mathrm{C}_{6} \mathrm{H}_{5} \mathrm{CH}_{2}\right)_{3}$ added was corrected by empirically adding a small value to the entire spectrum. The titration spectra (Figure 3-7) show no isosbestic points. The absorbance changes and the concentrations of the ligand are recorded in Table 3-6.

11, Triisopropyl Phosphine, Triphenyl phosphine and Tricyclohexyl Phosphine 


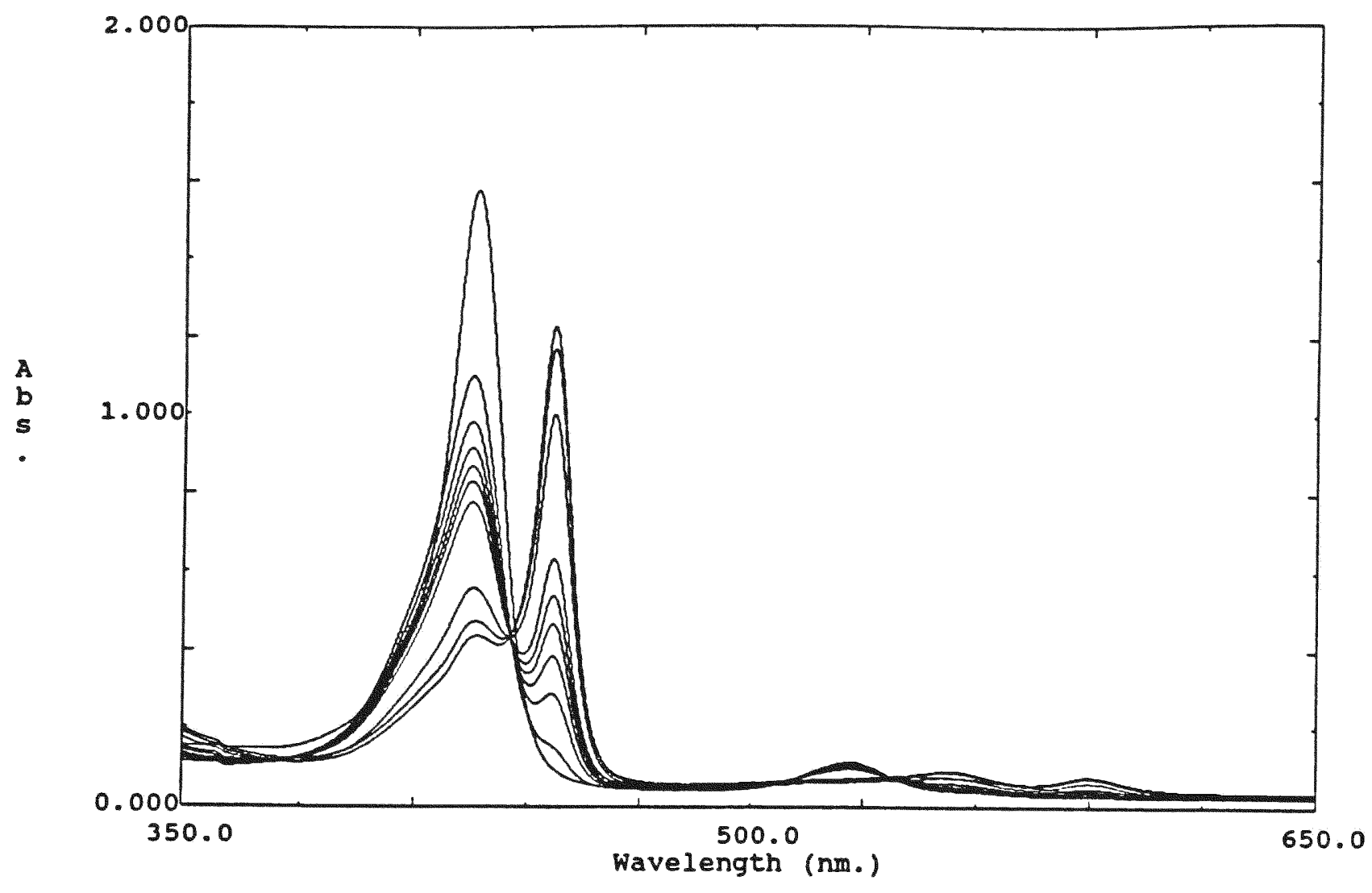

Figure 3-6a. UV-Visible spectrum of the titration of $\mathrm{Fe}^{(\mathrm{III})} \mathrm{TPP}$ with triisopropyl phosphite in THF. 


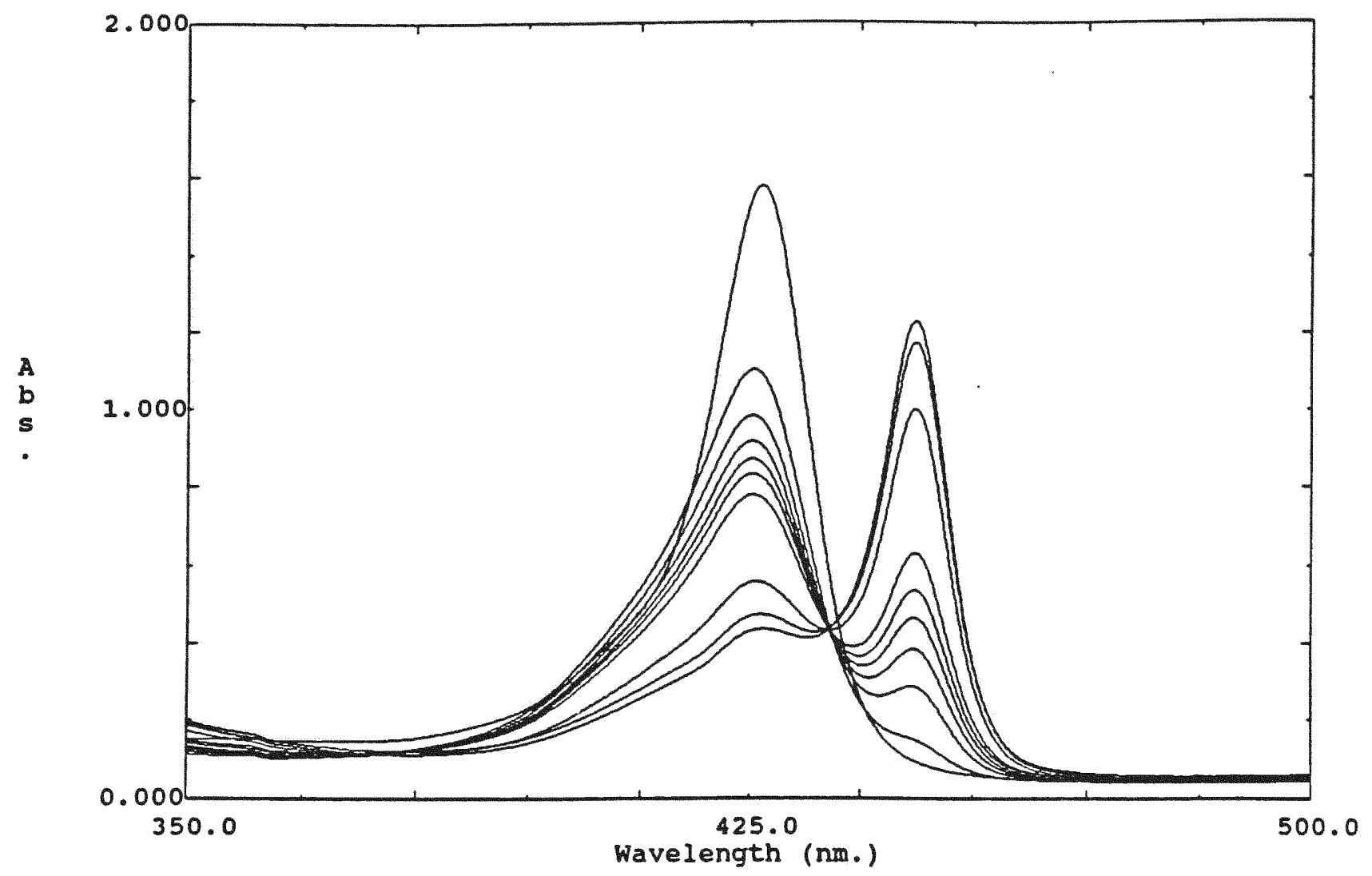

Figure 3-6b. Soret bands of the titration of $\mathrm{Fe}^{(\mathrm{II})} \mathrm{TPP}$ with triisopropyl phosphite in THF. New Soret band formed at $446 \mathrm{~nm}$. No clear isosbestic points are observed. 


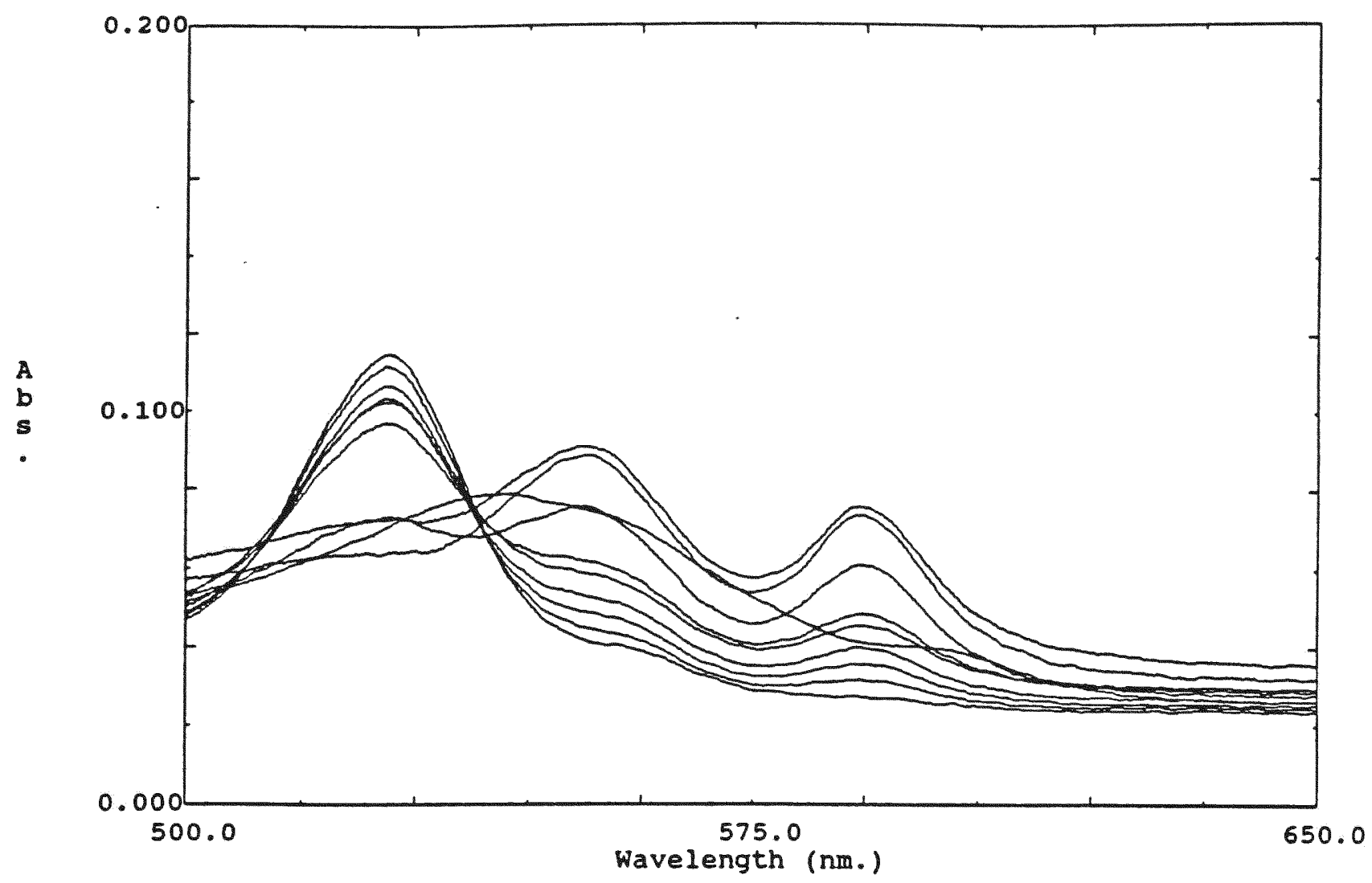

Figure 3-6c. $\quad \alpha-\beta$ region of the titration of $\mathrm{Fe}^{(\mathrm{III})} \mathrm{TPP}$ with triisopropyl phosphite. No clear isosbestic points are observed. 


\begin{tabular}{|c|c|c|c|c|c|}
\hline $\begin{array}{c}\text { Vol. of } \\
\text { P }\left(\mathrm{O}-\mathrm{i}-\mathrm{C}_{3} \mathrm{H}_{7}\right)_{3} \\
(\mathrm{uI})\end{array}$ & $\begin{array}{l}\text { Total } \\
\text { Conc. of } \\
\text { P(O-i-C. } \mathrm{C}_{3} \mathrm{H}_{3} \\
(\mathrm{M})\end{array}$ & $\begin{array}{c}A \\
(426.6) \\
(\mathrm{nm})\end{array}$ & $\begin{array}{c}A \\
(436.9) \\
(\mathrm{nm})\end{array}$ & $\begin{array}{c}A \\
(447.2) \\
(\mathrm{nm})\end{array}$ & $\begin{array}{c}\text { A } \\
(526.6) \\
(\mathrm{nm})\end{array}$ \\
\hline 0 & 0 & 1.577 & 0.462 & 0.097 & 0.071 \\
\hline 10 & $4.24 e^{-3}$ & 1.166 & 0.383 & 0.114 & 0.110 \\
\hline 20 & $8.39 e-3$ & 1.088 & 0.377 & 0.152 & 0.115 \\
\hline 40 & 0.016 & 1.016 & 0.377 & 0.225 & 0.113 \\
\hline 60 & 0.024 & 0.970 & 0.381 & 0.288 & 0.112 \\
\hline 100 & 0.039 & 0.904 & 0.386 & 0.386 & 0.107 \\
\hline 140 & 0.052 & 0.860 & 0.395 & 0.467 & 0.103 \\
\hline 180 & 0.065 & 0.822 & 0.404 & 0.539 & 0.102 \\
\hline 260 & 0.088 & 0.771 & 0.412 & 0.632 & 0.097 \\
\hline 280 (20pure) & 0.15 & 0.666 & 0.426 & 0.815 & 0.086 \\
\hline 320 (60pure) & 0.28 & 0.556 & 0.439 & 1.000 & 0.073 \\
\hline 400 ( 14 opure) & 0.51 & 0.474 & 0.459 & 1.170 & 0.072 \\
\hline Excess & & 0.437 & 0.461 & 1.226 & 0.064 \\
\hline
\end{tabular}

Table 3-5. Titration of $\mathrm{Fe}^{\mathrm{m}} \mathrm{TPP}$ with Trisopropyl Phosphite. The initial volume of FeTPP is $1.0 \mathrm{ml}(1.26 \mathrm{e}-3 \mathrm{M})$. 


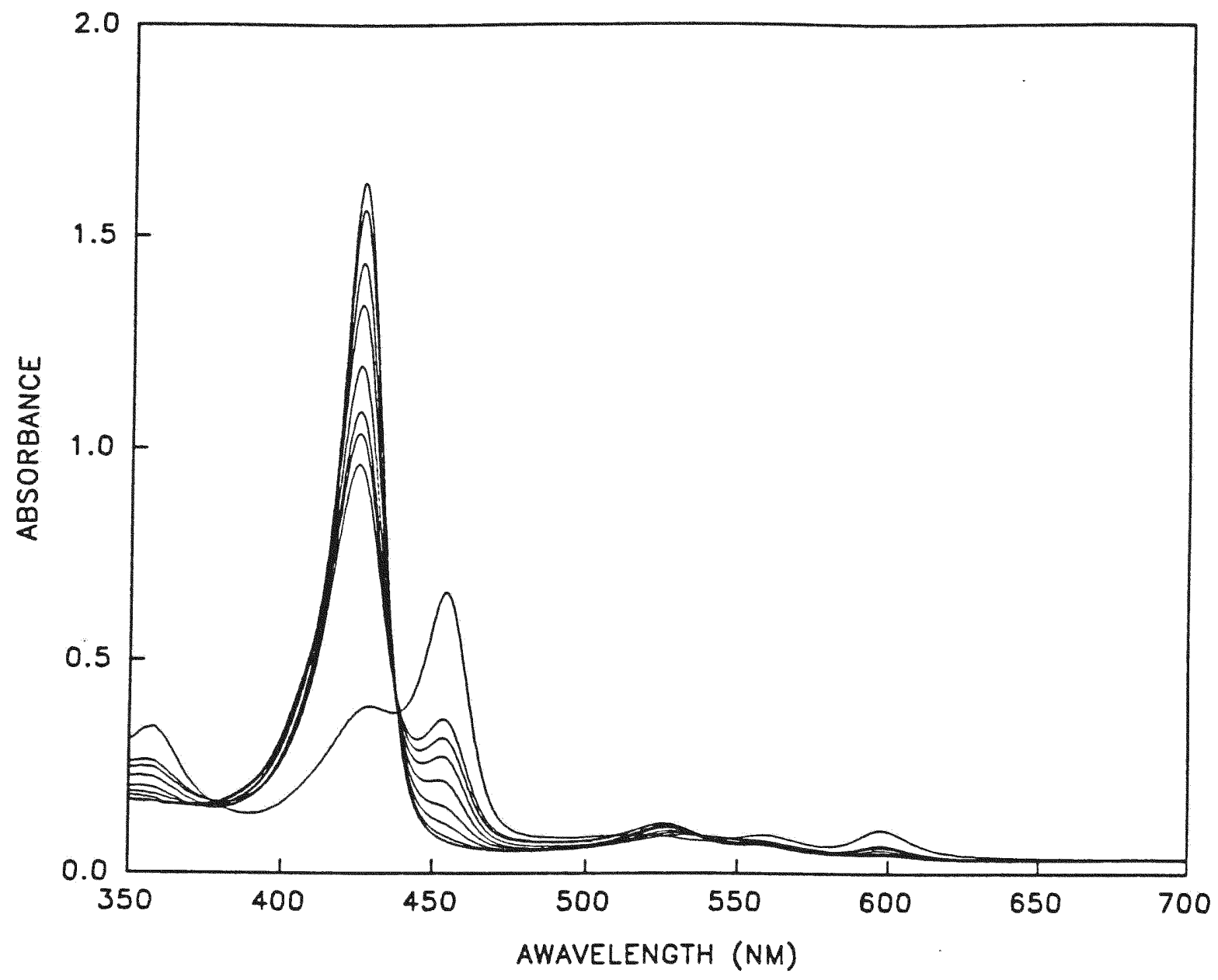

Figure 3-7. UV-Visible spectrum of the titration of FeTPP with tribenzyl phosphine in THF. 


\begin{tabular}{|c|c|c|c|c|c|}
\hline $\begin{array}{c}\text { Vol. of } \\
\mathrm{P}\left(\mathrm{C}_{6} \mathrm{H}_{5} \mathrm{CH}_{2}\right)_{3} \\
(\mathrm{UI})\end{array}$ & $\begin{array}{c}\text { Total } \\
\text { Conc. of } \\
\mathrm{P}\left(\mathrm{C}_{6} \mathrm{H}_{5} \mathrm{CH}_{2}\right)_{3} \\
(\mathrm{M})\end{array}$ & $\begin{array}{c}\mathrm{A} \\
(426.4) \\
(\mathrm{Nm})\end{array}$ & $\begin{array}{c}\mathrm{A} \\
(438.4) \\
(\mathrm{Nm})\end{array}$ & $\begin{array}{c}\mathrm{A} \\
(454.2) \\
(\mathrm{nm})\end{array}$ & $\begin{array}{c}\text { A } \\
(526.6) \\
(\mathrm{nm})\end{array}$ \\
\hline 0 & 0 & 1.703 & 0.376 & 0.070 & 0.079 \\
\hline 20 & $3.27 \mathrm{e}-3$ & 1.625 & 0.374 & 0.076 & 0.087 \\
\hline 40 & $6.42 \mathrm{e}-3$ & 1.562 & 0.374 & 0.087 & 0.093 \\
\hline 80 & 0.0124 & 1.435 & 0.373 & 0.115 & 0.098 \\
\hline 120 & 0.0179 & 1.336 & 0.378 & 0.155 & 0.106 \\
\hline 200 & 0.0278 & 1.188 & 0.380 & 0.214 & 0.107 \\
\hline 280 & 0.0365 & 1.078 & 0.385 & 0.271 & 0.110 \\
\hline 360 & 0.0442 & 1.026 & 0.397 & 0.314 & 0.115 \\
\hline 440 & 0.0510 & 0.951 & 0.401 & 0.359 & 0.116 \\
\hline ExCess & & 0.385 & 0.377 & 0.660 & 0.086 \\
\hline
\end{tabular}

Table 3-6. Titration of Fe ${ }^{(\mathrm{m})}$ TPP with Tribenzyl Phosphine. The initial volume of FeTPP is $1.0 \mathrm{ml}(1.47 \mathrm{e}-3 \mathrm{M})$. 
When a large excess amount of $\mathrm{P}\left(\mathrm{i}-\mathrm{C}_{3} \mathrm{H}_{7}\right)_{3}$ or $\mathrm{P}\left(\mathrm{C}_{6} \mathrm{H}_{5}\right)_{3}$ solution was added to $1.0 \mathrm{ml}$ of Fe(II)TPP solution (1.5e-3M) seperately, the UV-Visible spectra of both reactions showed changes. A new Soret band formed at wavelength of $456 \mathrm{~nm}$ in both reactions. However,the equilibrium constants for the two reactions are too small to be measured easily under these conditions. The spectrum of the reaction of $\mathrm{Fe}^{(\mathrm{II})} \mathrm{TPP}$ with tricyclohexyl phosphine showed no obvious changes when a large excess amount of tricyclohexyl solution was added to the $\mathrm{Fe}$ (II)TPP solution (1.5e-3M).

12, Reaction of $\mathrm{FeTPPClO}$, with imidazole

A $\mathrm{FeTPPClO}_{4}$ solution in chloroform $(4.11 \mathrm{e}-4 \mathrm{M})$ was prepared by dissolving $0.0316 \mathrm{~g}$ of $\mathrm{FeTPPClO}_{4}$ in a $100 \mathrm{ml}$ volumetric flask with $\mathrm{CHCl}_{3}$. The solution of imidazole (1.26e-2M) was made by dissolving $0.0215 \mathrm{~g}$ of imidazole in a $25 \mathrm{ml}$ volumetric flask with $\mathrm{CHCl}_{3}$. Aliqouts of the imidazole solutions were added successively to a $0.4 \mathrm{ml}$ volume of the $\mathrm{FeTPPClO}_{4}$ solution. Correction was made for the absorbance changes due to the volume added. The above titration was done at three tempratures: 14.9, 19.1 and 29.8 ${ }^{\circ} \mathrm{C}$. The titration spectra ( Figure 3-8, 3-9, 3-10) showed no clear isosbestic point in all three titrations. The concentration of the ligand and the absorbance changes at different wavelengths for the three titrations are recorded in Table 3-7, 3-8 and 3-9 respectively. 


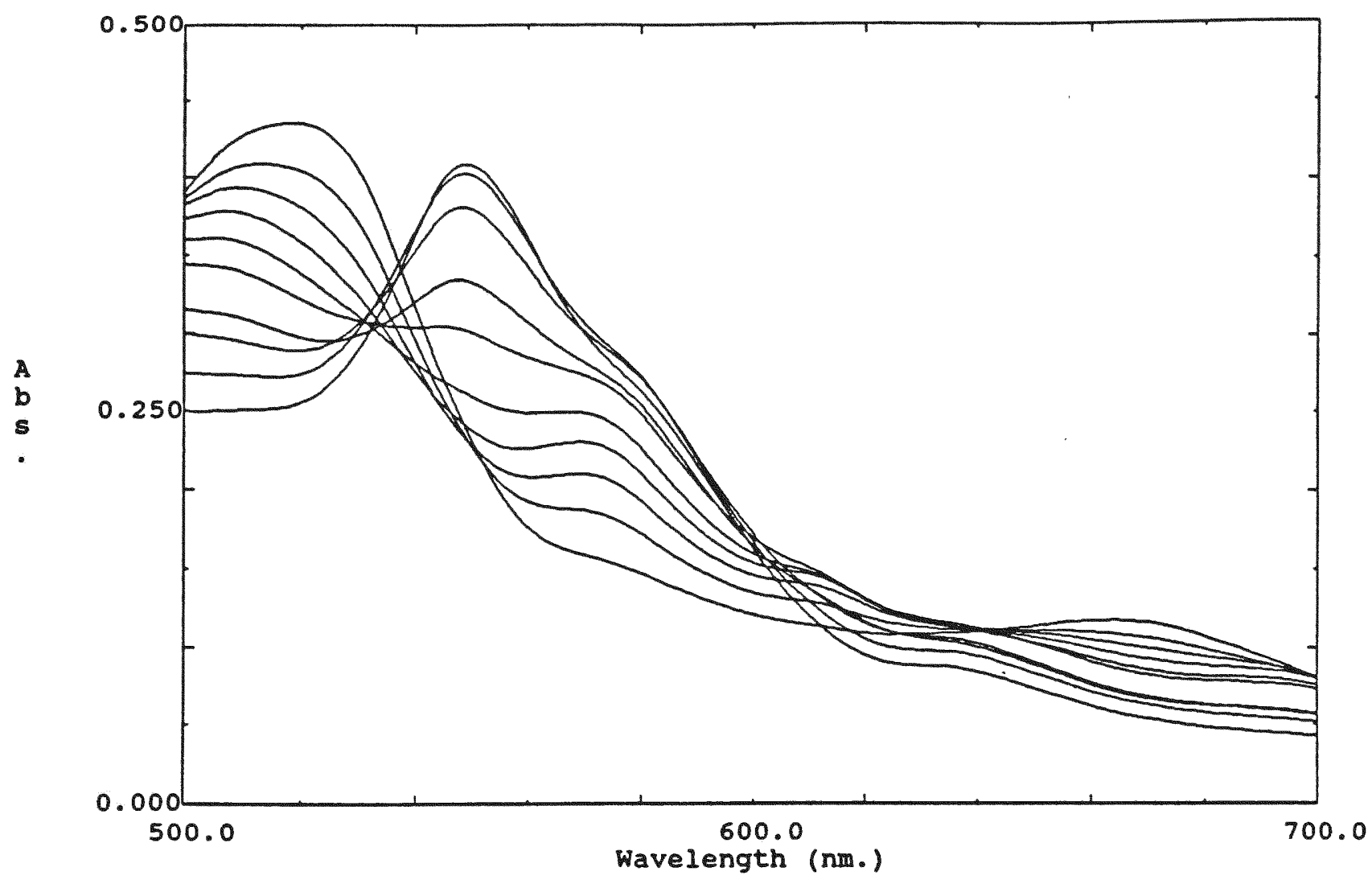

Figure 3-8. UV-Visible spectrum of the titration of $\mathrm{FeTPPClO}_{4}$ with imidazole in $\mathrm{CHCl}_{3}$ at $\mathrm{T}=14.9{ }^{\circ} \mathrm{C}$. 


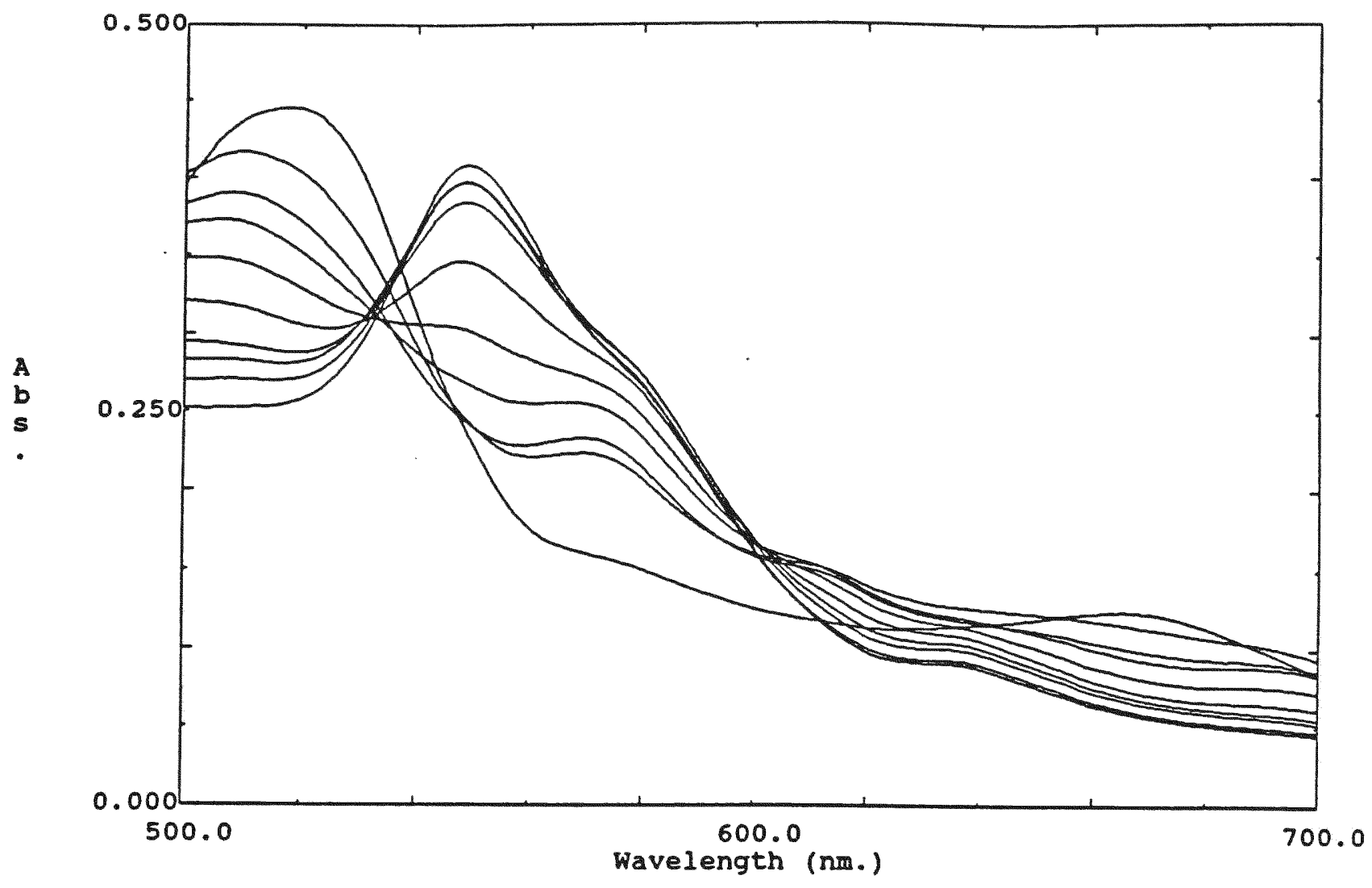

Figure 3-9. UV-Visible spectrum of the titration of $\mathrm{FeTPPClO}_{4}$ with imidazole in $\mathrm{CHCl}_{3}$ at $\mathrm{T}=19.8{ }^{\circ} \mathrm{C}$. 


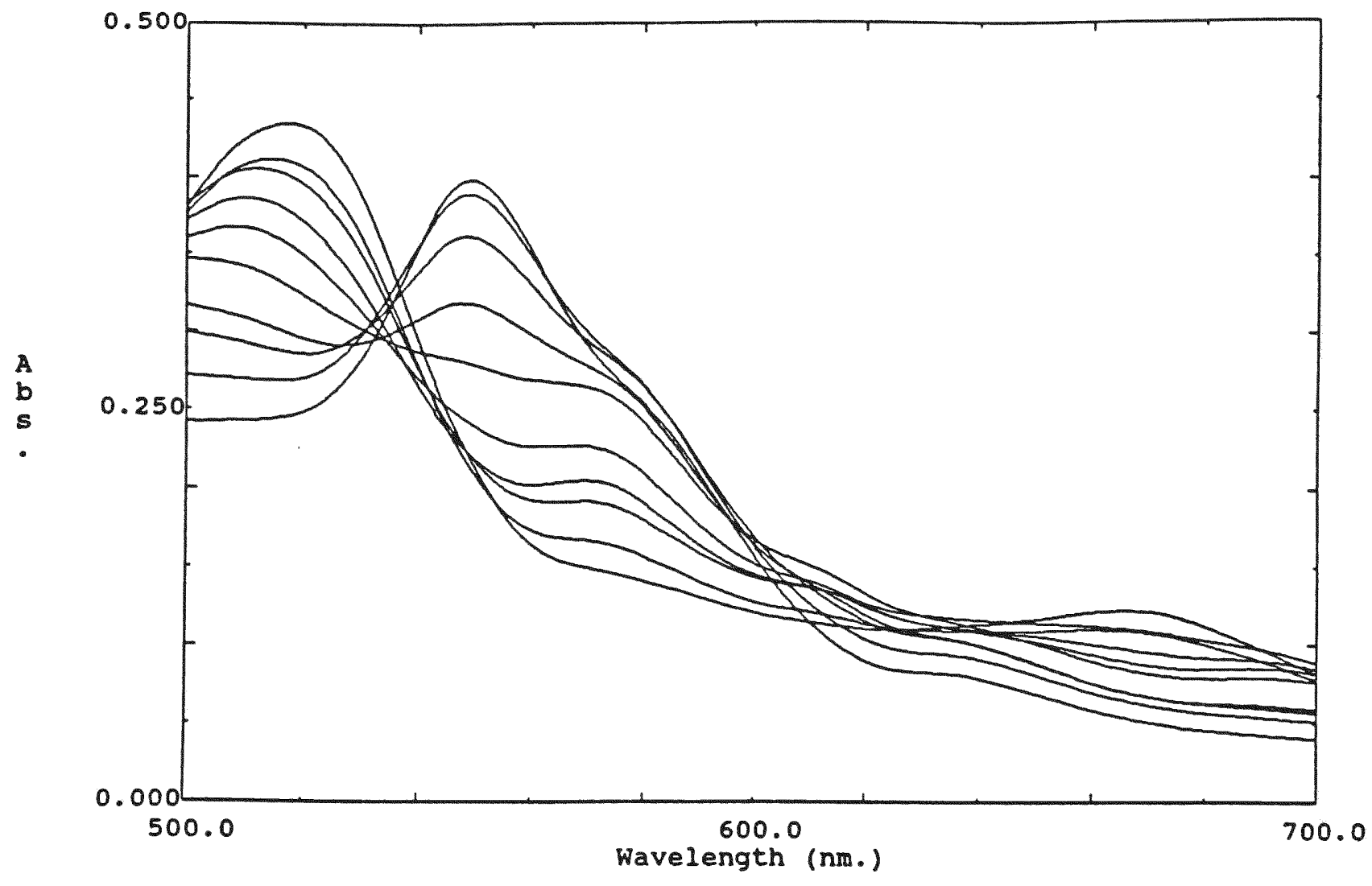

Figure 3-10. UV-Visible spectrum of the titration of $\mathrm{FeTPPClO}$ with imidazole in $\mathrm{CHCl}_{3}$ at $\mathrm{T}=29.8^{\circ} \mathrm{C}$. 


\begin{tabular}{|c|c|c|c|}
\hline $\begin{array}{c}\text { Total Vol. of } \\
\text { Imidazole } \\
\text { (ul) }\end{array}$ & $\begin{array}{c}\text { Total Conc. of } \\
\text { Imidazole } \\
(\mathrm{M})\end{array}$ & $\begin{array}{c}\text { A } \\
(519.2 \mathrm{~nm})\end{array}$ & $\begin{array}{c}\text { A } \\
(549.0 \mathrm{~nm})\end{array}$ \\
\hline 0 & 0 & 0.436 & 0.240 \\
\hline 3 & $9.38 \mathrm{e}-5$ & 0.405 & 0.235 \\
\hline 6 & $1.86 e-4$ & 0.383 & 0.234 \\
\hline 9 & $2.77 \mathrm{e}-4$ & 0.361 & 0.242 \\
\hline 12 & $3.67 \mathrm{e}-4$ & 0.341 & 0.262 \\
\hline 15 & $4.55 e-4$ & 0.324 & 0.303 \\
\hline 18 & $5.43 e-4$ & 0.299 & 0.335 \\
\hline 21 & $6.29 e^{-4}$ & 0.289 & 0.382 \\
\hline 27 & $7.97 \mathrm{e}-4$ & 0.274 & 0.403 \\
\hline excess & & 0.255 & 0.409 \\
\hline
\end{tabular}

Table 3-7. Titration of FeTPPC10, with imidazole at $\mathrm{T}=14.9^{\circ} \mathrm{C}$. The initial volume of FeTPPC10, is $0.4 \mathrm{ml}\left(4.11 \mathrm{e}^{-4} \mathrm{M}\right)$. 


\begin{tabular}{|c|c|c|c|c|}
\hline $\begin{array}{c}\text { Total Vol. } \\
\text { of Imidazole } \\
(\mathrm{ul})\end{array}$ & $\begin{array}{c}\text { Total Conc. } \\
\text { of Imidazole } \\
(\mathrm{M})\end{array}$ & $\begin{array}{c}\text { A } \\
(517.0 \mathrm{~nm})\end{array}$ & $\begin{array}{c}\text { A } \\
(537.2 \mathrm{~nm})\end{array}$ & $\begin{array}{c}\text { A } \\
(549.2 \mathrm{~nm})\end{array}$ \\
\hline 0 & 0 & 0.445 & 0.340 & 0.235 \\
\hline 3 & $9.38 \mathrm{e}-5$ & 0.417 & 0.315 & 0.231 \\
\hline 6 & $1.86 \mathrm{e}-4$ & 0.410 & 0.312 & 0.244 \\
\hline 9 & $2.77 \mathrm{e}-4$ & 0.379 & 0.293 & 0.243 \\
\hline 12 & $3.67 \mathrm{e}-4$ & 0.359 & 0.297 & 0.268 \\
\hline 15 & $4.55 \mathrm{e}-4$ & 0.334 & 0.306 & 0.302 \\
\hline 18 & $5.43 \mathrm{e}-4$ & 0.308 & 0.322 & 0.345 \\
\hline 21 & $6.29 \mathrm{e}-4$ & 0.288 & 0.339 & 0.384 \\
\hline 24 & $7.13 \mathrm{e}-4$ & 0.281 & 0.346 & 0.397 \\
\hline 30 & $8.79 \mathrm{e}-4$ & 0.270 & 0.342 & 0.397 \\
\hline excess & & 0.255 & 0.342 & 0.408 \\
\hline
\end{tabular}

Table 3-8. Titration of FeTPPClO, with imidazole at $\mathrm{T}=19.1^{\circ} \mathrm{C}$. The initial volume of $\mathrm{FeTPPClO}_{4}$ is $0.4 \mathrm{mI}(4.11 \mathrm{e}-4 \mathrm{M})$. 


\begin{tabular}{|c|c|c|c|}
\hline $\begin{array}{c}\text { Total Vol. of } \\
\text { Imidazo } \\
(\text { ul) }\end{array}$ & $\begin{array}{c}\text { Total Conc. of } \\
\text { Imidazole } \\
(\mathrm{M})\end{array}$ & $\begin{array}{c}\text { A } \\
(517.0 \mathrm{~nm})\end{array}$ & $\begin{array}{c}\text { A } \\
(549.2 \mathrm{~nm})\end{array}$ \\
\hline 0 & 0 & 0.435 & 0.219 \\
\hline 3 & $9.38 \mathrm{e}-5$ & 0.411 & 0.214 \\
\hline 6 & $1.86 \mathrm{e}-4$ & 0.402 & 0.221 \\
\hline 9 & $2.77 \mathrm{e}-4$ & 0.379 & 0.222 \\
\hline 12 & $3.67 \mathrm{e}-4$ & 0.357 & 0.242 \\
\hline 15 & $4.55 e-4$ & 0.330 & 0.280 \\
\hline 18 & $5.43 e-4$ & 0.300 & 0.318 \\
\hline 21 & $6.29 e-4$ & 0.287 & 0.362 \\
\hline 27 & $7.97 \mathrm{e}-4$ & 0.269 & 0.389 \\
\hline excess & & 0.246 & 0.398 \\
\hline
\end{tabular}

Table 3-9. Titration of FeTPPClO with imidazole at $\mathrm{T}=29.8^{\circ} \mathrm{C}$. The initial volume of $\mathrm{FeTPPClO}_{4}$ is $0.4 \mathrm{ml}(4.11 \mathrm{e}-4 \mathrm{M})$. 


\section{Chapter 4. Results and Discussion}

\section{Results}

\section{Titration of $\mathrm{Fe}$ (II)TPP With Phosphorus Ligands}

The reactions of $\mathrm{Fe}^{(\mathrm{II})} \mathrm{TPP}$ binding with a series of phosphine and phosphite ligands have been studied using the spectrophotometric method. The titration spectra from these binding reactions showed no clear isosbestic points which means there are more than two species in the solution absorbing light at the same time. The five-coordinate complex is present during the titration process.

The equilibrium constants $K_{1}, K_{2}$ and $K_{0}\left(K_{0}=K_{1} \times K_{2}\right)$, see Eq. 2-1, 2-2 and 2-3, for these reactions were calculated using the "least error" method discussed in Chapter 2.

Listed in Table 4-1 are the equilibrium constants, with average deviation error limits, determined for five phosphines and two phosphites. The equilibrium constants were determined using the average value of the results obtained from each of three different wavelengths for each phosphorus ligand, and the deviation of each equilibrium constant is the difference of the mean value from the value at each different wavelength.

To check the resulting values of $K_{1}$ and $K_{2}$ for each binding reaction the graphs of the experimental absorbance and the calculated absorbance (using the resulting values of $K_{1}$ and $K_{2}$ ) vs. ligand concentration were made at 526 $\mathrm{nm}$. Wavelength $526 \mathrm{~nm}$ was chosen because of its high sensitivity to the presence of the five-coordinate complex. A chemically reasonable match between the two curves has been achieved. Figure 4-1 is an example of such graphs for the ligand of $\mathrm{P}(\mathrm{O}-\mathrm{i}-\mathrm{Propyl})_{3}$ at wavelength of $526 \mathrm{~nm}$. At $526 \mathrm{~nm}$ 


\begin{tabular}{|c|c|c|c|c|c|}
\hline $\begin{array}{c}\text { Phosphine } \\
\text { or } \\
\text { Phosphite }\end{array}$ & $\log \mathrm{K}_{1}$ & $\log \mathrm{K}_{2}$ & $\begin{array}{c}\log \mathrm{K}_{0} \\
\left(\mathrm{~K}_{0}=\mathrm{K}_{1} \times \mathrm{KK}_{2}\right)\end{array}$ & $\mathrm{pK}^{30}$ & $\begin{array}{l}\text { Cone } \\
\text { Angle }\end{array}$ \\
\hline $\mathrm{P}(\mathrm{Me})_{3}$ & $5.53 \pm 0.07$ & $4.60 \pm 0.05$ & $10.13 \pm 0.12$ & 8.65 & $118 \pm 4$ \\
\hline $\mathrm{P}(\mathrm{Et})_{3}$ & $5.61 \pm 0.13$ & $4.30 \pm 0.05$ & $9.91 \pm 0.18$ & 8.69 & $132 \pm 4$ \\
\hline $\mathrm{P}(\mathrm{N}-\mathrm{Bu})_{3}$ & $6.13 \pm 0.05$ & $5.02 \pm 0.02$ & $11.15 \pm 0.07$ & 8.43 & $130 \pm 4$ \\
\hline $\mathrm{P}(\mathrm{OEt})_{3}$ & $3.87 \pm 0.06$ & $2.28 \pm 0.08$ & $6.15 \pm 0.14$ & 3.50 & $109 \pm 2$ \\
\hline $\mathrm{P}(\mathrm{O}-\mathrm{i}-\mathrm{Pr})_{3}$ & $3.28 \pm 0.05$ & $1.13 \pm 0.05$ & $4.41 \pm 0.10$ & $-\ldots--$ & $114 \pm 2$ \\
\hline
\end{tabular}

Table 4-1. The equilibrium constants of the reaction of Fe(11)TPP with phosphorus ligands. The $\mathrm{pR}_{\text {. values and cone angles }}$ for the phosphorus ligands are Iisted. 


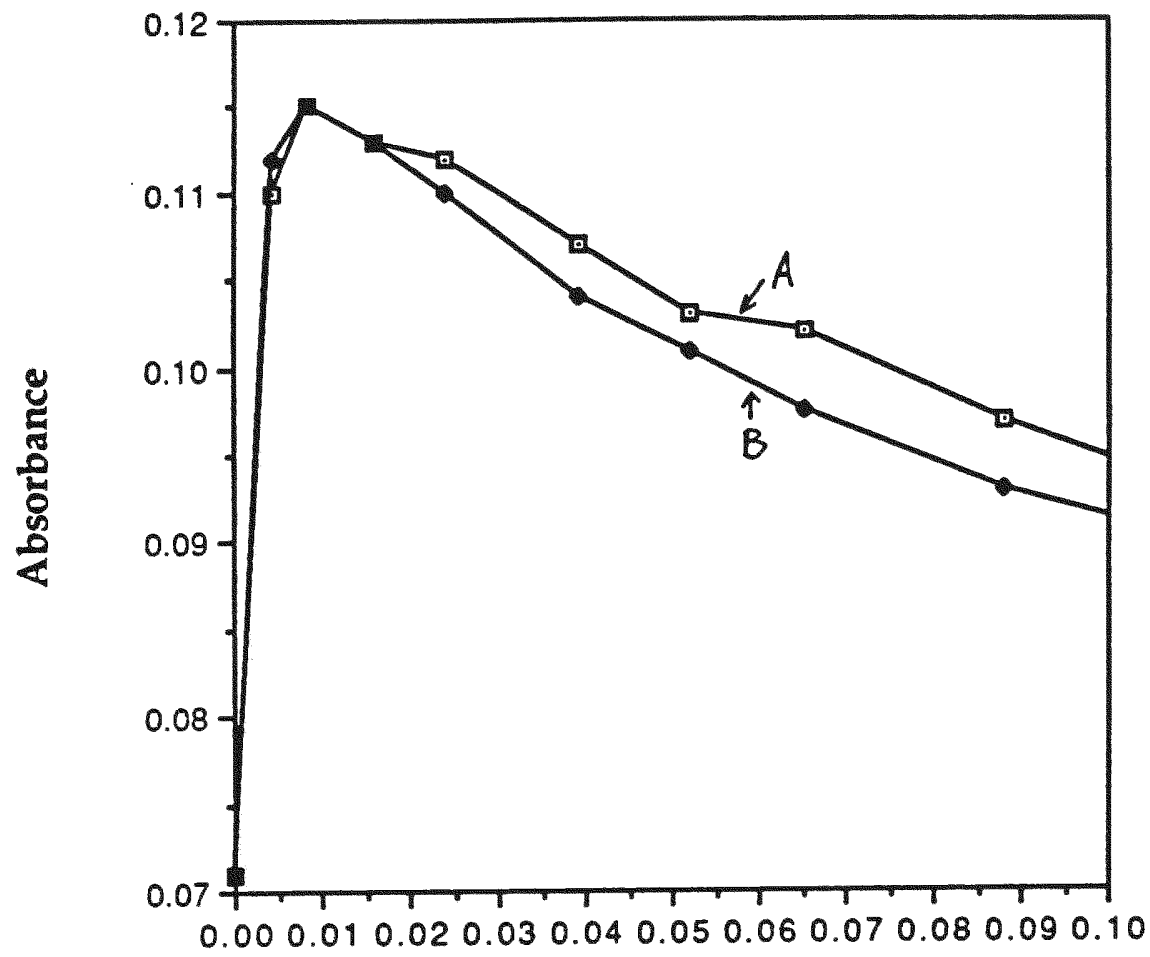

Lt (M)

Figure 4-1. The match plot of Abs(experimental) vs. total ligand concentration (line A) and Abs(calculated) vs.total ligand concentration (line B). The plot is made using the resulting $\mathrm{K}$ values of the titration of FeTPP with triisopropyl phosphite at wavelength $=526 \mathrm{~nm}$. 
the absorbance increases with formation of the five-coordinate phosphorous complex during the first portion of the titration and subsequentially decreases as the six-coordinate complex forms.

The UV-visible spectrum of the intermediate product, the fivecoordinate complex, was obtained. The absorbance of the five-coordinate complex is calculated using the program listed in Appendix 2-4. The spectra are obtained by ploting the calculated absorbance vs. wavelength at $4 \mathrm{~nm}$ intervals. Figure 4-2 to Figure 4-6 are spectra of the five-coordinate complexes, $\mathrm{Fe}^{(\mathrm{II})} \mathrm{TPPL}$, for the ligands of $\mathrm{P}(\mathrm{Me})_{3}, \mathrm{P}(\mathrm{Et})_{3}, \mathrm{P}(\mathrm{n}-\mathrm{Bu})_{3}, \mathrm{P}(\mathrm{OEt})_{3}$ and $\mathrm{P}(\mathrm{O}-\mathrm{i}-$ Propyl) $)_{3}$. In the UV-visible spectra of all the five-coordinate complexes the Soret band at $426 \mathrm{~nm}$ remained and a new peak formed at $525 \mathrm{~nm}$ in the $\alpha, \beta$ region. The peak formed at wavelength of $525 \mathrm{~nm}$ is consistent with the visible spectra of the five-coordinate complex of $\mathrm{Fe}^{(\mathrm{II})} \mathrm{TPP}, \mathrm{Fe}^{(\mathrm{II})}(\mathrm{cap})$ benzyl isocyanide. 20

\section{Titration of $\mathrm{FeTPPClO}_{4}$ With Imidazole}

The results of the titration of $\mathrm{FeTPPClO}$ with imidazole at different temperatures are listed in Table 4-2. A plot of $\ln \mathrm{K}_{0}$ vs. $1 / \mathrm{T}$ was made. (Figure 4-7). A straight line was obtained and the enthalpy change $(\Delta \mathrm{H})$ of the reaction was the slope of this straight line according to van't Hoff' s equation:

$$
\operatorname{lnK}=-\Delta H / R T+C
$$

The entropy change $(\Delta S)$ was computed from:

$$
\Delta G=-R T \ln K=\Delta H-T \Delta S
$$

The following values were obtained: $\Delta H=-23.8 \mathrm{~kJ} / \mathrm{mol} ; \Delta S=-32.4 \mathrm{eu}$. 


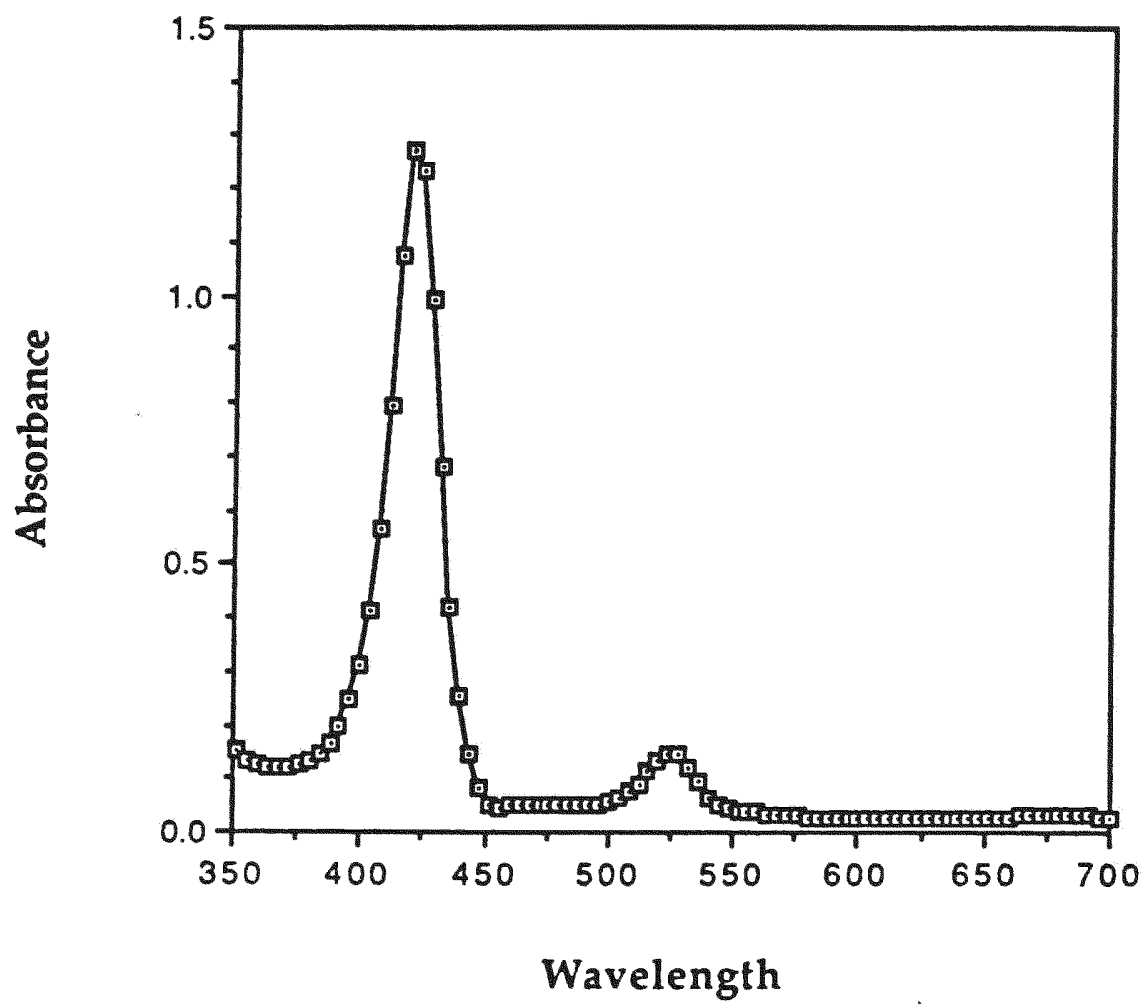

Figure 4-2. The calculated UV-Visible spectrum of the five-coordinate complex of $\operatorname{FeTPP}\left(\mathrm{P}(\mathrm{Me})_{3}\right)_{2}$. The Soret band at $426 \mathrm{~nm}$ remains and a new band formed at $525 \mathrm{~nm}$. 


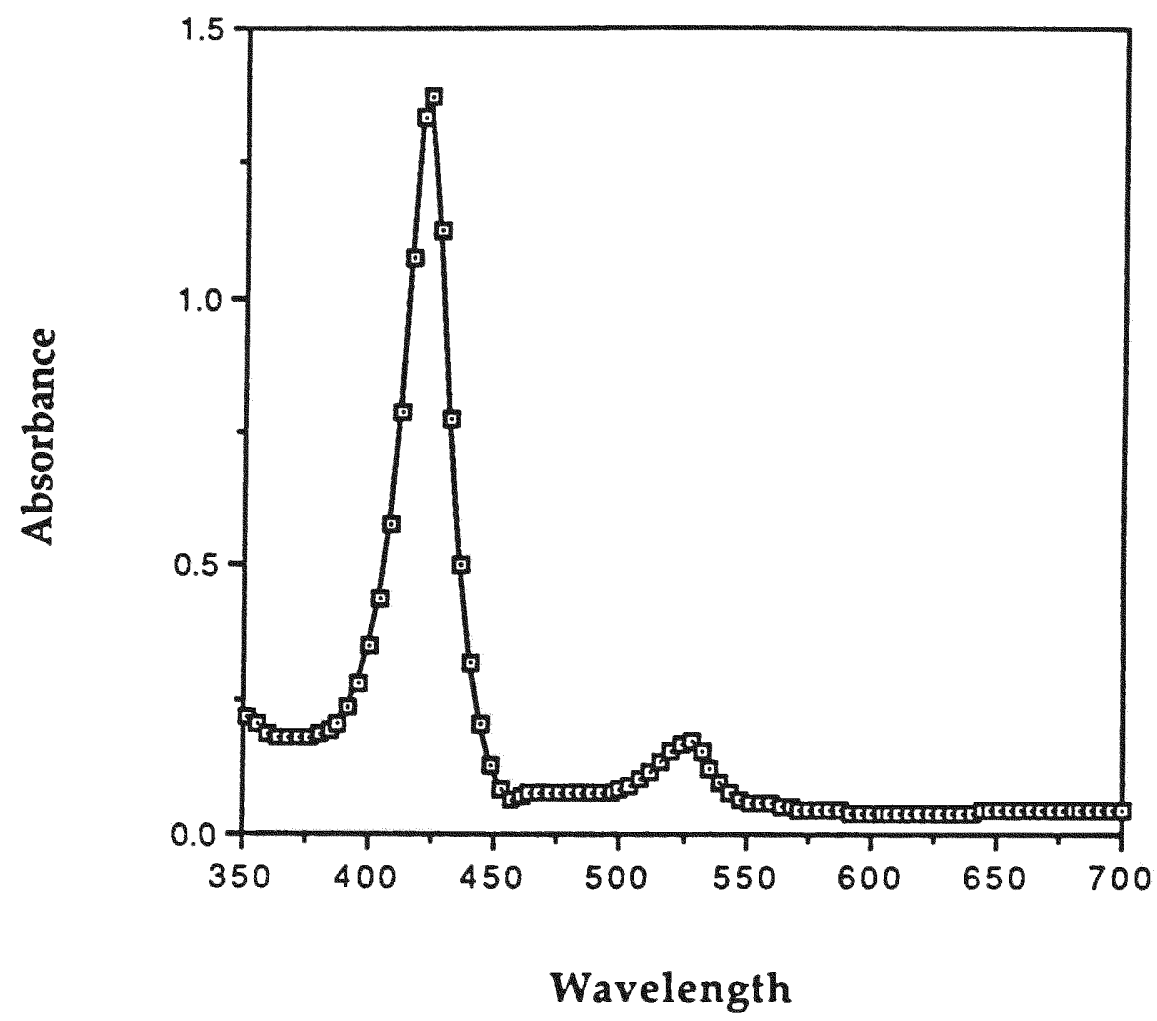

Figure 4-3. The calculated UV-Visible spectrum of the five-coordinate complex of $\operatorname{FeTPP}\left(P(E t)_{3}\right)_{2}$. The Soret band at $426 \mathrm{~nm}$ remains and a new band formed at $525 \mathrm{~nm}$. 


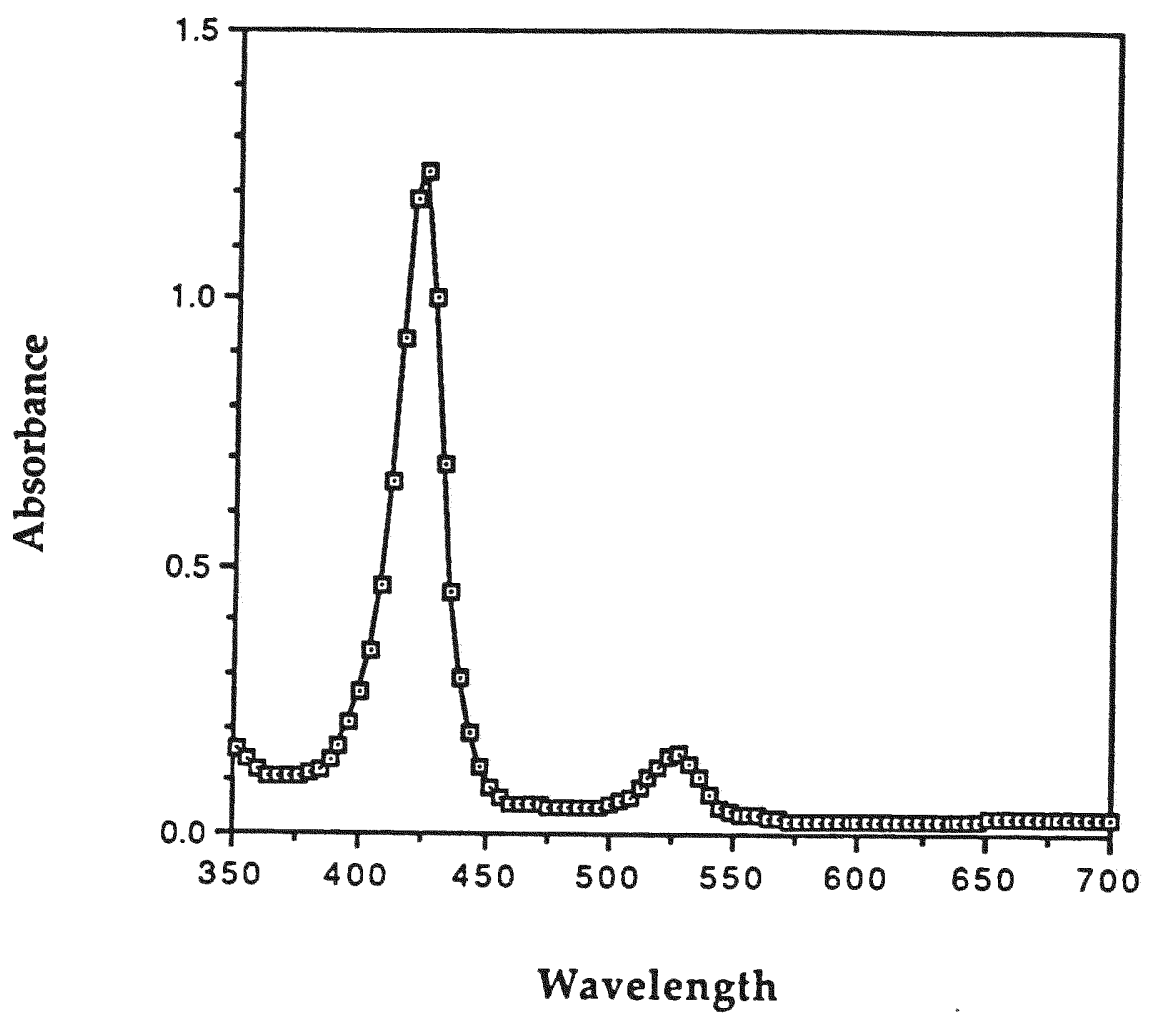

Figure 4-4. The calculated UV-Visible spectrum of the five-coordinate complex of $\operatorname{FeTPP}\left(\mathrm{P}(\mathrm{n}-\mathrm{Bu})_{3}\right)_{2}$. The soret band at $426 \mathrm{~nm}$ remains and a new Soret band formed at $525 \mathrm{~nm}$. 


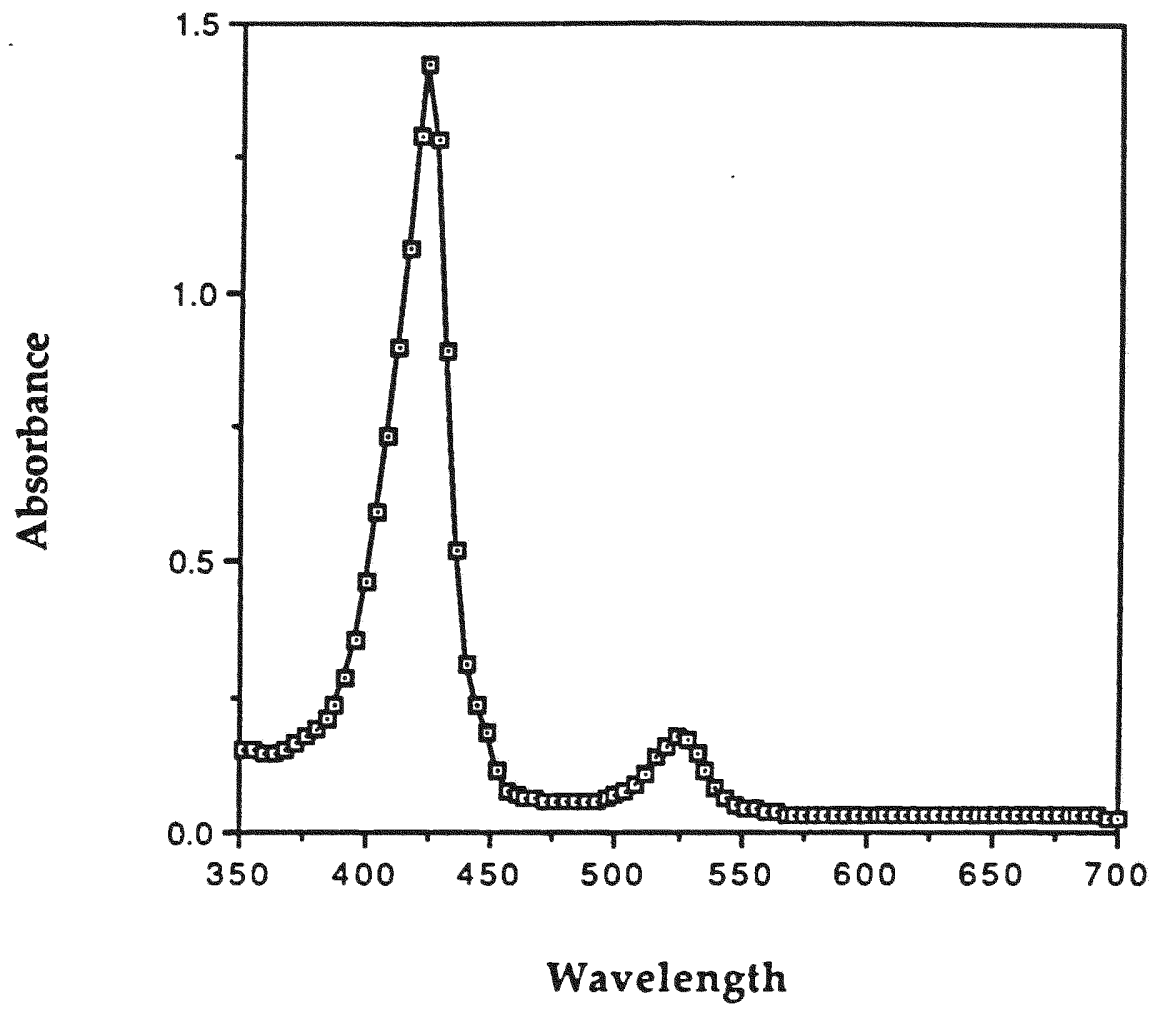

Figure 4-5. The calculated UV-Visible spectrum of the five-coordinate complex of FeTPP $\left(\mathrm{P}(\mathrm{OEt})_{3}\right)_{2}$. The Soret band at $426 \mathrm{~nm}$ remains and a new band formed at $525 \mathrm{~nm}$. 


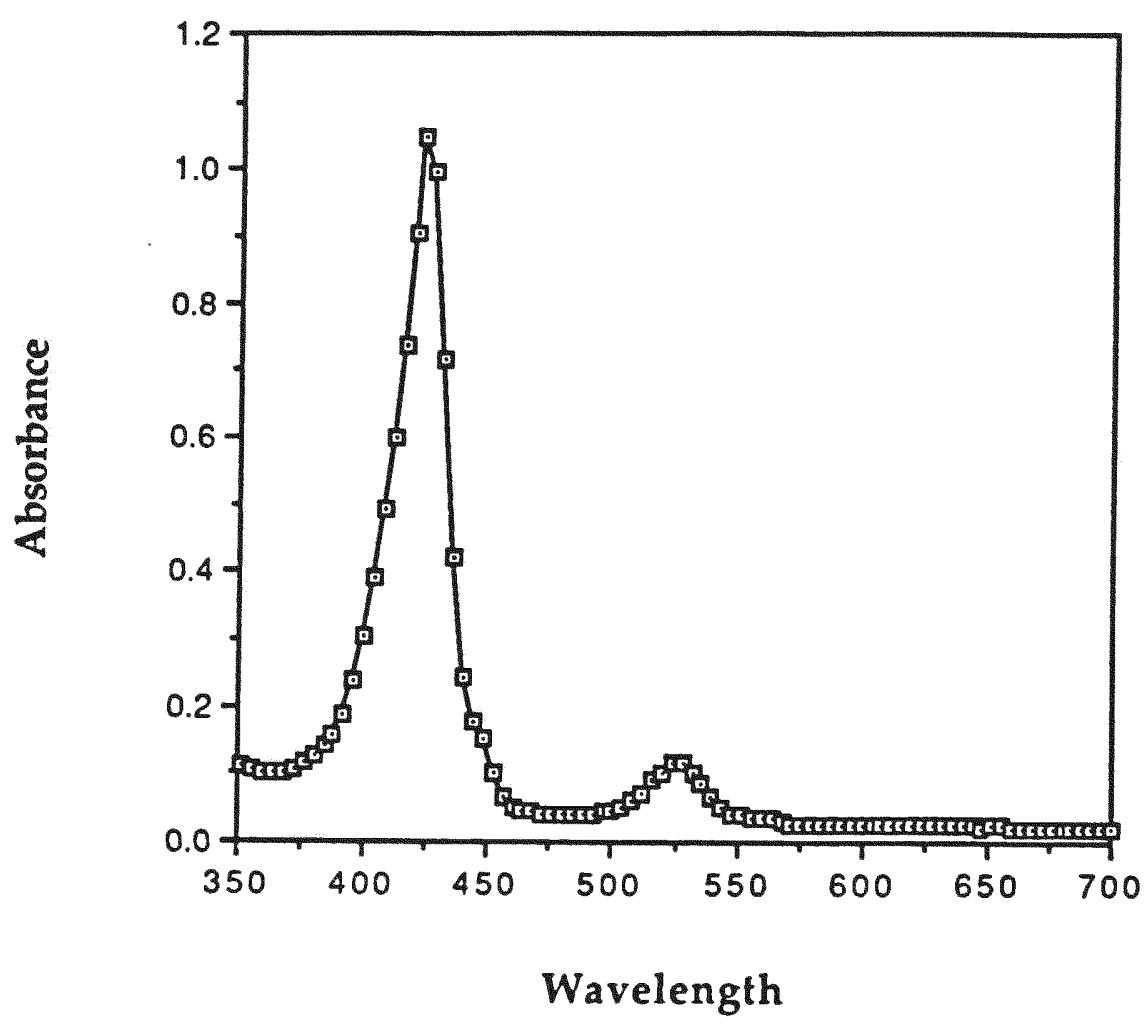

Figure 4-6. The calculated UV-Visible spectrum of the five-coordinate complex of FeTPP $\left(\mathrm{P}(\mathrm{O}-\mathrm{i}-\mathrm{Propyl})_{3}\right)_{2}$.The Soret band at $426 \mathrm{~nm}$ remains and a new band formed at $525 \mathrm{~nm}$. 


\begin{tabular}{|c|c|c|c|}
\hline $\begin{array}{c}\text { Temperature } \\
(\mathrm{K})\end{array}$ & 288 & 292 & 303 \\
\hline $1 / \mathrm{T}\left(\mathrm{K}^{-1}\right)$ & 0.00347 & 0.00342 & 0.00330 \\
\hline $\log \mathrm{K}_{4}$ & 5.60 & 5.50 & 5.40 \\
\hline $\log \mathrm{K}_{2}$ & 5.77 & 5.77 & 5.76 \\
\hline $\log \mathrm{K}_{0}$ & 11.4 & 11.3 & 11.2 \\
\hline $\ln \mathrm{K}_{0}$ & 26.2 & 26.0 & 25.7 \\
\hline
\end{tabular}

Table 4-2. Equilibrium constants for the titration of FeTPPClO, with imidazole at different temperatures.

$* K_{0}=K_{1} \times K_{2}$ 


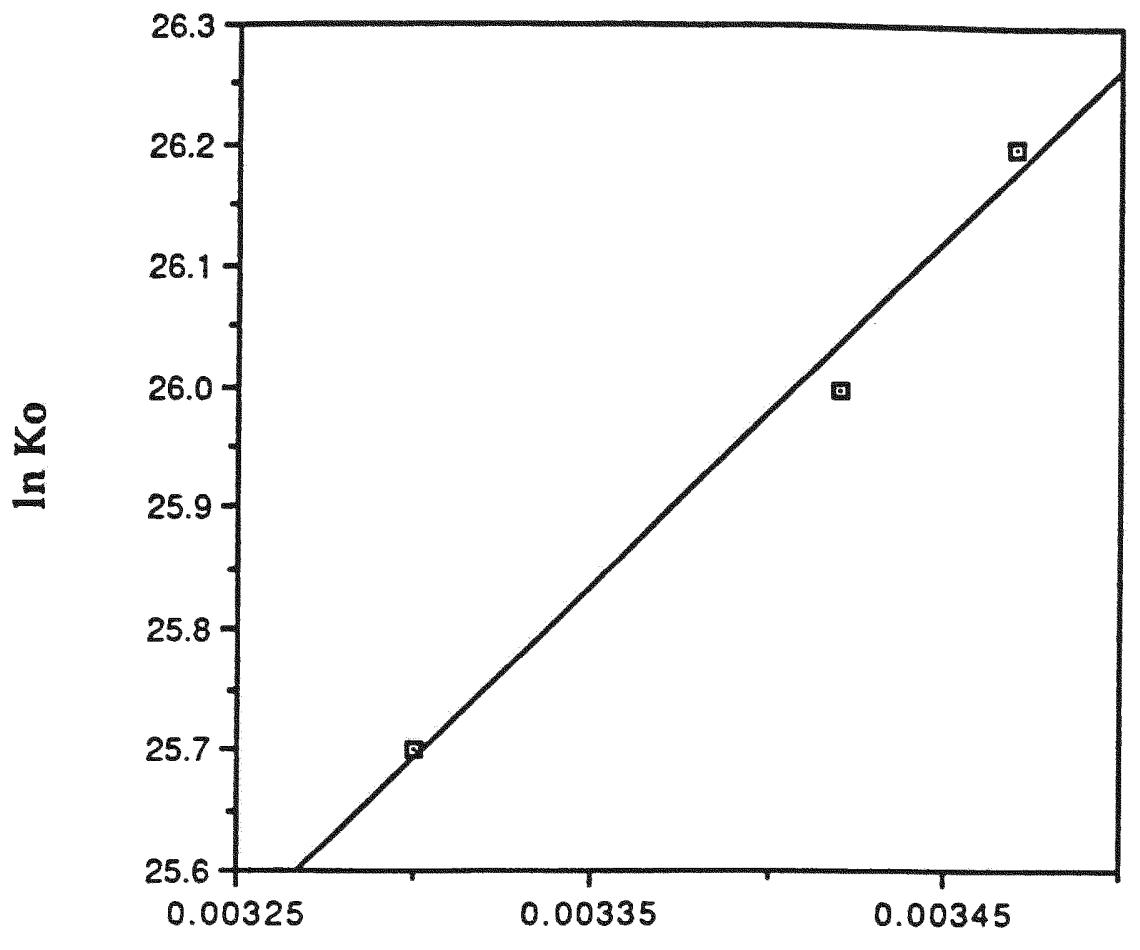

$1 / \mathrm{T}$

Figure 4-7. Plot of $\ln K_{0}$ vs. 1/T. $K_{0}$ 's are the equilibrium constants of the titration of $\mathrm{FeTPPClO}_{4}$ with imidazole at different temperatures, $\mathrm{T}$ is temperature in $\mathrm{K}$. The slope of the regression line is $2860.3 \pm 600 \mathrm{~K}, \mathrm{Y}$ intercept $=16.3 \pm 4$, and $\mathrm{r}^{2}=0.986$. 


\section{Conclusion}

The variation of the equilibrium constants for the reaction of $\mathrm{Fe}(\mathrm{II}) \mathrm{TPP}$ with phosphorus ligands is significant with changes in ligand structure. Both steric and electronic factors have been observed. Table 4-1 shows the equilibrium constant for each ligand with their cone angle and $\mathrm{pKa}$ values.

For the phosphine ligands the trend of increasing $K_{1}$ is observed through the series $R=M e, E t$ and $n-B u . K_{2}$ varies similarly but to a slightly greater extent. A plot of pKa vs. $\log \mathrm{K}_{0}$ is linear ( Figure 4-8).

Comparison of equilibrium constants for $\mathrm{P}(\mathrm{Et})_{3}$ and $\mathrm{P}(\mathrm{OEt})_{3}$ show a dramatic decrease in both $K_{1}$ and $K_{2}$ (about 2-3 orders of magnitude), associated with a decrease in the $\sigma$ basicity of the phosphite relative to the phosphine. The corresponding pKa's of these phosphorous ligands are shown in Table 4-1.

Variation in steric bulk can be seen to affect the values of $K_{\mathrm{eq}}$ 's in both phosphine and phosphite complexes. $K_{1}$ and $K_{2}$ for the large

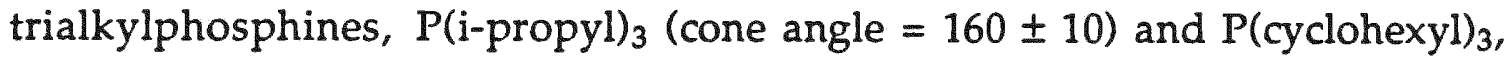
(cone angle $=179 \pm 10$ ) are quite small. $\mathrm{K}$ values for intermediate sized trialkylphosphines should be studied to determine the exact magnitude of the porphyrin/phosphine steric interaction, but such compounds are not commercially available.

Steric effects seen in the $\mathrm{P}(\mathrm{OEt})_{3} / \mathrm{P}(\mathrm{O}-\mathrm{i}-\mathrm{Pr})_{3}$ pair provide. some insight into the structural limitations that accompany the binding of the first and second ligands respectively. $K_{1}$ decreases but less rapidly than $K_{2}, K_{2}$ which corresponds to the formation of the six-coordinate complex requires iron to move into the porphyrin plane, increasing the porphyrin/phosphite steric 


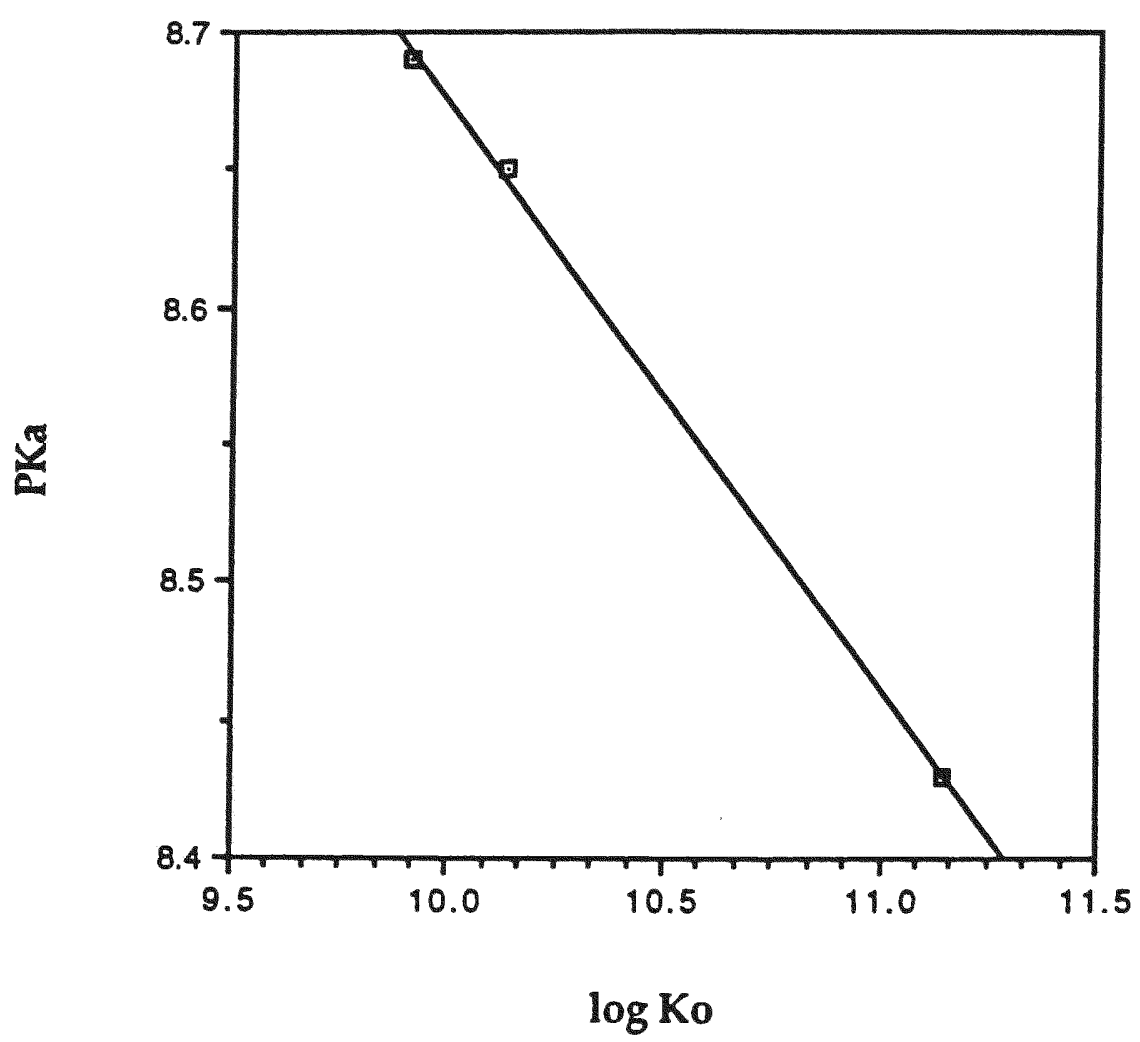

Figure 4-8. Plot of $\log \mathrm{K}_{0}$ vs. $\mathrm{pK} \cdot \mathrm{K}_{0}\left(\mathrm{~K}_{0}=\mathrm{K}_{1} \times \mathrm{K}_{2}\right)$ is the equilibrium - constant of the titration of $\mathrm{Fe}^{(\mathrm{II})} \mathrm{TPP}$ with phosphine ligands $\left(\mathrm{P}(\mathrm{Me})_{3}, \mathrm{P}(\mathrm{Et})_{3}\right.$ and $\left.\mathrm{P}(\mathrm{n}-\mathrm{Bu})_{3}\right)$. 
interaction for the already bound $\mathrm{P}(\mathrm{OR})_{3}$, and adding an equal amount of steric repulsion for the incoming ligand. Further study of this effect would be interesting and may provide some idea of the quatitative amount of this steric strain particularly if $\mathrm{K}_{\mathrm{eq}}$ measurements and crystal structures can be compared.

Overall, measurement of equilibrium constants for the binding of phosphine/phosphite to $\mathrm{Fe}^{(\mathrm{II})}$ porphyrins can be determined to a reasonable degree of accuracy and provide a means of studying both electronic and steric aspects of axial binding in iron porphyrins. 


\section{Refrence}

1. P. O'Carra, Porphyrins and Metalloporphyrins , K.M.Smith, Ed., Elsevier: Amsterdam, (1976), 123-130.

2. F.A.Cotton and G.Wilkinson, Advanced Inorganic Chemistry, Fourth Edition, John Wiley \& Sons: New York, (1980), 1320-1325.

3. J.P.Collman, L. Am. Chem. Soc., (1983), 105, 3038-3052.

4. J. E. Linard, P. E. Ellis, Jr., J. R. Budge, R. D. Jones and Fred Basolo I. Am. Chem. Soc. (1980), 102, 1896-1904.

5. B. B. Wayland, L. F. Mehne and J. Swartz, I. Am. Chem. Soc. (1978), 100, 2797-2383.

6. Alain Desbois, M. Momenteau, M. Lutz, Inorg. Chem. (1989), 28, 825-834.

7. C. J. Weschler, D. L. Anderson and Fred Basolo, I. Am. Chem. Soc. (1975), 97, 6707-6713.

8. B.B. Wayland and L.W. Olson, I. Am. Chem. Soc. (1974), 96, 6037-6041.

9. Daniel Brault and Michel Rougee, Biochem. Biophys. Res. Commun. (1974), 57, 654-659.

10. F. A. Walker, M. W. Luo, M. T. Ree, I. Am. Chem. Soc. (1976), 98, 55525560 .

11. S. J. Cole, G. C. Curthoys and E. A. Magnusson, I. Am. Chem. Soc. (1970) 92, 2991-2996.

12. P. E. Ellis, R. D. Jones, and F. Basolo, I. Am. Chem. Soc. (1980), 102, 18891896.

13. C. L. Coyle, P. A. Rafson, and E. H. Abbott, Inorg. Chem. (1973), 12, 20072010.

14. J. D. Satlerlee, G. N. La Mar, and J. S. Frye, I. Am. Chem. Soc. (1976), 98, 
7275-7282.

15. F.A.Cotton and G.Wilkinson, Advanced Inorganic Chemistry, Fourth Edition, John Wiley \& Sons: New York, (1980), 82-90.

16. C. A. Tolman, I. Am. Chem. Soc. (1970), 92, 2953-2956.

17. C. A. Tolman, I. Am. Chem. Soc. (1970), 92, 2956-2965.

18. W.M. Connor, and D.K. Straub, Inorg. Chem. (1977), 16, 491-497.

19. P.Hambright and A.J.Bearden,Porphyrins and Metalloporphyrins, K.M.Smith, Ed., Elsevier: Amsterdam, (1976), 540-542.

20. Toshie Ohya, H. Morohoshi and M.Sato, Inorg. Chem. (1984), 23, 1303-1305.

21. Houghron R. P., Metal Complexes in Organic Chemistry, Cambridge University Press: Cambridge, (1979),

22. P.Sodano and G. Simonneaux, I.Am. Chem. Soc. Dalton trans, (1988), 2615-2620.

23. R.M. Belani, et al., Can. I. Chem. (1988), 66, 2072-2078.

24. D.V. Stynes, D. Fletcher and X. Chen, Inorg. Chem. (1986), 25, 34833488.

25. P. E. Ellis, Jr., R. D. Jones, and Fred Basolo, I. Chem. Comm. (1980), 54-55.

26. A. V. Hill, I. Physiol (London), (1910), 40, 4-7.

27. J. P. Collman, J. L. Hoard, N. Kim, G. Lang, and C. A. Reed, I. Am. Chem. Soc. (1975), 97, 2676-2681.

28. Daniel Brault and Michel Rougee, Biochemistry (1974), 13, 4592-4597.

29. Kenneth A. Connors, "Binding Constants", $172-175$

30. C.A.Streuli, Analytical Chemistry (1960), 32, 985-987.

31 L.M.Epstein, Inorg. Chem. (1967), 6, 1720-1724. 
32 W.M.Cornor and D.K.Straub, Inorg. Chem. (1975), 15, 2289-2291. 


\section{APPENDIX}

2-1 Derivation of the Hill Equation

For reacton:

$$
\mathrm{M}+\mathrm{nL}====\mathrm{ML}_{\mathrm{n}}
$$

$$
\mathrm{K}=\frac{\mathrm{ML}_{\mathrm{n}}}{\mathrm{M}^{*} \mathrm{~L}^{\mathrm{n}}} ; \quad \mathrm{M}_{\mathrm{t}}=\mathrm{M}+\mathrm{ML}_{\mathrm{n}} ; \quad \mathrm{L}_{\mathrm{t}}=\mathrm{L}+\mathrm{nML}_{\mathrm{n}}
$$

At any concentration of $\mathrm{L}$ :

$$
\begin{aligned}
A_{o b s} & =A_{M}+A_{M L n} \\
& =\varepsilon_{M} * M+\varepsilon_{M L n} * M L_{n} \\
& =\varepsilon_{M} * M+\varepsilon_{M L n} *\left(M_{t}-M\right) \\
& =\varepsilon_{M} * M+\varepsilon_{M L n} * M_{t}-\varepsilon_{M L n} * M \\
A_{o b s} & =\varepsilon_{M L n} * M_{t}+\left(\varepsilon_{M}-\varepsilon_{M L n}\right) * M
\end{aligned}
$$

Given:

$$
\begin{aligned}
& A_{0}=\varepsilon_{M} * M_{t} ; \quad A_{c}=\varepsilon_{M L n} * M_{t} \\
& A-A_{0}=\left(\varepsilon_{M}-\varepsilon_{M L n}\right) * M-\left(\varepsilon_{M}-\varepsilon_{M L n}\right) * M_{t} \\
& A_{c}-A=-\left(\varepsilon_{M}-\varepsilon_{M L n}\right) * M
\end{aligned}
$$

And:

$$
\frac{A-A_{0}}{A_{C}-A}=\frac{M_{t}-M}{M}=\frac{M L_{n}}{M}=K L^{n}
$$

So: $\quad \log \frac{A-A_{0}}{A_{C}-A}=n \log L+\log K$

(Assumes no intermediates are formed, i.e.: $M L_{1}, M L_{2}, \ldots M L_{n-1}$ ) 
2-2. Formular used in the computer program to calculate the free porphyrin concentration $\mathrm{M}$; the concentration of the five-cordinate iron-porphyrin $\mathrm{ML}$ and the concentration of the six-coordinate iron-porphyrin $\mathrm{ML}_{2}$.

$$
\begin{aligned}
& \mathrm{M}=\mathrm{M}_{\mathrm{T}} /\left(1+\mathrm{K}_{1}{ }^{*} \mathrm{~L}_{\mathrm{F}}+\mathrm{K}_{1}{ }^{*} \mathrm{~K}_{2}{ }^{*} \mathrm{~L}_{\mathrm{F}}{ }^{2}\right) \\
& \mathrm{ML}=\left(\mathrm{M}_{\mathrm{T}}{ }^{*} \mathrm{~K}_{1}{ }^{*} \mathrm{~L}_{\mathrm{F}}\right) /\left(1+\mathrm{K}_{1}{ }^{*} \mathrm{~L}_{\mathrm{F}}+\mathrm{K}_{1}{ }^{*} \mathrm{~K}_{2}{ }^{*} \mathrm{~L}_{\mathrm{F}}{ }^{2}\right) \\
& \mathrm{ML}_{2}=\left(\mathrm{M}_{\mathrm{T}}{ }^{*} \mathrm{~K}_{1}{ }^{*} \mathrm{~K}_{2}{ }^{*} \mathrm{~L}_{\mathrm{F}}{ }^{2}\right) /\left(1+\mathrm{K}_{1}{ }^{*} \mathrm{~L}_{\mathrm{F}}+\mathrm{K}_{1}{ }^{*} \mathrm{~K}_{2}{ }^{*} \mathrm{~L}_{\mathrm{F}}{ }^{2}\right)
\end{aligned}
$$

In the above formular $\mathrm{M}_{\mathrm{T}}$ is the total concentration of iron-porphyrin; $\mathrm{LF}_{\mathrm{F}}$ is the free ligand concentration and $\mathrm{K}_{1}, \mathrm{~K}_{2}$ are equilibrium constants. ${ }^{9}$ 
2-3 An excample of computor program using the "least error" method to calculate $\mathrm{K} 1$ and $\mathrm{K} 2$

100 DIM LT(14), AB(14), ABSXML(14), L(1000), LF(14), M(14), ML(14), ML2(14)

150 LET LSTWQD $=0$

151 LET ERROR $1=0$

152 LET ERROR2 $=0$

153 LET ERROR3 $=0$

160 LET COUNT $=0$

170 LET $B=0$

300 FOR $N=1$ TO 7

310 READ LT(N)

312 NEXT N

313 FOR $N=1$ TO 7

320 READ AB(N)

330 NEXT N

331 READ EM, EML2

334 LET MT $=1.44 \mathrm{E}-3$

337 FOR K2 $=34000$ TO 44000 STEP 500

338 LET K1 $=200000$

340 FOR $N=1$ TO 7

345 LET $X=1$

350 LET G $=$ LT(N) $/ 10$

360 LET DENOM $=\left(1+\mathrm{K} 1^{*} \mathrm{G}+\mathrm{K} 1{ }^{*} \mathrm{~K} 2{ }^{*} \mathrm{G}^{\wedge} 2\right)$

370 LET $X=X+1$

$380 \mathrm{LET} \mathrm{LN}=\mathrm{LT}(\mathrm{N})-\left(\mathrm{MT}^{*} \mathrm{~K} 1^{*} \mathrm{G}\right) / \mathrm{DENOM}-\left(2^{*} \mathrm{MT}^{*} \mathrm{~K} 1^{*} \mathrm{~K} 2^{*} \mathrm{G}^{\wedge} 2\right) / \mathrm{DENOM}$

390 IF LN < 0 THEN GOTO 427

400 IF ABS ((G - LN)/LT(N)) < 1E-5 THEN GOTO 431

417 IF G - LN < 0 THEN GOTO 423

419 LET G $=\mathrm{G}-(\mathrm{G}-\mathrm{LN}) / 1000$

421 GOTO 360

$423 \mathrm{LET} \mathrm{G}=\mathrm{G}+\mathrm{ABS}((\mathrm{G}-\mathrm{LN}) / 1000)$

425 GOTO 360

427 LET G $=\mathrm{G} / 2$

429 GOTO 360

431 LET $L F(N)=G$

435 NEXT $N$

440 LET COUNT $=$ COUNT +1

500 LET SUMNUM1 $=0$

505 LET SUMNUM2 $=0$

506 LET VAL $=0$

507 LET VAL2 $=0$

508 LET NUM $1=0$

510 FOR $N=1$ TO 7

$515 \mathrm{LET} \mathrm{DEN}=\left(1+\mathrm{K} 1{ }^{*} \mathrm{LF}(\mathrm{N})+\mathrm{K} 1^{*} \mathrm{~K} 2^{*} \mathrm{LF}(\mathrm{N})^{\wedge} 2\right)$ 
520 LET $M(N)=M T / D E N$

530 LET ML(N) $=\left(\mathrm{MT}^{*} \mathrm{~K} 1 * \mathrm{LF}(\mathrm{N})\right) / \mathrm{DEN}$

540 LET ML2(N) $=\left(\mathrm{MT}^{*} \mathrm{~K} 1{ }^{*} \mathrm{~K} 2{ }^{*} \mathrm{LF}(\mathrm{N})^{\wedge} 2\right) / \mathrm{DEN}$

550 LET ABSXML(N) $=A B(N)-E M^{*} M\left(N 0-E M L 2^{*}\right.$ ML2(N)

560 LET NUM1 $=$ ABSXML(N) / ML(N) + NUM1

561 LET VAL $=$ ABSXML9N) $*$ ML(N)

562 LET VAL $2=\mathrm{ML}(\mathrm{N}) \wedge 2$

563 LET SUMNUM1 = SUMNUM + VAL

564 LET SUMNUM2 = SUMNUM2 + VAL2

600 NEXT N

601 LET EML $=$ NUM1 $/ 7$

603 LET SEML = SUMNUM1/SUMNUM2

604 PRINT "EML=", EML, "SEML=", SEML

612 FOR $N=1$ TO 7

613 PRINT LF(N), AB(N), EM*M(N)+SEML*ML(N)+EML2*ML2(N), $M(N)+M L(N)+M L 2(N)$

614 NEXT N

615 LET SUMERRORSQD $=0$

620 FOR $N=1$ TO 7

630 LET ERRORSQD $=(A B(N)-E M * M(N)-S E M L * M L(N)-E M L 2 * M L 2(N))^{\wedge} 2$

640 LET SUMERRORSQD = SUMERRORSQD = ERRORSQD

650 NEXT N

660 LET ERROR1 = ERROR2

670 LET ERROR2 = ERROR3

680 LET ERROR3 = SUMERRORSQD

690 PRINT "K1=", K1, "K2=", K2, "EML= ", EML

700 END 
2-4. Example of computor program used in calculating the five-coordinated $\mathrm{Fe}^{(\mathrm{II})} \mathrm{TPP}$ spectrum

100 DIM A0(90), A(90), AC(90), LAMBDA(90), EML(90), AML(90)

200 INPUT PROMPT "INPUT K1 AND K2 ?", K1 AND K2

300 FOR $N=1$ TO 88

310 READ AO(N)

320 NEXT N

325 FOR $N=1$ TO 88

330 READ A(N)

335 FOR $N=1$ TO 88

340 NEXT $N$

345 FOR N $=1$ TO 88

350 READ AC(N)

360 LET LAMBDA $(\mathrm{N})=704-\mathrm{N}^{* 4}$

400 NEXT N

500 LET MT $=1.5 \mathrm{E}-3$

600 LET LF $=1.12 \mathrm{E}-3$

700 LET DEN $=\left(1+\mathrm{K} 1{ }^{*} \mathrm{LF}+\mathrm{K} 1^{*} \mathrm{~K} 2^{*} \mathrm{LF}^{\wedge} 2\right)$

800 LET $M=M T / D E N$

900 LET ML $=$ MT*K1*LF/DEN

1000 LET ML2 $=\mathrm{MT}^{*}\left(\mathrm{~K} 1^{*} \mathrm{~K} 2^{*} \mathrm{LF}^{\wedge} 2\right) / \mathrm{DEN}$

1100 FOR $\mathrm{N}=1$ TO 88

1200 LET AML $(N)=A(N)-A 0(N) * M / M T-A C(N) * M L 2 / M T$

1300 LET EML(N) = AML(N)/ML

1400 PRINT LAMBDA(N), EML(N)*MT

1500 NEXT N

1600 DATA 